VICTORIA UNIVERSITY OF WELLINGTON

Te Whare Wānanga o te Ūpoko o te Ika a Māui

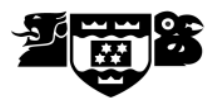

\title{
RESIDENTIAL RETROFIT POLICY IN CHILE AND NEW ZEALAND: AN ANALYSIS BASED ON ENERGY EFFICIENCY AND CO-BENEFITS
}

by

\author{
Alejandra Pérez \\ Thesis \\ ENVIRONMENTAL STUDIES 593
}

[2011]

A 90 point thesis submitted to Victoria University of Wellington, as partial fulfilment of requirements for the degree of Master of Environmental Studies

School of Geography, Environment and Earth Sciences

Victoria University of Wellington

[July, 2011] 


\title{
RESIDENTIAL RETROFIT POLICY IN CHILE AND NEW ZEALAND: AN ANALYSIS BASED ON ENERGY EFFIEICNY AND CO-BENEFITS
}

\author{
Alejandra Pérez
}

\begin{abstract}
Society's unsustainable patterns of energy consumption mean that residential energy efficiency plays a significant role in building a more sustainable society. This research analyses the process that has shaped residential retrofit policies in New Zealand and Chile; the first, a developed country with a long history of residential energy efficiency; the second, a developing country that is in the first stages of the retrofit policy process. Different theoretical approaches to residential energy efficiency were used, specifically, approaches within economic and behavioural economics theory, such as barriers theory, the rebound effect theory and co-benefits theory. A particular emphasis was given to co-benefits theory. The research found that in both Chile and New Zealand the retrofit policy process depends on critical contextual factors (e.g. global oil shocks, global financial crisis, energy security issues, electricity sector reforms and climate change mitigation policy) which trigger a sense of political urgency to address these factors. Local entities and the academic world have also contributed to shape retrofit policies. The multiple co-benefits of residential retrofit lead to a more resilient policy when governments and political will change. In the future, the cobenefits of health, fuel-poverty, fuel affordability, energy security and thermal comfort are likely to provide resilience to retrofit policies in Chile and New Zealand.
\end{abstract}

Key words: residential energy efficiency, retrofit policy, co-benefits, barriers, rebound effect, Chile, New Zealand. 


\section{Acknowledgements}

I would like to express my gratitude to everyone who helped me and guided me during my Masters research journey.

To my supervisor, Associate Professor Dr. Ralph Chapman who committed to me a large amount of his time in order to guide me academically and also on a personal level. Thank you very much Ralph for the large number of 'free coffees’ I shared with you, your friendship and advice.

Thanks to all my interviewees who generously gave me their time.

Also, I would like to thank the Student Support Centre's team for helping me to edit my thesis's chapters and understand many aspects of the kiwi language and culture.

Thank you Kent Smith, for grounding me many times and showing me that it is 'good to have fun in life'.

Very special thanks to Lukas Reichel for his love, 'endless patience' and support; and for helping me to 'find myself', especially in nature. Also, thanks to my mother who supported me from the other side of the world and helped me with the field work in Chile, and Juli Ungaro for her genuine friendship and 'many edits'. Finally I would like to thank all my friends in New Zealand, especially my friends from my Buddhist community and university (thanks Seema for those 'environmental curry talks') for their invaluable support during my research journey. 


\section{Contents}

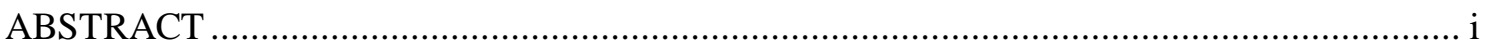

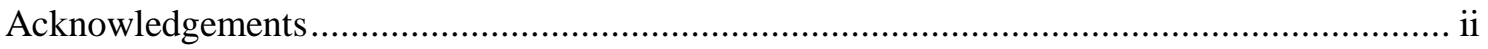

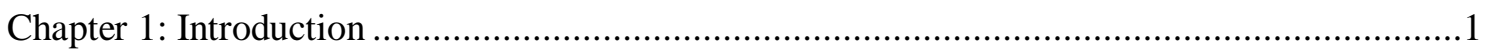

1.1. Relevance of residential energy efficiency: Direct benefits ........................................

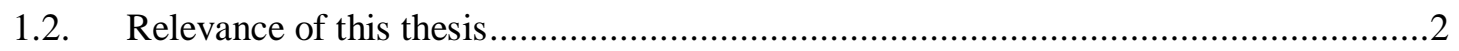

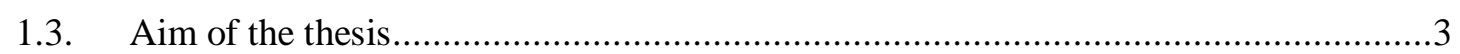

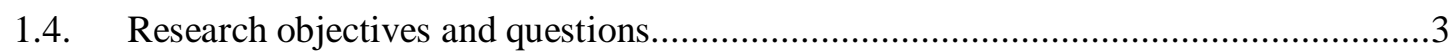

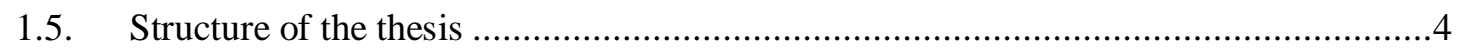

Chapter 2: Literature review. Energy efficiency in the residential sector ....................................

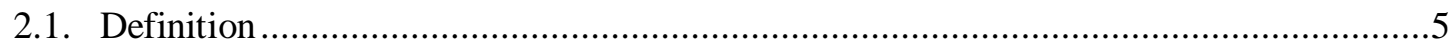

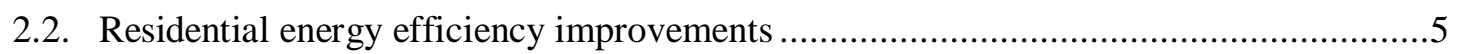

2.3. Residential energy efficiency policy theory...........................................................6

2.3.1. Economics and behavioural economics theory in residential energy efficiency

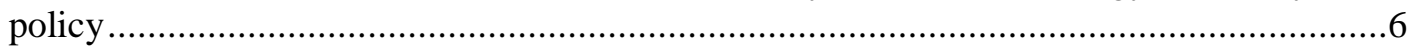

2.3.2. Residential energy efficiency policy and the sustainable development approach:

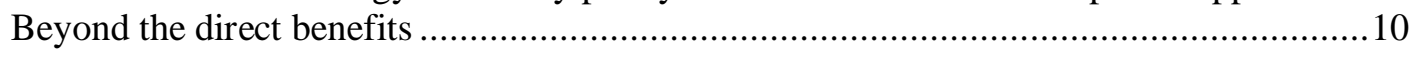

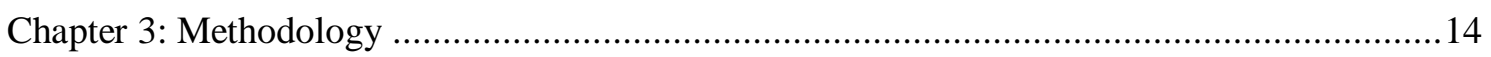

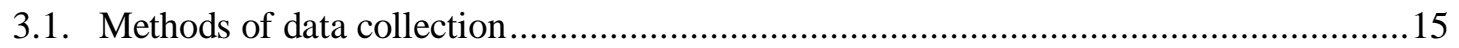

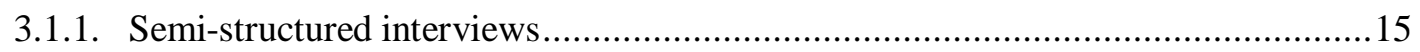

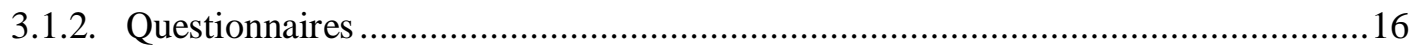

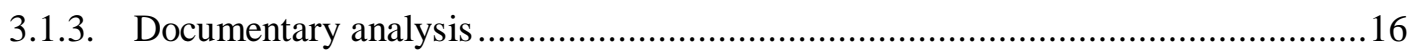

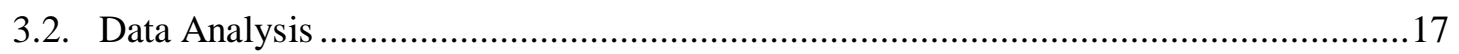

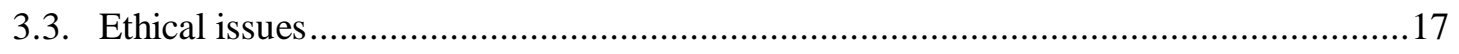

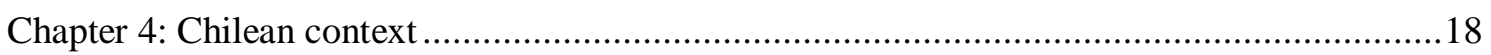

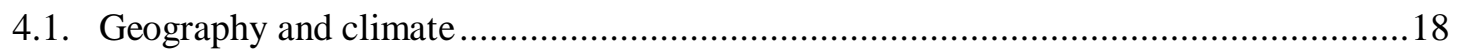

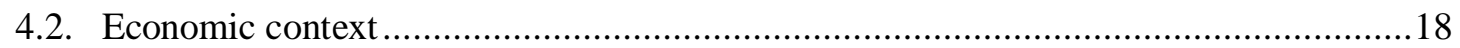

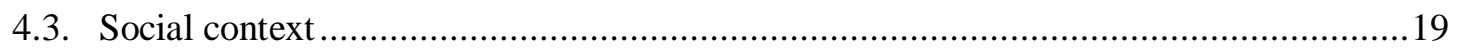

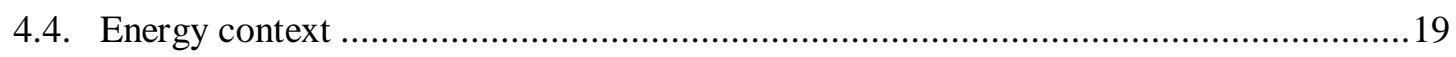

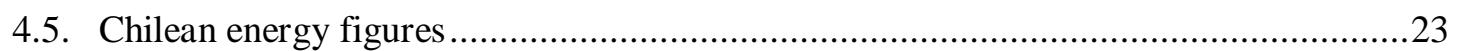

4.6. Key national organisations for the development of residential energy efficiency policies

4.7. Local authorities 28

4.8. Local context: Local air pollution in the comunas of Temuco and Padre las Casas .......31

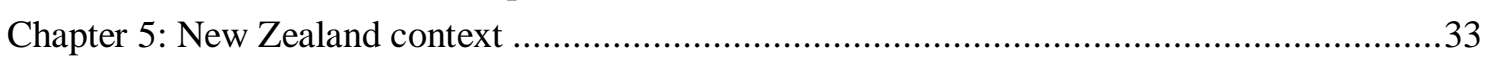

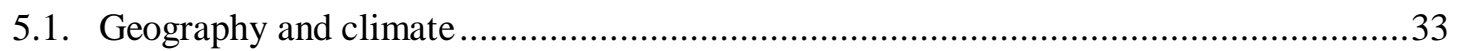

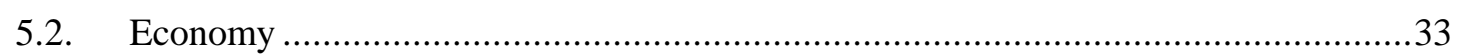

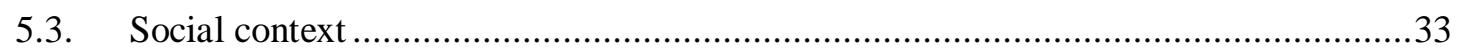

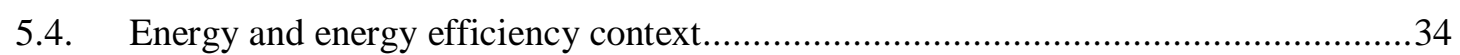

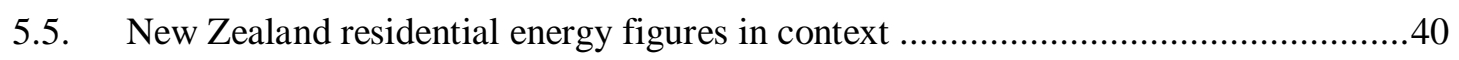

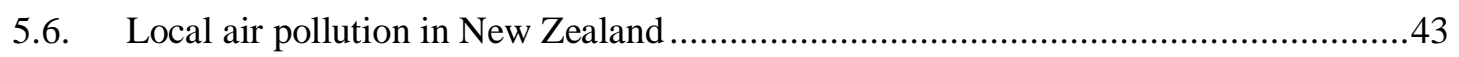

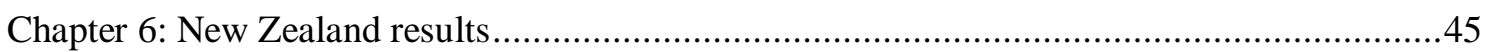




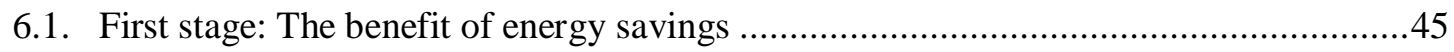

6.2. Second stage: Energy efficiency and local problems ..................................................48

6.3. Third stage: Health benefits and climate change........................................................5

6.4. Third stage: Employment and market development ....................................................56

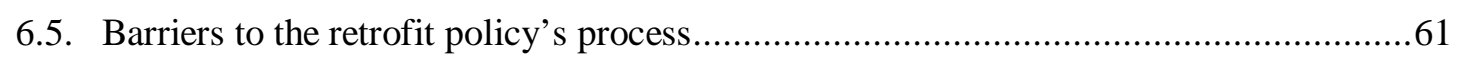

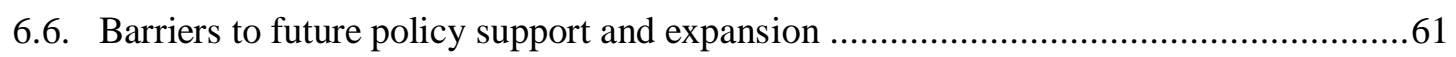

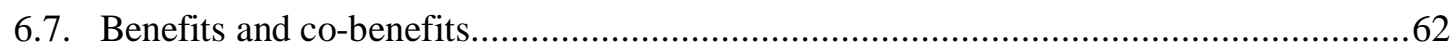

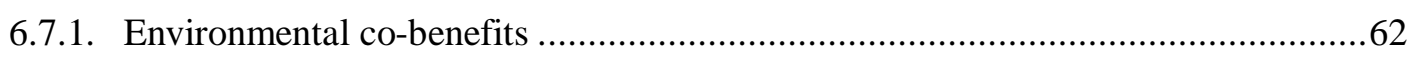

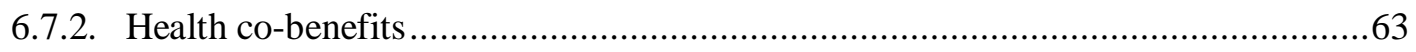

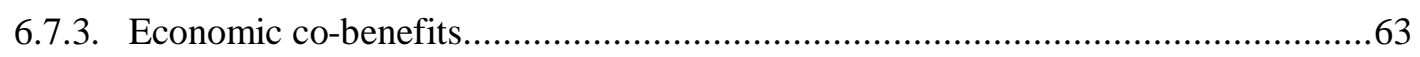

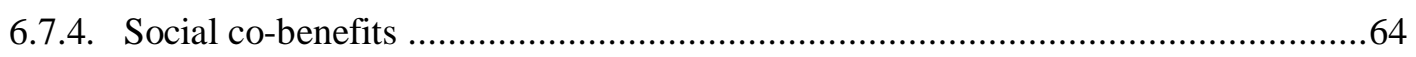

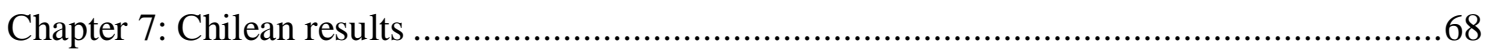

7.1. Development of residential thermal retrofit measures.................................................68

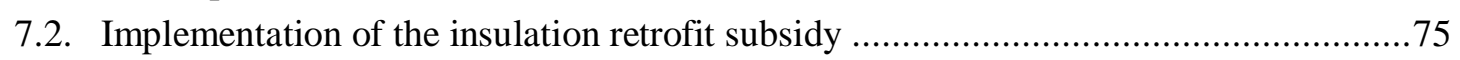

7.3. Barriers to the creation and implementation of the insulation retrofit subsidy (IRS) and

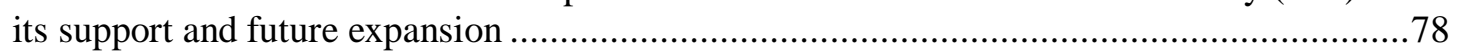

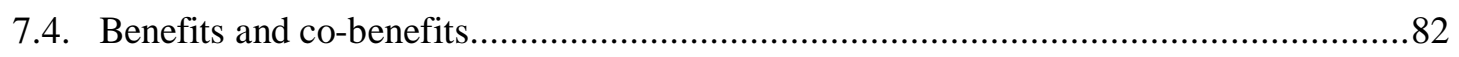

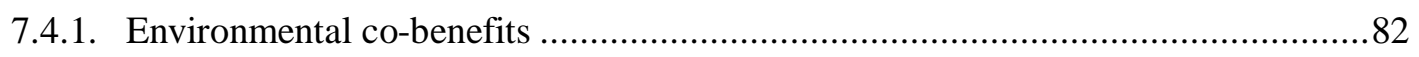

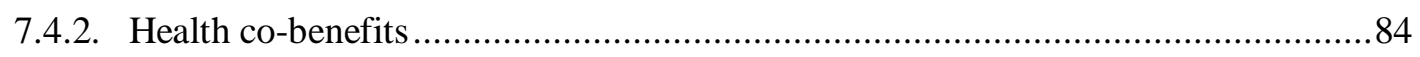

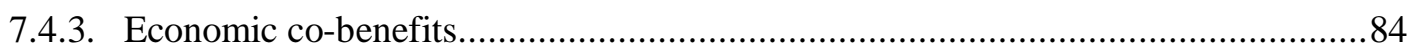

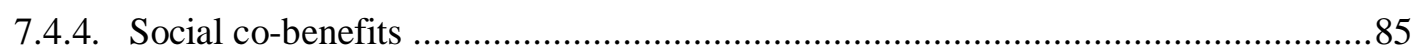

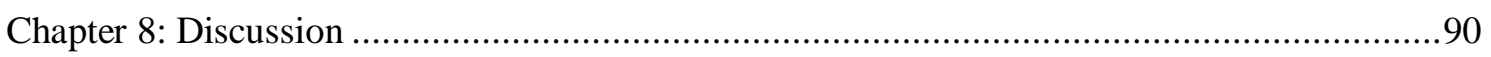

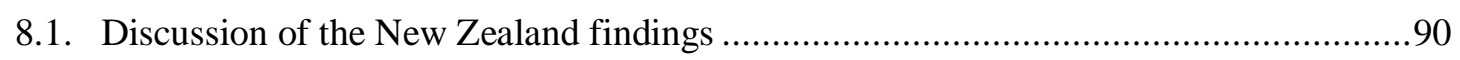

8.2. Implications of the propositions in New Zealand: Retrofit policy support and expansion

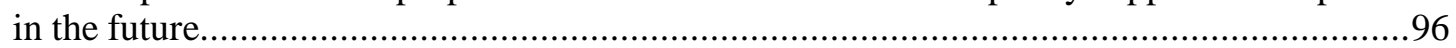

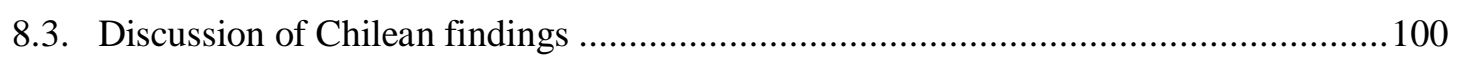

8.4. Implications of the propositions in Chile: Retrofit policy support and expansion in the

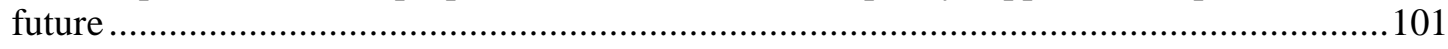

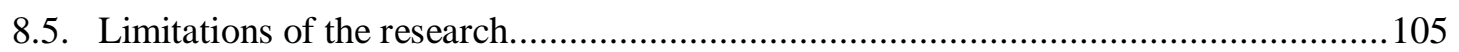

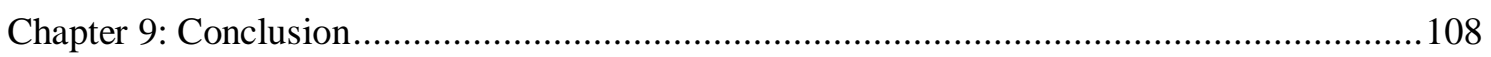

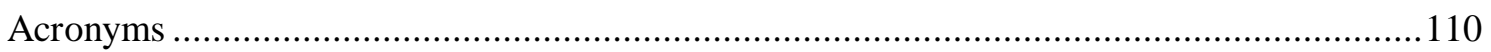

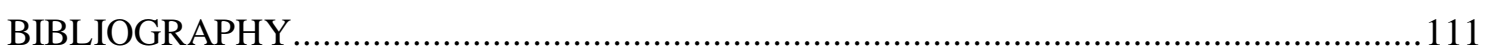

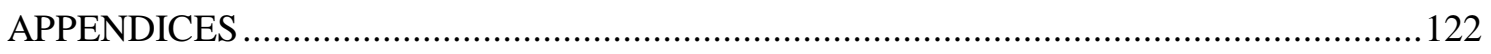




\section{Tables}

Table 4.1. Residential fuel real prices for residential space heating (NZ cents/kWh). .24

Table 5.1. Residential fuel real prices for residential space heating in 2009 (NZ cents/kWh)...42

Table 6.1. Warm Up New Zealand: Heat Smart grant, by households groups . .57

Table 6.2. Main nationwide retrofit programmes, source, resources, beneficiaries and rationale of the insulation retrofit subsidy.

Table 6.3. Average rating on 1 to 5 scale, of the relative importance of benefits and co-benefits in the creation of the Warm Up New Zealand scheme and its support or future expansion.

Table 7.1. NPV for a measure of retrofitting with insulation 720,000 dwellings over 10 years.73 Table 7.2. Source, resources, beneficiaries and rationale of the insulation retrofit subsidy.......77

Table 7.3. Average rating on 1 to 5 scale about perceptions of the relative importance of benefits and co-benefits in the IRS creation and support or future expansion. . .88

Table A1. Percentage of residential space heating fuels by type of dwelling used in Santiago and two large southern cities.

Table A.2. Residential space heating energy use ( $\mathrm{kWh})$ by type of fuel and type of dwelling in Santiago and two large southern cities.

Table A4. Income limits for receiving a Community Services Card.

Table A5.1. Chilean interviewees and the organisations to which they belonged

Table A5.2. New Zealand interviewees and the organisations to which they belonged. 129

\section{Maps}

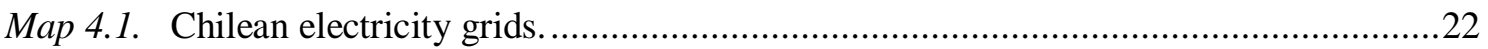

Map 4.2. Administrative regions of Chile. .........................................................................

Map 5.1. The North Island Council boundaries....................................................................38

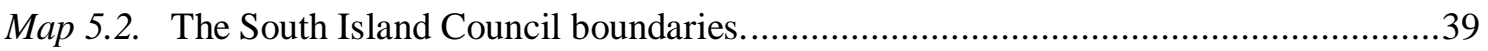




\section{Photos}

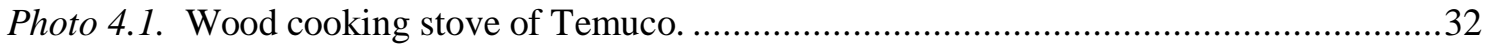

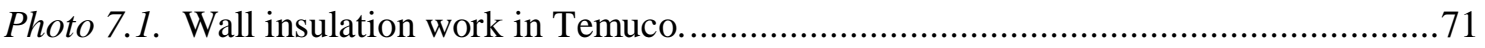

Photo 7.2. Wall insulation work in Temuco............................................................................

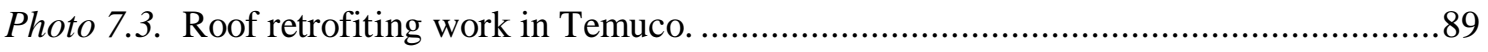

\section{Figures}

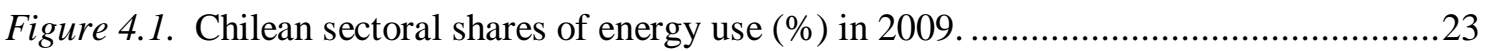

Figure 4.2. Chilean residential fuel use shares (\%) in 2009....................................................24

Figure 4.3. Total primary energy consumption (\%) in 2009................................................25

Figure 4.4. Energy intensity (total primary energy supply per unit of GDP)...........................26

Figure 4.5. Residential energy efficiency public authorities..................................................29

Figure 5.1. Key residential energy efficiency public authorities...............................................37

Figure 5.2. New Zealand total consumer energy by fuel in 2009...........................................40

Figure 5.3. New Zealand residential energy use shares (\%) in 2005......................................42 


\section{Chapter 1: Introduction}

\subsection{Relevance of residential energy efficiency: Direct benefits}

Society's unsustainable patterns of energy supply and consumption, the risk of catastrophic and irreversible damage to the global climate, and uncertainties about oil and gas supply result in energy efficiency playing a central role in the current and future world scenario (IEA, 2008). In fact, it has been estimated that energy use in buildings (residential and commercial/public buildings) makes up 35\% of global final energy consumption (IEA, 2006a). Additionally, in the period from 1990 to 2007, buildings' energy consumption around the world grew by $1.4 \%$ per year (IEA, 2010a).

In the residential sector, heating and cooling represent the largest use of energy. In fact, it has been estimated that in 1998, space heating and cooling accounted for $55 \%$ of the final energy use in residential buildings on average, for a group of 11 countries belonging to the IEA ${ }^{1}$. However, this figure depends on climatic conditions. For instance, in Australia, which was considered to have a mild climate, space heating and cooling accounted for $40 \%$ of the final energy consumption, whereas in Finland (cold climate) it represented 64\% in 1998 (IEA, 2006a).

The International Energy Agency (2010a) also estimated that, in 2003, the dominant fuel in residential buildings of the OECD (Organisation for Economic Cooperation and Development) countries was natural gas, whereas in the developing world biomass constituted 64\% of the total energy use in residential and commercial sectors. This pattern was maintained until the last date of research in 2007.

The residential sector has also a significant role to play in the climate change context. Although residential emissions have increased by 1.5\% per year from 1995 to 2007 (IEA, 2010a), it is recognised that the residential sector has potential to reduce the $\mathrm{CO}_{2}$ emissions among the OECD countries. Levine et al. (2007) surveyed 80 studies

\footnotetext{
${ }^{1}$ Australia, Denmark, Finland, France, Germany, Japan, Italy, Norway, Sweden, the United Kingdom and the United States.
} 
and concluded that, globally, buildings have the potential to reduce the projected emission baseline cost-effectively ${ }^{2}$ by $29 \%$ by 2020 .

\subsection{Relevance of this thesis}

Although there are diverse theoretical approaches to explain residential energy efficiency phenomena, there is a gap with regard to the policy making process of retrofit policy. In general, countries have developed thermal standards for new buildings in a relatively expeditious process (but with a certain level of impediments); however, the residential retrofit policy process seems to be more complicated since it faces a large number of barriers. This research analyses the main factors involved in the residential retrofit policy process in order to better understand its development and implementation as well as to examine its support and future expansion. A range of residential energy efficiency theoretical propositions are investigated and conclusions are drawn from the experience of the New Zealand retrofit policy programmes. The main focus of the research is on co-benefits (benefits in addition to the economic gains from energy saving). The conclusions are used to make policy recommendations for New Zealand and Chile and, in the future, they may assist government officials, policy makers, academics and other scholars to enhance the residential energy efficiency policy process.

Chile was the first country of South America that implemented thermal standards in 2000 and it has been advancing in the development and implementation of residential retrofit policy. Currently, an insulation retrofit subsidy has been implemented since 2008 along with other measures, such as heater replacement and housing energy efficiency certification; however these last two policies are in a very early stage. Due to the relatively longer implementation of the insulation retrofit subsidy, it is chosen as a policy for research. On the other hand, New Zealand has a long thermal standards and retrofit policy history which started in 1975. Currently, New Zealand has different

\footnotetext{
${ }^{2}$ The authors derived the baseline from a variety of sources, resulting in $\mathrm{CO}_{2}$ emissions of $11.1 \mathrm{Gt}$ in 2020 for the building sector.
} 
schemes which converge in one core one: the Warm Up New Zealand: Heat Smart scheme 2009.

Analysis of the process that has shaped energy efficiency measures for the residential sector, particularly with regard to the attainment of greater resilience of retrofit policy, is largely absent in the literature. There is a particular gap in relation to what developing countries can learn, if anything, from developed countries' policy programmes and achievements in residential energy efficiency. Consequently an analysis of the retrofit policy process and its future support and expansion in these two realities also provides an opportunity for research.

\subsection{Aim of the thesis}

The aim of the research is to understand and analyse the processes that have shaped residential energy efficiency retrofit policies in Chile and New Zealand. The intention is to explain the process of creation and implementation of the retrofit policy and the factors likely to enhance its future support or expansion. The main focus of the research is to analyse propositions from the literature relating to the factors influencing this process, particularly the role of co-benefits.

\subsection{Research objectives and questions}

Objective: To analyse how residential energy efficiency policies of Chile and New Zealand have been created, developed and could be supported or expanded in the future, focusing on co-benefits.

Research Questions:

1. How the policies were developed?

2. How the policies are being implemented?

3. How the policies could be supported or expanded?

4. To what extent energy efficiency benefits and co-benefits were taken into account in the policy development and implementation? 
5. To what extent energy efficiency benefits and co-benefits could be used as arguments to support or expand retrofit policy in the future?

\subsection{Structure of the thesis}

Chapter 1 , the introduction, has presented the rationale, purpose, research questions and objectives of the research.

Chapter 2 is the literature review. It presents the main theories, issues and gaps related to the research topic.

Chapter 3 is the methodology. It presents the approach, data collection methods, data analysis strategy and ethical issues.

Chapter 4 is the Chilean context. The main contextual issues that influenced the research topic are presented as well as a general picture of the country.

Chapter 5 is the New Zealand context. The main contextual issues that influenced the research topic are presented as well as a general picture of the country.

Chapter 6 is the New Zealand results.

Chapter 7 is the Chilean results.

Chapter 8 is the discussion. In this chapter the theory is developed and tested. The theory is used to forecast and enhance the future support and expansion of the retrofit policy in Chile and New Zealand and make policy recommendations.

Chapter 9 is the conclusion. 


\section{Chapter 2: Literature review. Energy efficiency in the residential sector}

\subsection{Definition}

Energy efficiency refers mainly to energy savings on the demand side of the energy market. In the residential sector, energy savings can be obtained by improvements in light, space heating, hot water, refrigeration and other areas. The World Energy Council (2004, p. 3) defined energy efficiency improvements as “a reduction in the energy used for a given energy service (heating, lighting, etc.) or level of activity”. This reduction involves technological, behavioural, and economic changes (Taylor, Govindarajalu, Levin, Meyer, \& Ward, 2008; World Energy Council, 2004).

\subsection{Residential energy efficiency improvements}

The potential for improving energy efficiency can be classified as theoretical (energy savings related to thermodynamic considerations when minimizing heat losses), technical (energy savings by implementing, at a given time, the most energy-efficient technology), economic (energy saving resulting from a shift toward the most energyefficient technologies that are still cost-effective for a given time horizon and given market prices), and societal (the cost-effective savings resulting from the reduction of externalities such as health impacts, air pollution, global warming, ecological impacts, etc.) (Jochem, 2000). However, these potentials can overlap in practice.

In the residential sector, opportunities for energy efficiency improvements include the design, building envelope (window weatherization, shell insulation and retrofits); heating, cooling and ventilation; and lighting and appliances. However, local conditions (e.g. energy prices, health impacts) will influence whether such actions are costeffective.

When considering the measures for improvement of energy efficiency in the residential sector, it is necessary to distinguish between new and existing residences. In new buildings, energy efficiency measures (such as ventilation, orientation, design, etc.) are often less salient than other factors (such as building cost, location, etc.), in the purchase decision, even though energy efficiency factors are part of the dwelling's costs 
and overall performance (Affordable Housing Energy Efficiency Alliance, 2008; Taylor et al., 2008). In fact, studies show that in the case of thermal envelope enhancement, a significant reduction of energy use for heating can be achieved at a few percent increase in the total costs of residential buildings (Levine et al., 2007, p. 395). In the case of existing buildings, retrofits are more costly, so the investment pay back period can be significantly longer than in new buildings (Taylor et al., 2008). Residential retrofits refer to energy efficiency improvements in existing buildings. The improvements include different installations such as insulation of ceiling, floors, walls and hot water cylinders, heater replacement, draught-stopping, and efficient lights, among others.

\subsection{Residential energy efficiency policy theory}

\subsubsection{Economics and behavioural economics theory in residential energy efficiency policy}

The International Energy Agency (IEA), the World Energy Council and the World Bank have undertaken a broad range of studies on energy efficiency policy. These studies analyse different energy efficiency policy instruments that have been implemented around the world. The most common analysis characterises policy instruments as the stick, the carrot and the sermon, with the sticks representing regulations (prescriptions and proscriptions), carrots representing economic means (subsidies, grants, taxes, fees, etc.), and sermons representing information (encouragements and warnings) (Bemelmans-Videc \& Vedung, 1998). In this regard, the most common energy efficiency policies in the residential sector around the world are regulation of electrical appliances (labelling and standards) and regulation of buildings (codes and standards). Other common policies for energy efficiency are financial incentives (direct subsidies and fiscal incentives), mandatory audits, ESCOs (Energy Service Companies), and information tools (World Energy Council, 2008).

Another approach classifies these policies according to modes of governing. Bulkeley and Kern (2006) and Sims (2009) argue that in the context of international climate change policies, in which energy efficiency plays a role, modes of governing are: (1) leadership (targets), (2) authority (regulatory measures such as market interventions and schemes), (3) provision (usually financial incentives), (4) enabling 
(guidance measures such as education, promotion of technologies, demonstrations, creating improved awareness by stakeholders, and also support for RD\&D), and (5) self-governing (voluntary actions).

Other studies are those undertaken by experts in context, in order to create and implement residential energy efficiency policies in a particular country. In general, these studies use cost-benefit analysis to determine the feasibility of a proposed energy efficiency policy. However, scholars agree that a cost-benefit analysis based solely on energy savings will underestimate the real economic value of residential energy efficiency policies. This is because residential energy efficiency measures have an indirect positive impact on an array of different social, environmental and economic aspects, that are usually absent in the decision making. These indirect benefits will be discussed later.

Another discussion on energy efficiency policy, at a theoretical level, addresses the importance of local governments, economic agents, and civil society in the achievement of environmental energy efficiency targets. Although the IEA has recognized the importance of local governments for influencing citizens' energy choices through an array of different measures (Sims, 2009), there is a lack of research at a practical level. Only one study has analyzed how municipalities of three countries in transition could get involved in the market for energy efficiency equipment (Rezessy, Dimitrov, Urge-Vorsatz, \& Baruch, 2006). Studies about the participation of local governments, economic society and civil society in achieving residential energy efficiency goals are absent in the literature.

Most of the studies on energy efficiency policy address the barriers to energy efficiency policy development. Extensive investigations of energy efficiency barriers have been carried out by Martinot and McDoom (2000), Golove and Eto (1996), Jochem (2000) and Levine et al. (2007) among many others. These barriers have been broadly classified as market failures that result in a lack of energy efficiency improvements. The most cited barriers can be summarised as follows:

(1) Misplaced incentives (split incentives) occur when energy efficiency investors do not receive the benefits accrued from the investments. This barrier generally 
occurs in the residential sector, where landowners do not have incentives to invest in energy efficiency improvements as the property is being rented.

(2) Lack of access to financing, and historically or socially formed investment patterns refers to restrictions on capital availability for potential borrowers. This restriction particularly affects low-income people and small business.

(3) Flaws in market structure refer to a market failure when powerful firms inhibit the entrance of new energy efficient or cost-effective products.

(4) Mis-pricing imposed by regulation occurs when the price of some products such as electricity is set by authorities under the production marginal costs. This leads to an over-consumption of the incentivised product or lack of incentive to improve energy efficiency.

(5) Decisions influenced by custom and lack of information or misinformation refer mainly to future uncertainty about prices, cost of transactions, and advertised misinformation. Most households do not have enough information about the energy savings options.

(6) Gold plating occurs when customers must purchase more features than desired and inseparability of features occurs when availability is restricted by technological limitations.

(7) Legal and administrative obstacles are country specific. In general, countries have given low importance to energy efficiency measures when there are more urgent and important needs. In addition, due to the invisibility of energy efficiency measures compared with other energy measures such as photovoltaic or solar thermal collectors, energy efficiency measures have not been a topic for media or politicians.

Other barriers to energy efficiency usually present in the developing world are those related to government failures. These obstacles has been largely recognised as lack of political will, gaps in legislation and regulations, lack of awareness and technical skills, lack of planning and information about energy use, lack of energy efficiency standards, lack of alternatives or options to enhance energy efficiency, and conflicting investment priorities (Jochem, 2000; World Bank, 2000). 
The final barrier to energy efficiency that was found is related to the utility theory and rationality. Within utility theory, the rational actor model assumes that if individuals have sufficient information, they will make rational choices to maximise their utility, given budget constraints (Jackson, 2005; Wilson \& Dowlatabadi, 2007). Behavioural economics challenges utility theory arguing that human behaviour is not only affected by self-interest and rationality. Behaviour is influenced by a number of different variables including social, moral, interpersonal factors, habits, loss aversity, and time inconsistency among many others. In the case of residential energy efficiency, policies based on utility theory may not result in satisfactory outcomes (Jackson, 2005; Wilson \& Dowlatabadi, 2007). For instance, a study on non-energy benefits of weatherisation measures in the U.S. concluded that consumers value comfort at $60 \%$ of the value of energy savings (Skumatz, Dickerson, \& Coates, 2000). Another study showed that customers apply a smaller discount rate to weatherisation than other energy efficiency measures such as refrigerators and water heaters (Train, 1985,Wilson \& Dowlatabadi, 2007). In other words, customers at present prefer to invest in other energy efficiency measures rather than on weatherisation.

An important approach to residential energy efficiency is the rebound or take-back effect. It can be explained, in terms of standard economic theory, as an increase in energy use resulting from lower marginal costs of using the energy service (Quirion, 2004 cited in Oikonomou, Becchis, Steg, \& Russolillo, 2009, p. 4975). In practical terms, the rebound effect explains the difference between predicted and calculated energy savings resulting from energy efficiency policies. There is a wide range of literature on this issue. For instance, in New Zealand, evidence shows that improvements in retrofitted insulation are not likely to produce significant savings in energy costs, and energy efficiency gains seem to be taken mainly in comfort enhancement and health savings (Howden-Chapman et al., 2009). Greening, Greene, and Difiglio (2000) analysed 75 rebound effect studies in the literature and concluded that the rebound was $10-30 \%$ for space heating, $0-50 \%$ for space cooling, $10-40 \%$ for water heating, 5-12\% for residential buildings and $0 \%$ for appliances. Milne and Boardman (2000) researched the rebound effect in retrofit energy efficiency projects in low-income households undertaken in Britain over a 20 years period. The authors 
concluded that for low-income housing at a temperature of $14^{\circ} \mathrm{C}, 50 \%$ of the potential energy savings will be achieved; at $16.5^{\circ} \mathrm{C}, 30 \%$ of the potential energy savings will be taken as extra warmth; and at around $19^{\circ} \mathrm{C}, 80 \%$ will be taken as energy saving. Thus, the rebound effect diminishes as temperatures increase. As low-income households generally are not warm enough, any reduction in unit heating cost will likely lead to only a small energy saving and largely an increase in comfort.

\subsubsection{Residential energy efficiency policy and the sustainable development approach: Beyond the direct benefits}

As mentioned in Chapter 1, the direct benefits of residential energy efficiency policies has been broadly discussed in the international energy arena as energy savings and more recently associated to $\mathrm{CO}_{2}$ emission reductions; however, there is an array of other benefits that emerge from residential energy efficiency measures. The literature has referred to these other benefits as ancillary benefits, co-benefits and non-energy benefits.

These concepts are applicable to a broad range of energy policies, because of the multifunctional character of energy issues. In particular, residential energy efficiency policies are multifunctional because they have a direct impact on energy savings, local air pollution reduction, health, quality of life, comfort improvements, employment and new bussiness creation, social welfare enhancement, and poverty alleviation, among others. For that reason, the implementation of residential energy efficiency policies may assist in attaining sustainable development goals. From a policy perspective, “Sustainable development ... entails recognition that environmental problems cannot be considered in isolation from economic, social and also institutional aspects, since they are inextricable linked” (Bartelmus, Moll, Bringezu, Nowak, \& Bleischwitz, 2004).

However, investments in energy efficiency often ignore co-benefits and ancillary benefits and focus only on the direct benefits of energy savings. This omission excludes significant positive social and environmental externalities of energy efficiency measures, which leads to an underestimation of energy efficiency cost-effectiveness in the policy making process (Jakob, 2006; Jochem \& Madlener, 2003; Ürge-Vorsatz, Novikova, Köppel, \& Boza-Kiss, 2009). 
Ancillary benefits and co-benefits are terms found within the macroeconomics and welfare economic literature. In the OECD Workshop on Ancillary Benefits and Costs of Greenhouse Gas (GHG) Mitigation Strategies in 2000, the definition of these two concept was stated as: "The term co-benefits (sometimes also referred to as multiple benefits), signals (monetised) effects that are taken into account as an explicit (or intentional) part of the development of GHG mitigation policies. The term ancillary benefits, indicates impacts that arise incidental to mitigation policies” (Davis, Krupnick, \& McGlynn, 2000, p. 10).

Although ancillary benefits and co-benefits concepts are being currently applied in climate change debate (which is inextricably linked with energy efficiency issues), they were previously applied in the residential energy efficiency research area.

Most of the current research on environmental co-benefits targets GHG emission reduction policies and its impact on local air quality and human health. Jack and Kinney (2010) made a comprehensive literature review of the most recent investigations about this issue and found that despite the large number of co-benefits associated with GHG mitigation policies, their impact on the policy making process has been limited.

Within the energy efficiency field, the earliest research on this issue studied the theoretically possible non-energy benefits derived from energy efficiency policies. Mills and Rosenfeld (1996) classified these co-benefits as improved indoor environment, comfort, health and safety; reduced noise; labour and time savings; improved process control; increased amenity or convenience; water savings and waste minimization; and direct and indirect economic benefits from down-sizing of equipment

In the residential sector, Schweitzer and Tonn (2003) analysed the non-energy benefits of the U.S. Weatherization Assistance Program. Their approach divided the non-energy benefits according to the beneficiaries, which include utility ratepayers, households and societal. The results show that at a discount rate of $3.2 \%$ and over a 20 year time horizon, the Net Present Value (NPV) was positive, and societal co-benefits (including environment) were the highest in terms of NPV. Jakob (2006) calculated that in the Swiss residential building stock, the economic valuation of co-benefits from thermal insulation (i.e. additional insulation, improved window systems, ventilation and heating systems and architectural concepts), may be equal to energy related benefits. On 
the other hand, investments on buildings envelope insulation (walls, roofs or cellars) are profitable in most of the cases if assuming an increasing trend of energy prices and ancillary benefits are taken into account (thermal comfort, reduction of noise and comfort from better ventilation systems).

In another study, Stoecklein and Skumatz (2007) analysed a number of techniques for measuring co-benefits of residential energy efficiency policies. They were classified as direct computational approaches and survey-based approaches (such as willingness to pay, willingness to accept, relative scaling and contingent valuation among others). The authors used labeled magnitude scaling technique to value non-energy benefits obtained from double glazing and super isulation measures of the New Zealand Zero and Low Energy Homes (ZALEH) programme, concluding that the magnitude of non-energy benefits is $26 \%$ of the annual energy savings in the case of double glazing and $37 \%$ in the case of super insulation. Other studies in New Zealand examined residential energy efficiency co-benefits using cost-benefit analysis. The first one showed that the benefitcost ratio is close to 2:1 for a measure of retrofitting houses with insulation. The cobenefits were valued as health gains (savings in medical visits, hospital admissions and days off school/work), energy savings (reduced energy expenditure on electricity and mains gas) and $\mathrm{CO}_{2}$ emissions savings (accrued from electricity and mains gas) (Chapman, Howden-Chapman, Viggers, O’Dea, \& Kennedy, 2009). In New Zealand, another study showed that investments in healthy heaters (heat pumps, wood pellet burners or flued gas heaters), over a payback period of 12 years and with a discount rate of $5 \%$, are justified by the avoidance of the costs associated with asthma, and when savings in energy use and $\mathrm{CO}_{2}$ emissions are accounted, the benefit-cost ratio was slightly greater than 1 (Preval, Chapman, Pierse, \& Howden-Chapman, 2010).

A comprehensive literature review of residential co-benefits was undertaken by (Ürge-Vorsatz et al., 2009).

Within residential energy efficiency measures, the most salient co-benefits are fuel poverty alleviation and health improvement. The term 'fuel poverty' has been used to describe the situation in which households need to expend more than $10 \%$ of their income on fuel to heat their residences to an 'adequate' level of warmth (Boardman, 1991). This level has been set by the World Health Organization as $21^{\circ} \mathrm{C}$ in the living room and $18^{\circ} \mathrm{C}$ in the other occupied rooms (DEFRA \& DTI, 2001). Fuel poverty and 
health have been particularly important to set out policies to improve low-income households' energy condition especially in the U.K. In New Zealand it has been estimated that approximately 10-14\% of households face fuel poverty (Lloyd, 2006; Preval et al., 2010). In general, the issue of energy efficiency in low-income households has been addressed by specific programmes that subsidise thermal improvements in existing houses, heating, and appliances such as the Low Income Home Energy Assistance Program (LIHEAP) and the Weatherization Assistance Program in the U.S., the Warm Front Scheme in the U.K., and the New Zealand Energy Efficiency and Conservation Strategy (including the current Warm Up New Zealand: Heat Smart programme).

One recognised problem for incorporating ancillary benefits and co-benefits in the policy cost-benefit analysis is the difficulty of estimating and agreggating their economic value. Ürge-Vorsatz et al. (2009) stated that a common worldwide approach for measuring co-benefits and their barriers lacks supporting research, although it is highly relevant. However, even if these co-benefits were quantified, it is not clear about the real impact of such estimation on the policy process. Thus, stakeholders' perceptions (including politicians, government officials and academic experts) of the relative importance of co-benefits and ancillary benefits of residential energy efficiency are crucial to determine their possible impact on residential energy efficiency creation, implementation, support and extention. Therefore, this issue requires more specific research. 


\section{Chapter 3: Methodology}

The research used a mixed methods approach due to its nature and purpose. To determine the research approach a literature review on residential energy efficiency policy was carried out. The literature review provided information about the main issues and focus of investigation, as well as the current gaps in research. As shown in Chapter 2, scholars have used propositions from economic and behavioural economics theories to explore residential energy efficiency issues. These propositions can be summarised as economic (cost benefit analysis based on energy savings and based on co-benefits), energy efficiency barriers approach (including market, government and psychological barriers) and the rebound effect theory. They have been used by scholars, central government and local body officials, and politicians to develop or enhance residential retrofit policies. This research uses these propositions to analyse the factors that have shaped the retrofit policy process in Chile and New Zealand. A qualitative approach was used. This approach was appropriate for exploring and understanding a phenomenon that has so far not been fully explored in Chile and has been studied in New Zealand with some of the propositions already mentioned. In the case of this research, the qualitative approach allowed the researcher to obtain in-depth information in order to reconstruct the policy development process, explore its implementation, and analyse how the policy could be supported or expanded in the future. At the same time, the perceived significance of benefits and co-benefits within the policy process was studied using a mixed methods approach. A questionnaire was used to gain additional information about co-benefits that may have been missed in the interviews or the documentary analysis alone. The use of mixed methods enabled data triangulation.

In New Zealand and Chile, in its origin, the research included politicians; however, they were not available for this research (more details about this issue are given in Chapter 8, limitations of the research). Therefore, the interviews were focused on central government and local body officials as well as academic experts who manage the retrofit policy details.

In New Zealand, the policy analysis focused on the Warm Up New Zealand: Heat Smart scheme, and its predecessors: the ENERGYWISE Home Grants programme, the 
Energy Saver Fund scheme and the first New Zealand insulation policies in the mid1970s.

In Chile, the residential energy efficiency policy analysis focused on the insulation retrofit subsidy for low-income people (IRS). The rationale for this decision was that other measures for enhancing the energy efficiency of existing dwellings are in the initial stages (Chapter 4).

\subsection{Methods of data collection}

\subsubsection{Semi-structured interviews}

The interview questions were designed in advance, but they were flexible and able to be modified within the conversation in order to obtain more detailed information on emerging issues and also to make them more appropriate for a particular context and interviewee (Robson, 1993). The interview questions are provided in Appendix 8.

The Chilean sample was purposive and included current and former officials of the central and local authority, two academic experts, one community leader and one social property management entity representative. The aim of interviewing former employees was to gain a richer sense of the issues involved. Seventeen interviewees were selected on the basis that they were involved in the policy making process or they are currently involved in the policy implementation. Some of the interviewees were contacted prior to the field study, others were contacted while doing the field study and others after the field study, in order to refer back to specific topics. The Chilean interviewees are presented in Appendix 5.

The large number of interviewees enabled the researcher to reduce the bias associated with the lack of familiarity of most respondents with the concept of cobenefits. This issue is explained with more detail in Chapter 8 (Limitations of the research). To reconstruct the policy making process, only those interviewees who were originally involved in the policy making process were chosen.

In New Zealand the sample was purposive and included two current officials of the central authority, two academic experts, one community group leader, one government adviser and one social entrepreneur. The selected interviewees have been actively involved in retrofit policy creation and/or implementation. One additional 
government officer was interviewed in Christchurch to collect information about the local air pollution policy. The high relevance of air pollution in the policy process of Chile merited a comparison with New Zealand. Some of the interviewees were contacted prior to the field study and others were contacted while doing the field study. The New Zealand interviewees are presented in Appendix 5.

\subsubsection{Questionnaires}

The questionnaires were designed to obtain information about the importance of some specific benefits and co-benefits in the policy making process, the implementation process and the future support or expansion of the policy. The implementation process questionnaire was jettisoned because most of the interviewees confused it with the policy making process. The (remaining) two questionnaires, a policy creation co-benefit questionnaire and a policy support or future expansion questionnaire, prompted the interviewees to think of co-benefits that were underlying or absent in the policy making process as well as those co-benefits that could be important as arguments for future policy. The questionnaires were used to gather indicative data, without any aim of obtaining a statistically significant result. The justification for this decision was the purpose of the questionnaire and the size of the sample.

The co-benefit questionnaire contained questions that consisted of a ranking from one to five for different co-benefits. One indicated 'not important' and five indicated 'very important'. Averages indicate assigned importance, but with no statistical significance imputed ${ }^{3}$.

In Chile, the policy creation co-benefit questionnaire was administered to seven government officials involved in the respective process. The policy support or future expansion questionnaire was administered to 14 participants (national and local government officials and two academic experts).

\subsubsection{Documentary analysis}

The main sources used in the Chilean documentary analysis were national decrees and their modifications, public organisations' internal mandates (resoluciones exentas),

\footnotetext{
${ }^{3}$ Averages: Very important $=4.8-5.0 ;$ Important $=4.0-4.7$; Moderate $=3.0-3.9 ;$ Low $=2.0-2.9$; Very low $=1.0$ - 1.9.
} 
policy creation and implementation studies, energy statistics obtained from the Chilean National Institute of Statistics and the National Commission of Energy and information from the Congressional Library (such as presidential speeches, bills, territorial information, etc.). Information on co-benefits was mainly obtained from the social and economic studies associated with the policies analysed. Most of the information is available online; however, other information was formally requested from the government through the Transparency Law (Ley de Transparencia).

The main sources used in New Zealand were Acts, Bills, public and private organisations' annual reports, Parliamentary debates and academic studies. Most of the information is available online; however, some information was provided by interviewees or obtained from the Parliament Library.

\subsection{Data Analysis}

In both Chile and New Zealand an inductive approach was used. Further data was obtained in an iterative process, "weaving back and forth between data and theory" (Bryman, 2008, p. 12). The Grounded Theory approach to data analysis was used as a strategy for generating theory from data. In the case of the research, this approach enabled the researcher to organise disaggregated or incomplete pieces of information into codes to categorise data (open code), put it in a different way (axial code) and interrelate or validate it (selecting code) (Bryman, 2008).

\subsection{Ethical issues}

The Victoria University‘s Human Ethics Committee granted approval for this research. Each interviewee was given information, prior to the interview, about the thesis purpose and methods. The interviewees signed the consent form declaring their preferences as to confidentiality, recording data and data review. 


\section{Chapter 4: Chilean context}

\subsection{Geography and climate}

Chile is a long and narrow strip of land with a broad range of climates and unique geography. Chile’s sovereign area consists of Polynesian, South-American continental and Antarctic territories. Chile extends from $17^{\circ} 30^{\prime}$ latitude south to $56^{\circ} 30^{\prime}$ latitude south excluding the Antarctic territory.

The country covers four climate domains (desertic tropical, subtropical, temperate and polar) and a broad range of climates. Despite the differences in latitude, the temperatures do not vary significantly from north to south due to the oceanic influence, the Humboldt Current and the air masses; however precipitation varies from less than $1 \mathrm{~mm}$ per annum in Arica (north) to 4,800 mm in Magallanes (south) (INE, 2010). More information is provided in Appendix 6.

\subsection{Economic context}

Chile is characterised by an open and liberal economy based on commodity exports (mainly copper) (IEA, 2009). In 2009, the GDP reached US\$ 243 billion (OECD, 2010) and, by 2016, the GDP is estimated to reach US\$ 371 billion which implies an annual growth of 6\% (IMF, 2010). Chilean governments have maintained a budget surplus since 2001, through a fiscal rule, with the surplus reaching US\$ 21.5 billion in 2008 (12\% of the GDP) because of the rising price of copper between 2006 and 2008 (IEA, 2009). More information is provided in Appendix 6.

In January 2009, Chile became the first South American country to join the OECD and the second Latin American country after Mexico. The current OECD recommendations for residential and commercial sectors emphasise the management of energy demand and energy conservation measures, taking into account the environmental, social and economic benefits of those measures (OECD, 2011). 


\subsection{Social context}

The Chilean population was approximately 16.6 million in 2009 (MIDEPLAN, 2010) and, by 2020 and 2050, it has been estimated at 18.5 million and 20.2 million respectively (INE \& CEPAL, n.d.). The most populated area is the Metropolitan region in which Santiago, the capital, is located. In this region the population reached 6.75 million in 2009, 41\% of the total Chilean population (MIDEPLAN, 2010).

Chile has the lowest poverty rate in Latin America (European Commission, 2010). The rate of the poor population dropped from $20.2 \%$ of the total population in 2000 to $15.1 \%$ in $2009^{4}$.

Despite its social and economic achievements, Chile still has high income and wealth inequality. In 2006, Chile’s Gini coefficient was 52 (World Bank, 2011a) with the richest 20\% sharing 56.8\% of the national income in 2006 (World Bank, 2011b). The Gini coefficient is more unequal than that of New Zealand (31.7 in 2007). More information is provided in Appendix 6.

\subsection{Energy context}

As mentioned before, Chile is characterized by an open and liberal economy. This feature has also affected the electricity sector, which was privatized in the 1980s. Actually, Chile has increased its installed capacity from 4,426 MW in 1990 to 16,154 MW in 2009 (Ministerio de Energía, 2010).

Chilean geography has shaped the four existing electricity systems that are distributed longitudinally along the country (Map 4.1). The most important two grids are the Interconnected System of the Great North (Sistema Interconectado del Norte Grande, SING) that supplies about 25\% of the total Chilean electricity consumption and the Central Interconnected System (Sistema Interconectado Central, SIC) that supplies about 74\% (Aguirre, 2008). SING electricity comes mainly from thermal production (coal, gas, diesel and others) and supplies only 6\% of Chilean domestic electricity consumption but over $90 \%$ of the mining and big industry sector electricity

\footnotetext{
${ }^{4}$ In 2009, the poverty line was defined as a monthly income per capita less than NZ\$176 (\$64,000 Chilean pesos) in urban areas and NZ\$ 118 (\$43,000 Chilean pesos) in rural areas (MIDEPLAN, 2010).
} 
consumption (Aguirre, 2008). On the other hand, SIC combines hydro and thermal electricity production in relatively similar proportions and supplies more than $92 \%$ of Chilean population. In 2009, electricity produced for SING was 14,900 GWh and for SIC 41,700 GWh (CNE, n.d.).

In Chile, energy efficiency issues gained prominence recently because of the high dependence on imported gas and hydropower electricity generation. In the 1990s Chile started to import gas from Argentina, reducing the cost of fuel supply and decreasing the risk of lack of hydropower supply in dry seasons (Tokman, 2007). At the end of 1999, the lack of investments in energy supply projects resulted in a small gap between installed capacity and maximum demand. In addition, gas supply from Argentina showed high instability (Tokman, 2007). This scenario has led Chile to face three periods of electricity deficit during the last decade. The last one in 2007, was the result of a combination of a drought that affected hydro generation and unpredictable reductions of Argentinean gas supply (IEA, 2009).

In order to overcome Chilean energy security risks, the Government has launched different policies. From the demand side, the government created the National Energy Efficiency Programme (Programa País de Eficiencia Energética, PPEE) in 2005. As Borregaard $^{5}$ stated, the PPEE was proposed in 2004 to the Ministry of Economy as a long term policy to "promote the efficient use of the electricity beyond the habitual savings campaigns” (Borregaard interviewed by Rubio, 2008). The creation of the PPEE involved the participation of different ministries and private organisations. The PPEE started with US\$100.000 (coming from the private sector) and in 2008 it reached US\$13 million (Borregaard interviewed by Rubio, 2008). In 2008 the PPEE was transferred to the National Commission of Energy (Comisión Nacional de Energía, $\mathrm{CNE}$ ) that worked on the development a Chilean energy efficiency long term policy and the enhancement of the energy efficiency administration (Tokman, 2007).

The Chilean Ministry of Energy was created in 2009 and the PPEE was transferred from the National Commission of Energy to this Ministry. In 2010, the PPEE was transformed into the Energy Efficiency Chilean Agency (Agencia Chilena de Eficiencia Energética, AChEE). The AChEE is a public-private agency that promotes

\footnotetext{
${ }^{5}$ Economist, former government official of the Ministry of Economy. She promoted energy efficiency issues for first time in Chile and presented the PPEE proposal to the Minister.
} 
energy savings in all sectors of the economy and society as well as of all types of energy. The AChEE seeks the decoupling of energy use from GDP in all economic sectors and also promotes an energy efficiency market emphasising the industry sector (Cárdenas-Lailhacar, 2010).

Most Chilean energy efficiency initiatives have been channelled through the PPEE. In the residential sector, the PPEE funds the light bulb replacement programme and the insulation retrofit subsidy, both focused on vulnerable households. The light bulb replacement programme’s budget was NZ\$6.3 million in 2008 and NZ\$ 6.7 million in 2009, for a replacement of approximately 1,400,000 bulbs per year.

With regard to thermal enhancement of dwellings, new households have been targeted with the thermal standards of 2000 and 2007 whereas measures for existing dwellings are in an initial stage. Authorities have been addressing thermal enhancement of existing households through the development of three retrofit measures: insulation, housing certification and heater replacement. While an insulation subsidy for lowincome people has been implemented from 2008, housing energy certification and heater replacement have not yet been fully implemented. The certification will be managed by MINVU and the Energy Efficiency Chilean Agency and it will start as a voluntary measure that includes space and water heating, and lighting. The idea is to generate information about household's energy performance to stimulate the residential energy efficiency market (Bardi, personal communication, November 24, 2010) ${ }^{6}$. The heater replacement measure is being addressed by the Ministry of the Environment as a part of the pollution reduction plan of Temuco and Padre las Casas and in other cities in the south of Chile. The Ministry is developing a heaters emission standard and is planning to replace 4,000 heaters during 2011. The definitive measure is still being studied, but it will likely operate as a co-payment orientated to all income groups. One thousand heaters will be replaced in Temuco and Padre las Casas (Araucanía region) and 700 in Coyhaique (Aysén region) as pilot. The budget for this is NZ\$ 3.3 million (Silva, personal communication, November 26, 2011) ${ }^{7}$.

\footnotetext{
${ }^{6}$ Ms. Carla Bardi is an official of the Ministry of Energy.

${ }^{7}$ Ms. Jimena Silva is an official of the Ministry of the Environment.
} 
Map 4.1. Chilean electricity grids ${ }^{8}$.

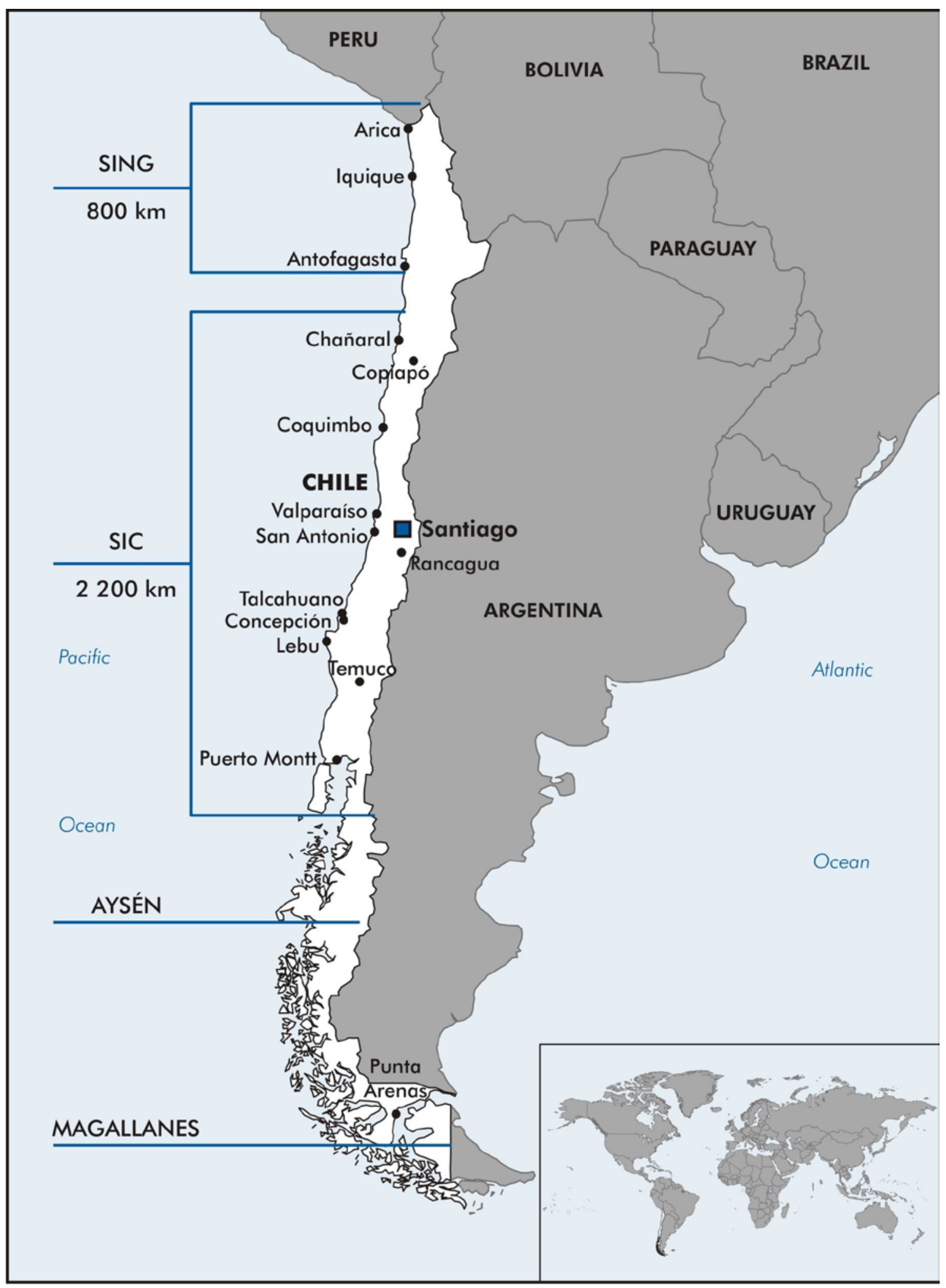

${ }^{8}$ Map used with permission from the International Energy Agency. Chile Energy Policy review 2009 (C) OECD/IEA, map 1, page 20. 


\subsection{Chilean energy figures}

In 2009, the Chilean economy sectors consumed 1,046 PJ altogether. Energy use was shared by transport (34.6\%), industry and mining (36\%), commerce-publicresidential (25.6\%) and energy sector (3.9\%). Residential sector energy use made up $20.8 \%$ of the total energy consumption in 2009, with the main fuels being wood, liquefied gas and electricity (Ministerio de Energía, 2010).

Figure 4.1. Chilean sectoral shares of energy use (\%) in 2009.

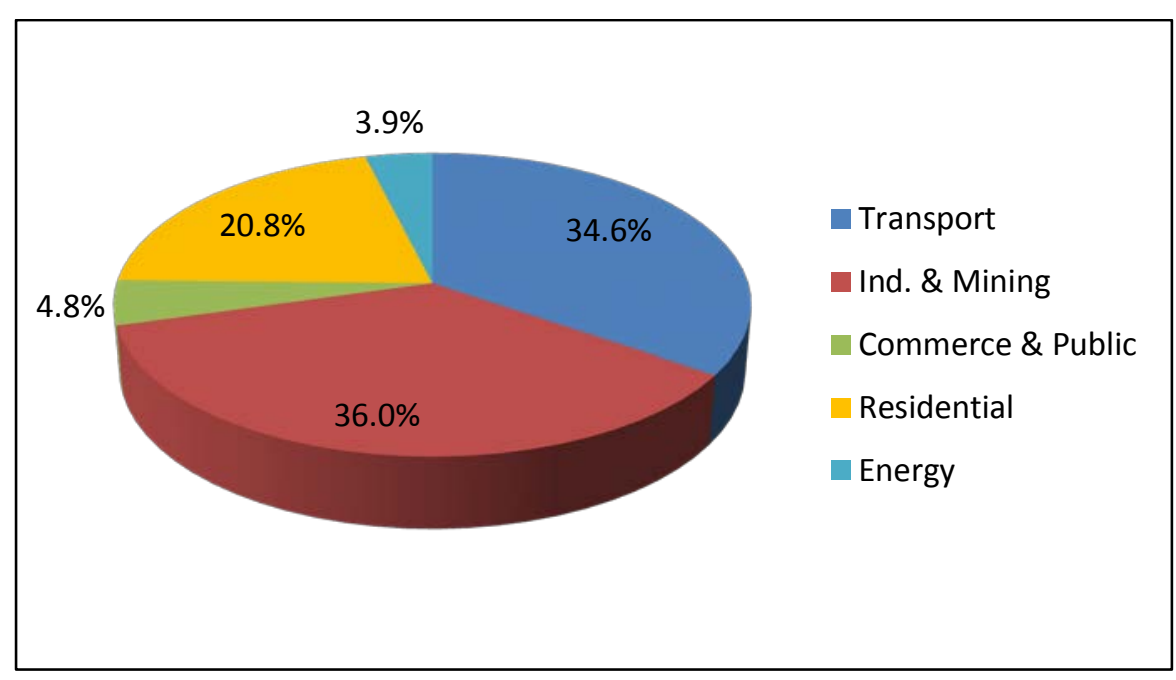

Source: Ministerio de Energía (2010). 
Figure 4.2. Chilean residential fuel use shares (\%) in 2009.

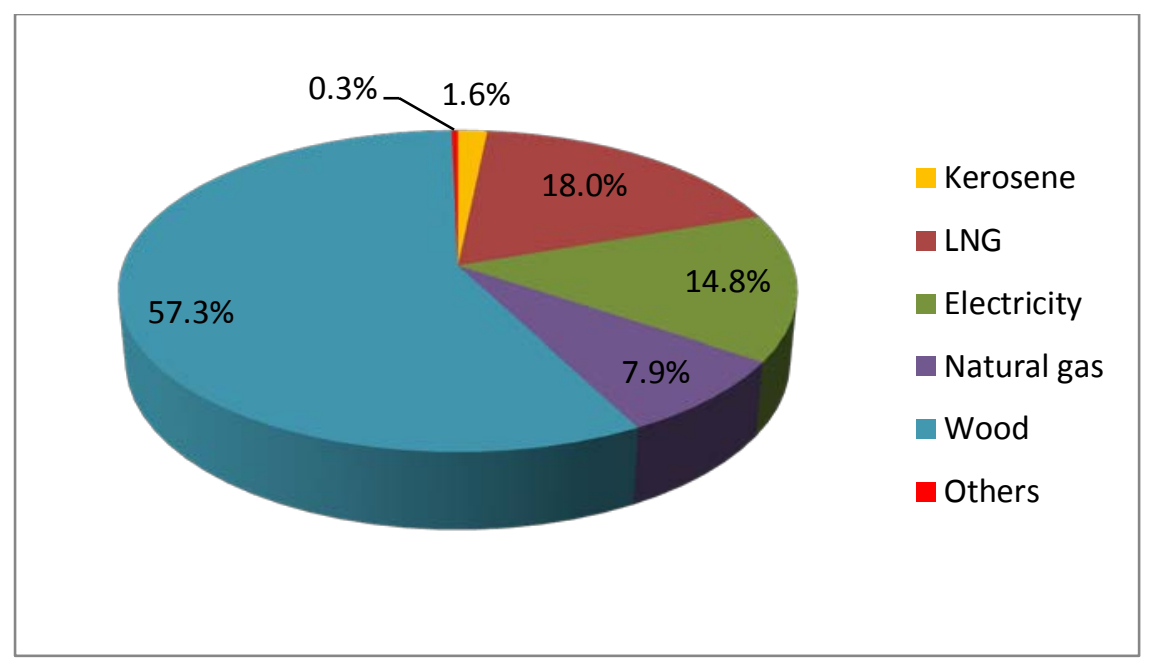

Source: Ministerio de Energía (2010).

Residential space heating fuels used in three different Chilean cities from Santiago to the South are presented in Appendix 1. Wood is the cheapest fuel and it is extensively used in the south of Chile for space heating and cooking (Table 4.1). Residential electricity is not common for space heating because it is more expensive than other fuels (NZ 36 cents $/ \mathrm{kWh})^{9}$ and because of the heaters' capital costs. The prices presented below are selling prices to consumers so they do not take into account capital costs of heaters.

Table 4.1. Residential fuel real prices for residential space heating (NZ cents/kWh) ${ }^{10}$.

\begin{tabular}{|l|c|c|c|c|}
\hline & Liquefied gas & Kerosene & Wood & Natural gas \\
\hline Average & 16 & 13 & 9 & 17 \\
\hline
\end{tabular}

Source: Adapted from (Ambiente Consultores \& PRIEN, 2007).

Fossil fuels represent $71 \%$ of the total primary Chilean energy consumption, whereas renewable sources, such as hydro wind and biogas represent 29\%. Fossil fuel

\footnotetext{
${ }^{9}$ The price of the electricity is at April 2011 (www.chilectra.cl).

${ }^{10}$ The prices were adjusted using a Chilean Consumer Price Index (IPC) of 9.8\% from December 2007 to February 2011 and then using a money exchange rate of: \$ 1 NZ = \$ 364 Chilean pesos. The prices are an average of three big cities: Santiago, Concepción and Temuco.
} 
dependence is underlined by the fact that $97 \%$ of the oil consumption is imported, along with 95\% of imported coal and 27.5\% of gas (Ministerio de Energía, 2010).

Figure 4.3. Total primary energy consumption (\%) in 2009.

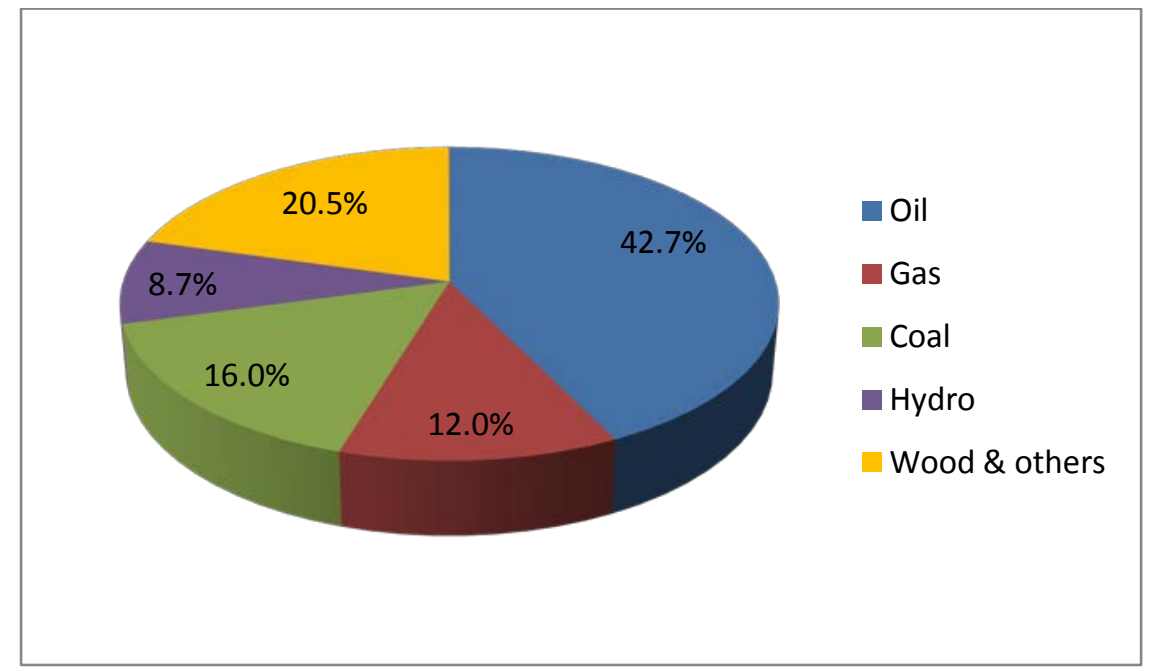

Source: Ministerio de Energía (2010).

In Chile, energy use - GDP ratio (energy intensity) has decreased from 0.19 in 2000 to 0.16 in 2007 whereas the OECD countries in total reduced the ratio from 0.19 in 2000 to 0.17 in 2008. This figure shows that Chile has improved energy efficiency over the last decade, however; still there is space for improvement (Ministerio de Energía, 2010). 
Figure 4.4. Energy intensity (total primary energy supply per unit of GDP) ${ }^{11}$.

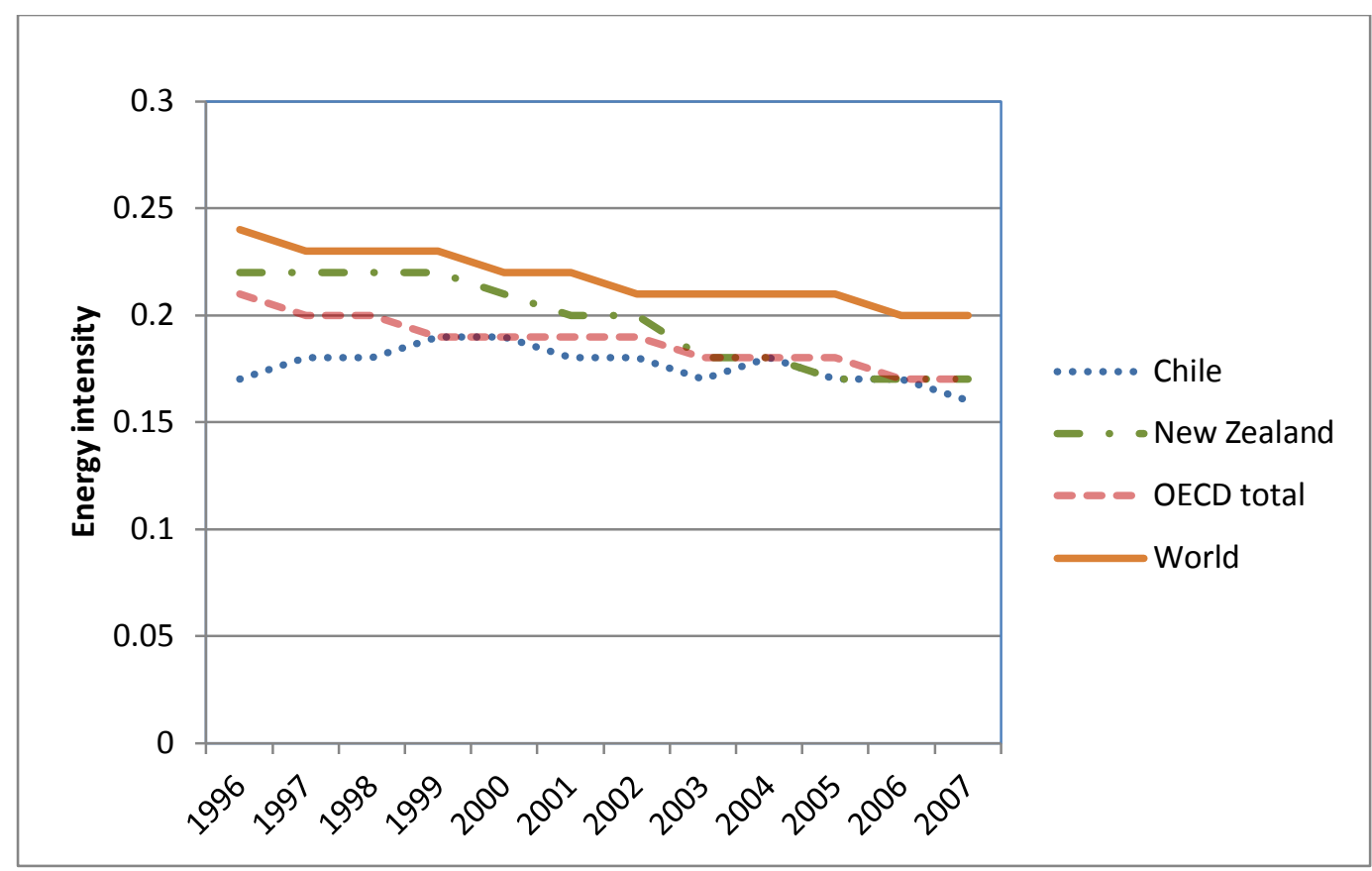

Source: OECD (2010).

Energy demand is forecast to increase in all economic sectors. Including energy efficiency policies, it is estimated that by 2020, 13,000 MW of new electricity capacity will be necessary to meet the demand. In the commercial, public, and residential sectors electricity demand is estimated to increase sharply at $6.5 \%$ per year until $2030^{12}$. In contrast, whereas other fuels such as natural and liquefied gas are only estimated to increase at a rate of $3.3 \%$ annually, and wood is projected to increase by $2.3 \%$ per year $^{13}$ (O`Ryan, 2008).

With regard to water supply for hydro electricity generation, it has been projected that climate change will likely reduce the annual rainfall in the central part of the country (where most of the Chilean population is concentrated), due to changes in El Niño and La Niña currents. A decrease in the amount of snowfall in the Andes is also expected (CNE, 2008).

\footnotetext{
${ }^{11}$ Tonnes of oil equivalent (toe) per thousand 2000 US dollars of GDP calculated using PPPs.

${ }^{12}$ Disaggregated information for the residential sector was not found.

${ }^{13}$ Projections for other residential fuels such as kerosene, coal and diesel have a low level of confidence (O'Ryan, 2008); therefore, they are not presented in this research.
} 
With regard to climate change, Chile promulgated the Kyoto Protocol in 2005 and it committed to develop policies in an array of areas including energy efficiency. However, Chile did not commit to reduce GHG (Protocolo de Kyoto, 2005). It has been estimated that Chile produces $0.3 \%$ of the global carbon emissions; however, the expected increase of electricity produced by coal fired power plants in the future, is likely to result in a carbon emission increase of 130\% by 2050 (PRIEN, 2008, cited in CNE, 2008).

\subsection{Key national organisations for the development of residential energy efficiency policies}

Ministry of Housing and Urbanism (Ministerio de Vivienda y Urbanismo, MINVU): has the primary responsibility for improving housing, neighbourhoods and cities. A main focus for MINVU is low-income households.

Ministry of Economy, Development and Reconstruction (Ministerio de Economía, Fomento y Reconstrucción): The Ministry created and assumed the coordination of the Energy Efficiency National Programme (Programa País de Eficiencia Energética, PPEE) created in $2005^{14}$.

National Energy Commission (Comisión Nacional de Energía, CNE): Is a decentralized public organisation that ensures national electricity supply. In 2008 the PPEE was transferred to the CNE in order to develop a Chilean energy efficiency. In 2010, after the creation of the Chilean Energy Efficiency Agency, the CNE ceased being responsible for energy efficiency issues.

Ministry of Energy (Ministerio de Energía): has the primary responsibility for energy policy creation, coordination and compliance as well as for energy advice to the government in energy issues.

Ministry of the Environment, former National Commission of the Environment (Ministerio del Medio Ambiente, ex Comisión Nacional del Medio Ambiente): Provides

\footnotetext{
${ }^{14}$ The PPEE has been supported for a number of public organisations (including the ministries of Economy; Secretariat General of the Presidency; Public Works, Transport and Telecommunications; Education; Housing and Urbanism, Mining and the National Commission of Environment, the Municipalities Association and the National Energy Commission).
} 
advice to the Chilean president on matters related to the development of environmental policies, including climate change policies and pollution reduction plans.

Chilean Energy Efficiency Agency (Agencia Chilena de Eficiencia Energética, $A C h E E)$ : Is a legal person that involves public and private participation. The members of the AChEE include representatives of the Ministry of Energy and the Chilean Treasury and various representatives of the economy and society such as universities, universities and companies.

Building Institute (Instituto de la Construcción): is a non-profit private corporation that gives advice to the government on building issues. The board includes representatives of the government as well as the private sector.

\subsection{Local authorities}

Chile is divided into 15 administrative regions (Map 4.2). Each region has a number of provinces which, in turn, are divided into comunas. The major authority of each region is the intendente who represents the president directly. Every province governed by a gobernador and every comuna by an alcalde. The highest level of administration of a region is the responsibility of the regional government. The regional government consists of the intendente and the regional council (consejo regional), the gobernadors and the economic and social provincial council (consejo económico y social provincial) (Ley Orgánica Constitucional sobre Gobierno y Administración Regional, 2005). The smallest administrative areas or comunas rely on autonomous public corporations called municipalities (Ley Orgánica de Municipalidades, 1988).

Ministries also have regional representation. Every region has a Regional Ministerial Secretariat (Secretaría Regional Ministerial, SEREMI). The Ministry of Housing and Urbanism has an additional regional entity, the Housing and Urbanisation Service (Servicio de Vivienda y Urbanización, SERVIU) responsible for housing policy implementation at a regional level.

Regional Energy Efficiency Board (Mesa Regional de Eficiencia Energética): is a group work that seeks the regional energy efficiency It comprises of public and private organisations including the intendente, gobernador, regional ministerial secretariats and universities. 
Figure 4.5. Residential energy efficiency public authorities.

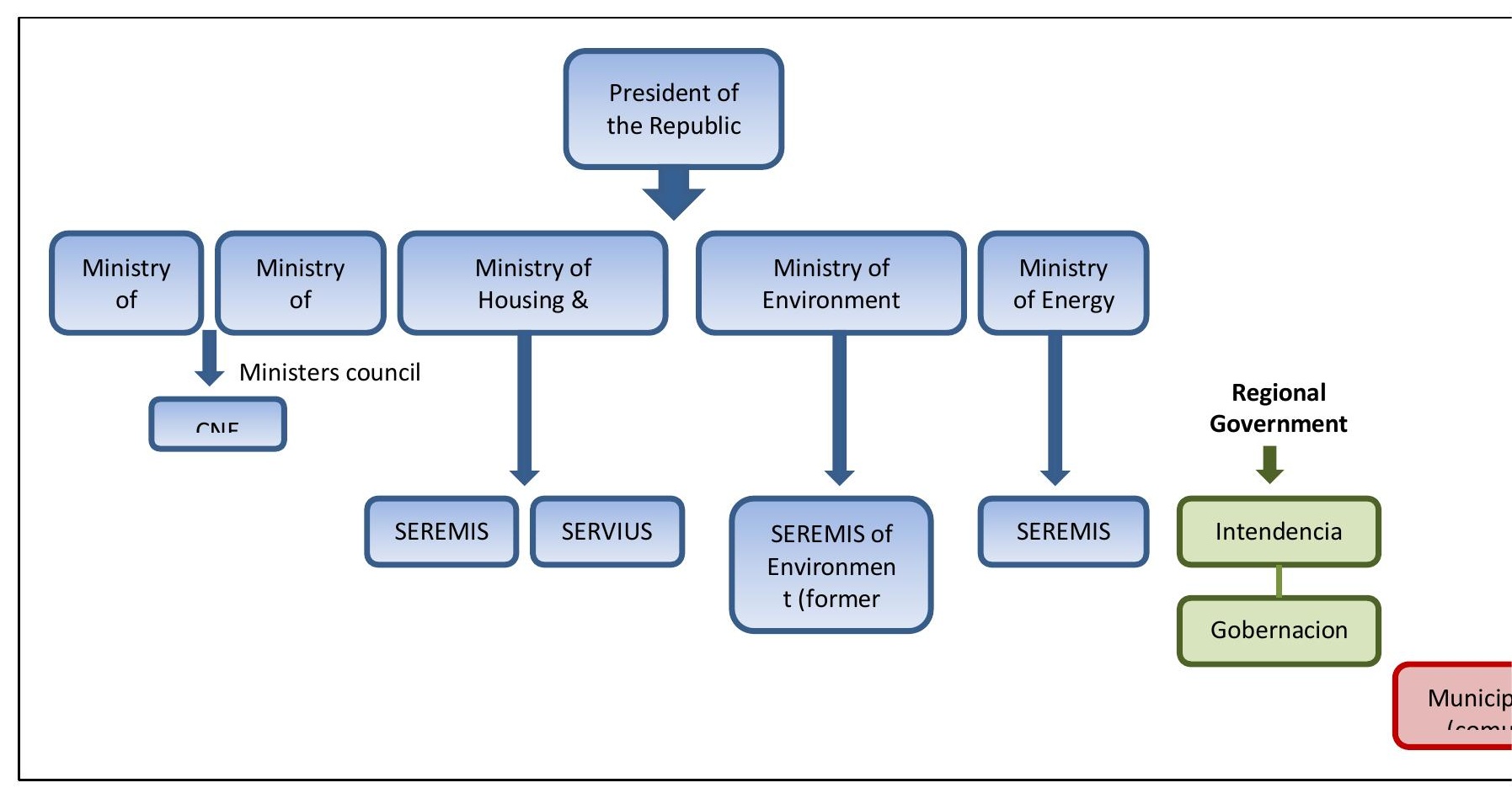

Author: Alejandra Pérez. 
Map 4.2. Administrative regions of Chile ${ }^{15}$.

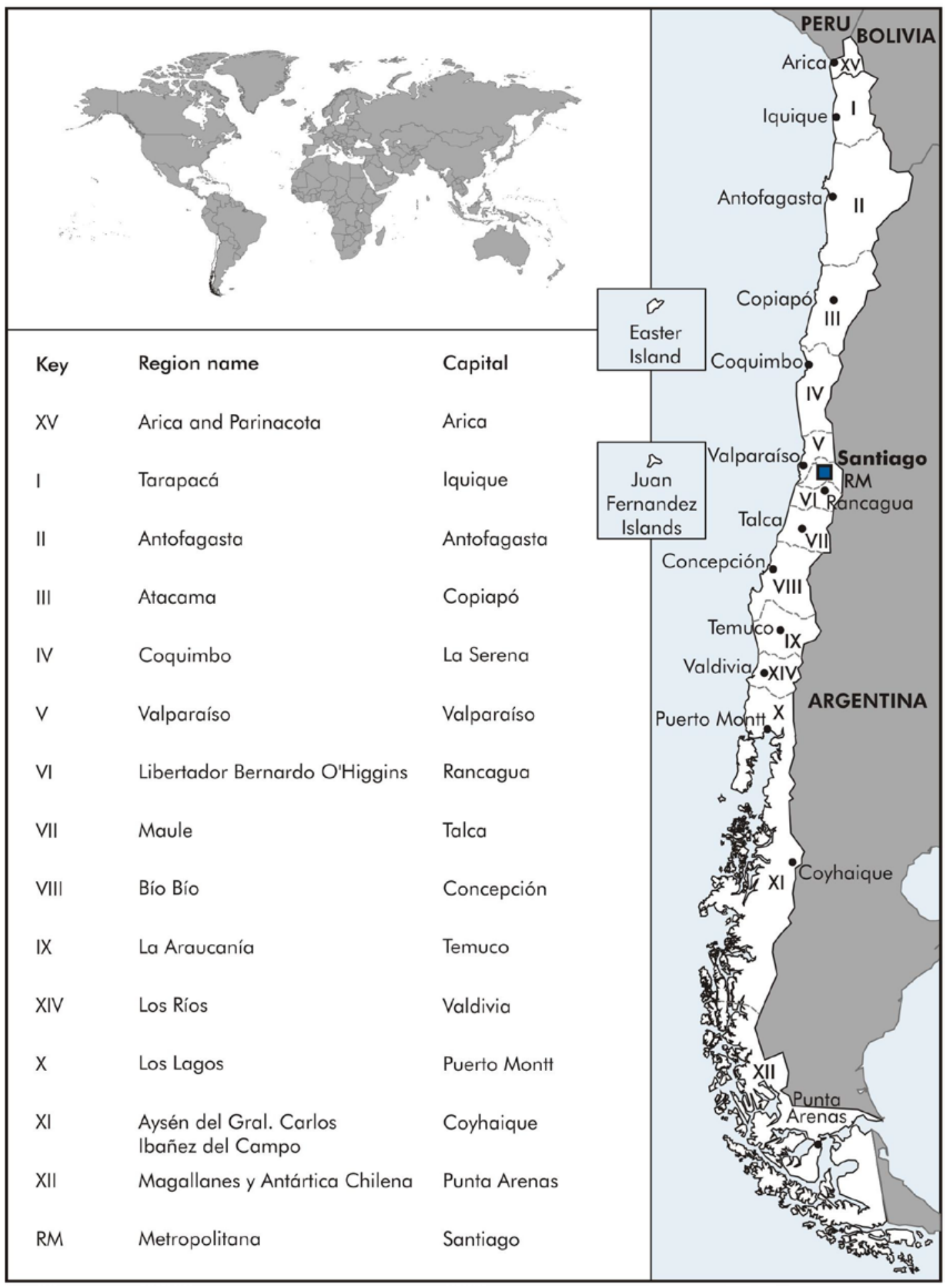

\footnotetext{
${ }^{15}$ Map used with permission from the International Energy Agency. Chile Energy Policy review 2009 ○ OECD/IEA, map 1, page 20.
} 


\subsection{Local context: Local air pollution in the comunas of Temuco and Padre las} Casas

Temuco and Padre las Casas two comunas of The Araucanía region. The region is situated approximately in the middle of Chile, and extends from $37^{\circ} 35^{\prime}$ and $39^{\circ} 37^{\prime}$ latitude south and from the Argentinean border to the Pacific Ocean. For more details about the comunas see Appendix 2.

With regard to residential energy consumption, the most important residential fuel is wood. Its use has produced severe air pollution problems in the comunas of Temuco and Padre las Casas. It has been estimated that residential wood burning for cooking and space heating is responsible for $87 \%$ of the particulate material (PM) concentration in the air (Sanhueza, 2005). The two comunas were declared as $\mathrm{PM}_{10}$ saturated zones in 2005 (Decreto $\left.N^{\circ} 35,2005\right)^{16}$ and consequently, a pollution reduction plan has been implemented from the same year ${ }^{17}$.

In Temuco and Padre las Casas as well as in other areas of the South of Chile, local air pollution due to firewood use for space heating and cooking has become a major environmental problem. Wood is part of the Chilean southern culture and traditions used by all social levels in urban and rural areas. Wood is also a very cheap energy resource; however "The market for the production commercialization and consumption of wood is highly informal and it lacks technical and environmental practices” which results in high humidity wood consumption and consequently, on nonefficiency use of wood and high amounts of fine particulate matter in the air (DICTUC, 2008, p. 73).

\footnotetext{
${ }^{16}$ A saturated area is defined when the $\mathrm{PM}_{10}$ standards are exceeded. This occurs when the percentile 98 of 24 hours, registered in any period of the year by an official monitoring station, is over $150 \mathrm{mg} / \mathrm{m}^{3} \mathrm{~N}$ and the annual average of $\mathrm{PM}_{10}$ exceeds $50 \mathrm{ug} / \mathrm{m}^{3}$ during three consecutive years (Decreto $N^{\circ} 59,1998$ ).

${ }^{17}$ According to the Chilean legislation, once a zone is declared $\mathrm{PM}_{10}$ saturated, it is possible to create a pollution reduction plan (Ley sobre BasesGenerales del Medio Ambiente, 1994; Decreto N 94, 1995).
} 
Photo 4.1. Wood cooking stove of Temuco.

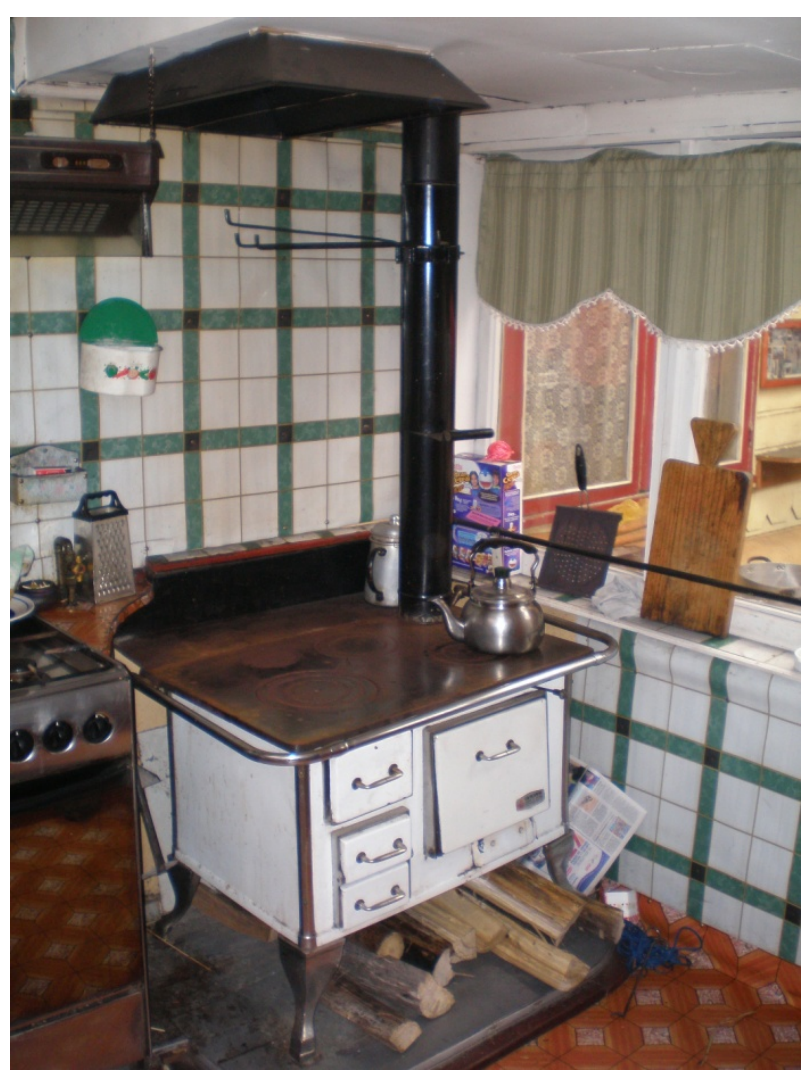

Note: In Temuco and Padre las Casas wood stoves are used for cooking and for space heating.

Author: Alejandra Pérez. 


\section{Chapter 5: New Zealand context}

\subsection{Geography and climate}

New Zealand is located in the south-west Pacific Ocean and consists of two main islands: the North Island $\left(113,729 \mathrm{~km}^{2}\right)$ and the South Island $\left(150,437 \mathrm{~km}^{2}\right)$ and a number of other small islands. Altogether, the islands comprise an area of $270,500 \mathrm{Km}^{2}$. Administratively; New Zealand extends from $33^{\circ}$ to $53^{\circ}$ south latitude. Its length exceeds 1,600 km and its widest part is $450 \mathrm{~km}$ (Statistics New Zealand, n.d.). The climate varies dramatically from warm subtropical in the most northern area to cool temperate in the southern areas (Statistics New Zealand, n.d.a). Annual precipitation ranges from 600 to 1,600 $\mathrm{mm}$ in most areas of New Zealand with a dry period in summer. The mean annual temperatures vary from $10^{\circ} \mathrm{C}$ to $16^{\circ} \mathrm{C}$ and the coldest month is July (NIWA, n.d.). More information is provided in Appendix 7.

\subsection{Economy}

New Zealand has one of the most de-regulated economies among the OECD countries (The Treasury, 2010). From 2000 to 2007, the GDP expanded by 3.5\% on average per year; however, in the March quarter of 2008, New Zealand entered an economic recession accentuated by the global financial crisis (The Treasury, 2010)

In terms of fiscal accounts, New Zealand ran a surplus of NZ\$ 8.0 billion in the period 2006-2007 and NZ\$ 2.4 billion in 2007-2008. However, in the year 2008-2009, the country registered a fiscal deficit of NZ\$10.5 billion (The Treasury, 2010). In 2009, the GDP was NZ\$ 185 (The Treasury, 2010) and by 2020, the GDP is forecast to grow at a rate of around 3\% per annum until 2020 and around 2\% annually from 2020 to 2030 (MED, 2010a). More information is provided in Appendix 7.

\subsection{Social context}

In June 2011, the population in New Zealand was approximately 4.41 million (Statistics New Zealand, n.d.b) and projections for 2026 are estimated at 5 million 
people (Ministry of Social Development, 2010). By 2020, the New Zealand population is expected to reach 4.8 million and by 3030, 5.1 million, with the number of households forecast to increase by 1.2\% per year, reaching 1.9 million in 2020 (MED, 2010c) and 2.1 million by 2030 (Statistics New Zealand, 2010a).

The proportion of poor people in 2009 was $15 \%{ }^{18}$, which is slightly higher than in the 1980s, but less than the rate's peak in the mid-1990s. The current rate is a result of a rise in the proportion of housing costs to household income (Ministry of Social Development, 2010). Although the percentage of poor people is around the same as in Chile, the poverty threshold in terms of income per capita is higher in New Zealand than in Chile (around 6 times higher). Considering that prices for space heating in New Zealand (as shown later) are cheaper than in Chile, relative fuel affordability for Chilean low-income households compares poorly with New Zealand.

In terms of inequality, New Zealand’s Gini coefficient was 32.3 in 2009 (based on disposable income before deducting housing costs), which was higher than in 2007 (31.7), showing an increase of inequality in the last years (Perry, 2010). More information is provided in Appendix 7.

\subsection{Energy and energy efficiency context}

In New Zealand the thermal insulation standards were created in 1978, as a reaction to the oil price shock of the 1970s (Lah, 2009). Another initial advance in this matter were the interest free loans for ceiling retrofits available in the period from 1975 to 1983, which covered approximately 133,000 homes (McChesney, Smith, \& Baines, 2006). However, it was not until 1995 that the Energy Saver Fund, a more systematic programme, was introduced with a budget of NZ\$18 million over five years (McChesney et al., 2006).

The Energy Efficiency and Conservation Authority (EECA), set up in 1992 as part of the Ministry of Commerce, is the government organisation responsible for

\footnotetext{
${ }^{18}$ Population living below a threshold of $60 \%$ of the median household income. The overall median household income in 2009 was estimated at NZ\$ 61,000 or NZ\$ 30,700 per equivalent adult, after tax and before housing costs (Perry, 2010).
} 
energy efficiency. EECA managed the Energy Saver Fund the subsequent programmes: the ENERGYWISE ${ }^{\mathrm{TM}}$ home grants and the Warm Up New Zealand: Heat Smart.

A significant advance in terms of energy efficiency was introduced in 2000, when New Zealand stated its energy efficiency objectives in the Energy Efficiency and Conservation Act 2000. The Act's purpose is to promote energy efficiency, energy conservation and the use of renewable energy. After the enactment of the Conservation Act 2000, EECA has been operated as an independent government agency (IEA, 2001). Nowadays, EECA is one of the main crown entities ${ }^{19}$ responsible for giving advice to the government in energy efficiency matters and implementing energy efficiency policies.

The broader energy context is that energy advice, and energy policy development and implementation are the responsibility of the Ministry of Economic Development (MED). In 2007, the Ministry released the New Zealand Energy Strategy which established significant goals for carbon emission reductions and renewable energy production such as the creation of an Emission Trading Scheme and a goal of 90\% of electricity to be produced from renewable sources by 2025. However, the strategy is currently under review, after the election of the National Party government in late 2008 (APEC, 2009). In 2010, a draft of the Strategy was published for public consultation (MED, 2010b).

Energy efficiency issues were addressed in 2007 a New Zealand Energy Strategy' companion document: the New Zealand Energy Efficiency and Conservation Strategy whose purpose is "to promote and increase the uptake of energy efficiency, energy conservation and renewable energy programmes across the economy and to make doing so part of the normal behaviour of New Zealanders” (EECA, 2007, p. 10).

In terms of energy and climate change, New Zealand ratified the Kyoto Protocol in 2002, committing to a GHG emission reduction to 1990 levels over the period from 2008 to 2012 or to take responsibility for any deficit by buying traded credits to cover this deficit (Ministry for the Environment, 2010). Although New Zealand's GHG emission represents only about $0.3 \%$ of total global emissions, in terms of per capita

19 “... subject to the Crown Entities Act 2004. It is governed by a Board of eight members with experience in energy, the environment, community services, commerce, the public sector and science and technology. The Board reports to the Minister of Energy and Resources” (EECA, 2010, p. 7). 
emissions, it ranks $12^{\text {th }}$ globally (MED, 2007). Since 1988, the Ministry of the Environment has been coordinating climate change programmes. Nowadays, it leads administration of the Emission Trading Scheme (ETS) that includes all sectors of the economy, including the agricultural sector, under the Climate Change Response Act 2002. This Ministry is also responsible for other national environmental issues such as air pollution.

Climate change is also a matter of local government. Under the Local Government Act 2002 and the Resource Management Act 1991, local government is responsible for considering climate change effects and energy efficiency (Ministry for the Environment, 2008): “All persons exercising functions and powers under it, in relation to managing the use, functions and powers under it, in relation to managing the use, development, and protection of natural and physical resources, shall have particular regard to the efficiency of the use of energy as well as the effects of climate change" (Resource Management Act, 1991). Regional councils shall consider energy efficiency and the effects of climate change in decisions about water, air and land resources management; biosecurity; and natural hazards management, among others. The same applies for city and district councils, whose functions include land-use planning and decision making; building control, and community services, among others (Ministry for the Environment, 2008).

In New Zealand, local government is carried out by regional councils and territorial authorities (city councils or district councils) (Map 5.1 and 5.2) which, as in Chile, are autonomous. In total, there are 12 regional councils and 74 territorial authorities (16 city councils and 58 district councils). Also, local authorities represent their communities and communicate with central government agencies (Local Government Online, n.d.). Many local authorities have also developed their own retrofit programmes. For instance, the Auckland Council has recently expanded an existing programme available only for the West Auckland to the whole Auckland region. The 'Retrofit your Home' scheme is based on the Warm Up New Zealand: Heat Smart Programme and a partnership with EECA to provide insulation and clean heater devices. The mechanism is a loan up to NZ\$ 5,000 that beneficiaries can pay back to the Council over a period of 10 years through their property rates. The Retrofit your Home 
initiative has a budget of \$3 million for the period 2011 to 2012 (Auckland Council, 2011).

Figure 5.1. Key residential energy efficiency public authorities.

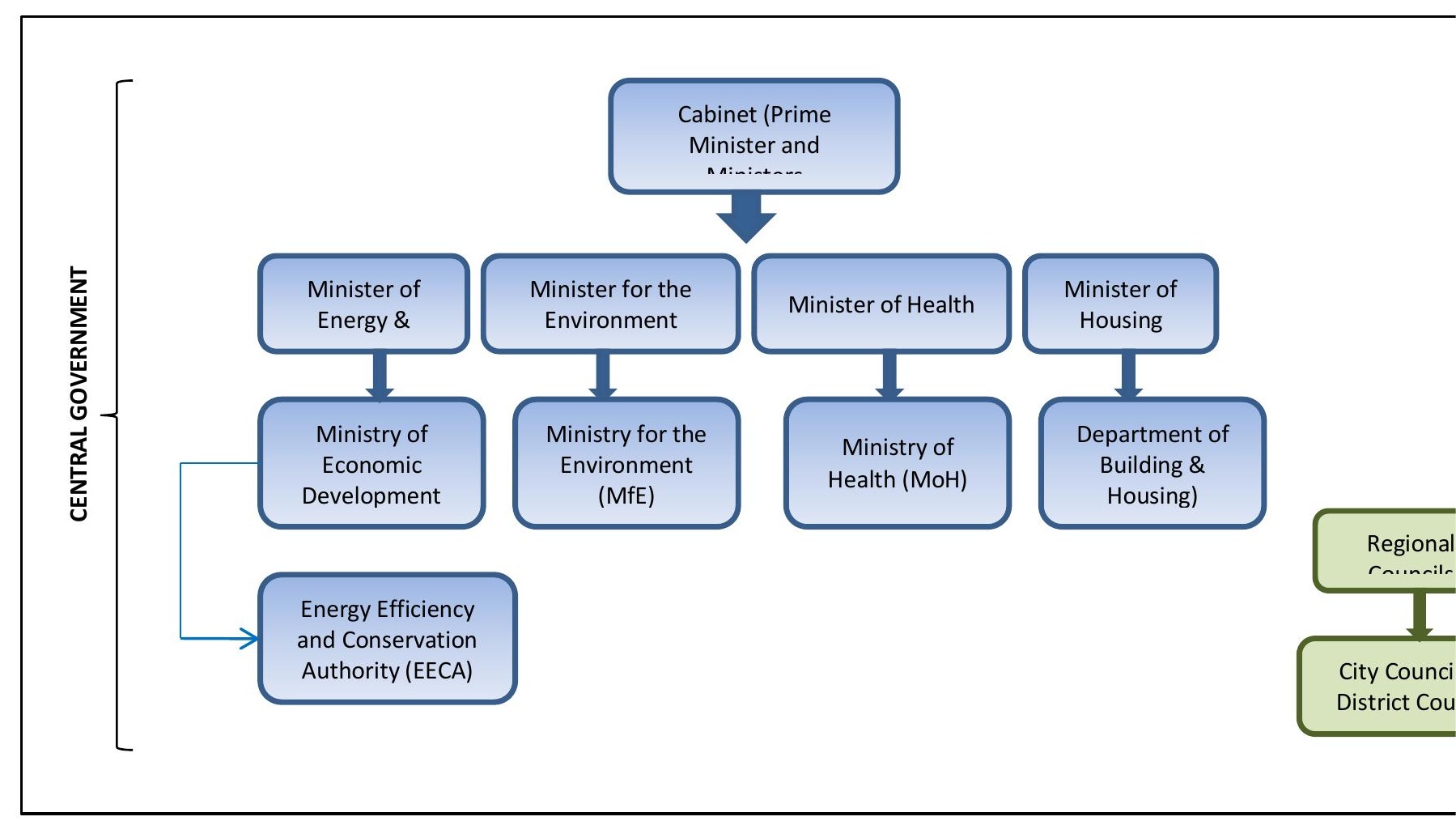

Author: Alejandra Pérez. 
Map 5.1. The North Island Council boundaries.

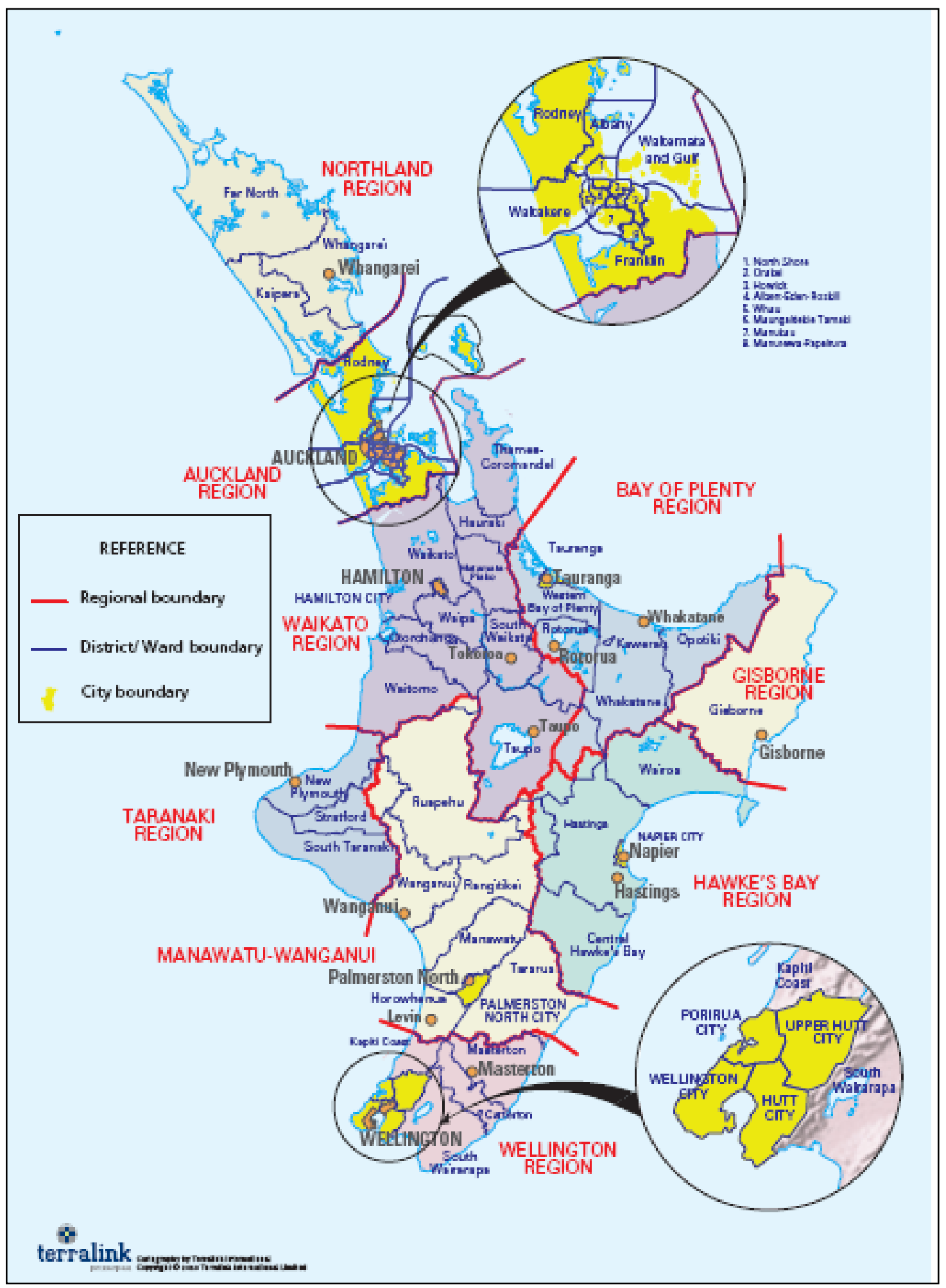

Source: Local Government New Zealand (2011). 
Map 5.2. The South Island Council boundaries.

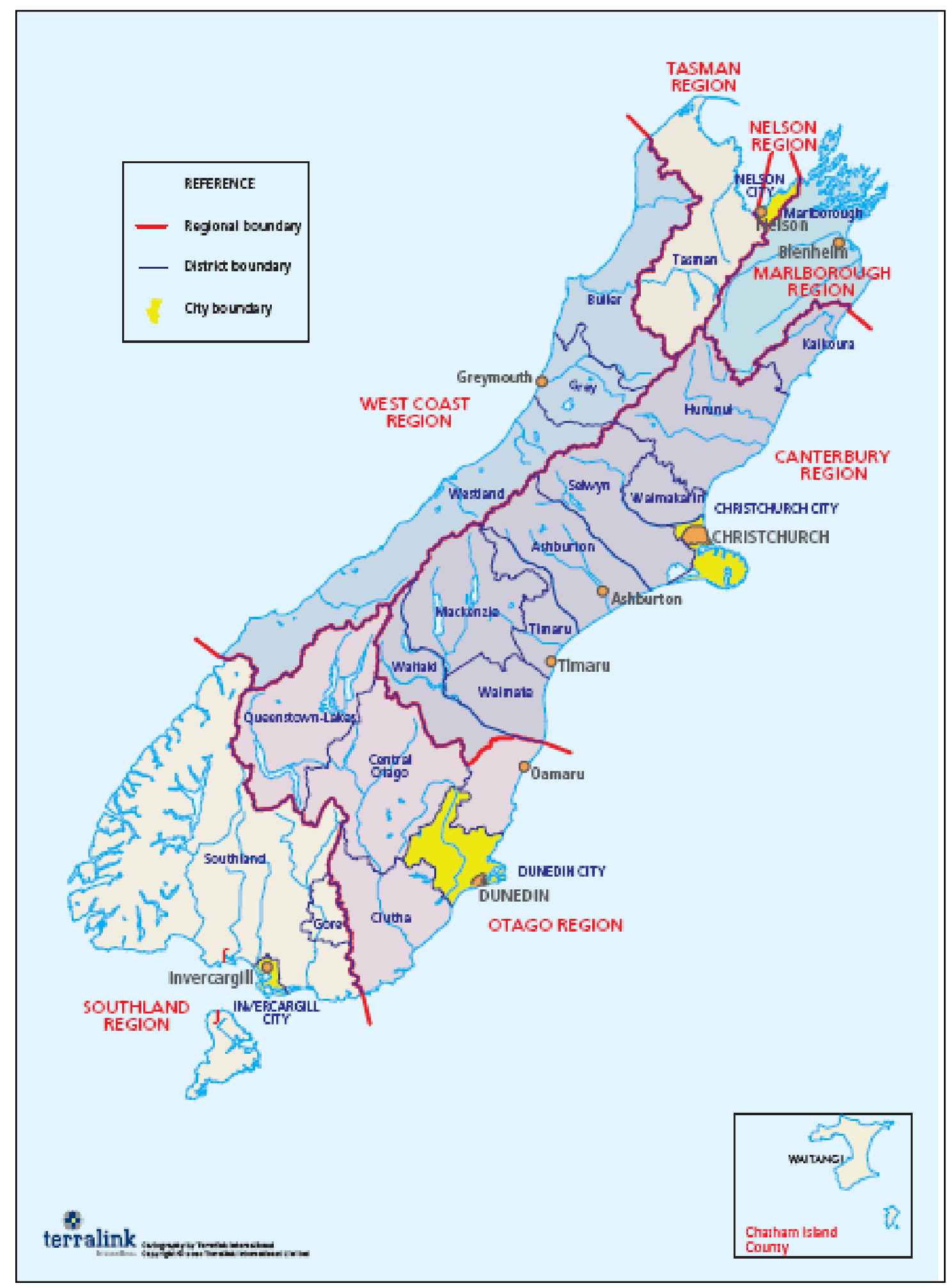

Source: Local Government New Zealand (2011). 


\subsection{New Zealand residential energy figures in context}

New Zealand has relatively abundant renewable energy and fossil fuels resources and it is a highly fossil fuel dependent economy. Total consumer energy use in 2009 was $524 \mathrm{PJ}$ (half of the Chilean consumption, but double in terms of per capita energy use) dominated by oil (47\%) whilst gas and coal represented $11 \%$ and $4 \%$ respectively (MED, 2010c). In 2009, New Zealand imported 322 PJ of oil and exported 114 PJ. The total amount of gas consumed in 2009 (59 PJ) was produced in New Zealand; however, import projects of liquefied natural gas (LNG) are being studied in case that locally produced gas decrease (MED, n.d.). With regard to coal, indigenous production (117 PJ in 2009) enables exports and a marginal amount of imports. Renewable energy directuse for heat applications has a significant representation (12\%) including geothermal, wind, solar and bioenergy (MED, 2010c). Electricity represented 26\% of total consumer energy use in 2009. In terms of electricity generation, in 2009, 151 PJ were produced nationwide, of which hydro represented 57\%, followed by gas (20\%) (MED, 2010c). Electricity generation from other renewable sources including wind, bioenergy and solar play an important role (12\% of generation) in comparison to Chile, where renewable energy, excluding hydro electricity, has hardly any representation. Hydro electricity generation has similar importance in both countries.

Figure 5.2. New Zealand total consumer energy by fuel in 2009.

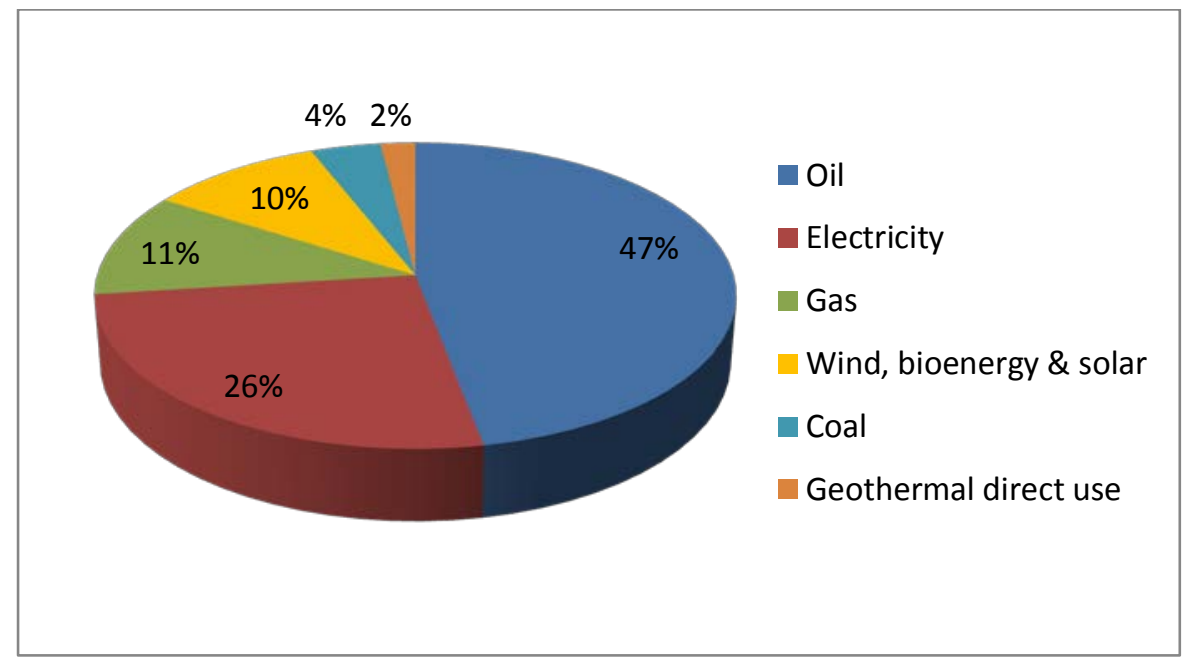

Source: MED (2010c). 
In 2009, the residential sector constituted 13\% the New Zealand energy consumption while other sectors' consumption were transport (39\%), industry (34\%), commercial (9\%) and agriculture (5\%) (MED, 2010c). These figures are relatively similar to energy use in Chile, although residential energy use in New Zealand is lower of the total (residential use makes up $21 \%$ of the total Chilean energy consumption). In the residential sector, energy use was 65 PJ in 2009 (MED, 2010c), with the main fuels being electricity (69\%), solid fuel (20\%), gas (9\%) and LPG (2\%) (Isaacs et al., 2010). That is also different from Chile, where electricity represents only around $15 \%$ of the total residential energy use. However, in both countries, space heating represents the major residential energy use.

In New Zealand, space heating is the dominant residential energy end-use (34\%). There is a study that shows that solid fuel represents $56 \%$ of the total space heating fuels, followed by electricity (24\%), reticulated gas (14\%) and LPG (6\%) (Isaacs et al., 2010). However, these figures underestimate the rental housing sector. Also, due to a number of heater replacement programmes, fuels representation in the total residential space heating is currently uncertain. The average annual space heating energy use per household is estimated at 3,820 $\mathrm{kWh}$ and the average residential total energy use at 11,410 kWh (Isaacs et al., 2010). 
Figure 5.3. New Zealand residential energy use shares (\%) in 2005.

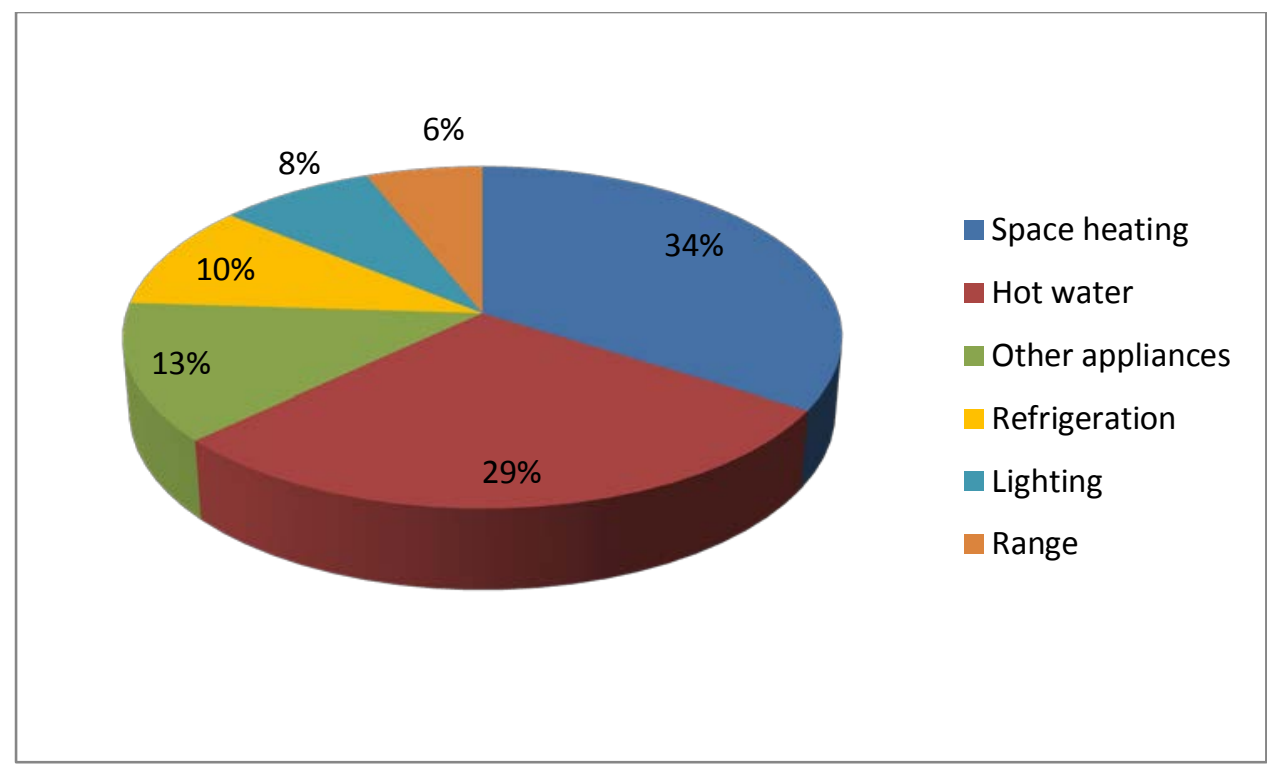

Source: Isaacs et al. (2010).

As in Chile, wood is the cheapest residential space heating fuel and electricity the most expensive, in New Zealand. However, in New Zealand, wood prices (except for free firewood) compete with gas, probably because, contrary to Chile, New Zealand is self-sufficient in gas production. Additionally, all energy prices are lower in New Zealand than in Chile, and the same pattern is observed for energy consumption. The prices presented below are selling prices to consumers so they do not take into account capital costs of heaters.

Table 5.1. Residential fuel real prices for residential space heating in 2009 (NZ cents/kWh).

\begin{tabular}{|c|c|c|c|c|}
\hline & Electricity* & LPG** & Wood (pellets) $^{* *}$ & Reticulated gas** $^{*}$ \\
\hline Average & 24 & 13.2 & 7.3 & 7.6 \\
\hline
\end{tabular}

*MED (2010c).

**Central Heating New Zealand (2011) ${ }^{20}$.

Energy intensity has decreased on average 1\% per annum since 1990. However, in 2007, New Zealand's energy intensity was higher than the IEA countries' average

\footnotetext{
${ }^{20}$ Prices are indicative and they do not represent a New Zealand average.
} 
because a large proportion of its economy is based on energy-intensive sectors (Figure 4.4) (IEA, 2010b). Nevertheless, energy intensity is forecast to improve 22\% by 2030. Despite this fact, electricity use in New Zealand is projected to grow at $1.4 \%$ per year and in the residential sector it is estimated to increase by $1.3 \%$ annually. To meet this expected demand by 2030, 1,500 MW of new electricity capacity will have to be developed. Due to these new generation investments, the wholesale electricity prices are forecast rise 29\% by 2030 (MED, 2010a).

With regard to energy supply for electricity hydro generation, studies about the effects of climate change on this resource suggest a possible deficit of water supply in some areas. For instance, NIWA (2008) has estimated that, by 2090, the average annual rainfall is forecast to increase in the west and decrease in the north and east in winter and spring. However, during summer and autumn seasons the pattern is reversed. Also, climate extremes such as droughts are estimated to increase in frequency in areas that are currently drought prone.

\subsection{Local air pollution in New Zealand}

As in Chile, the use of solid fuel (wood) represents around half the energy-use for residential space heating in New Zealand. This pattern has also produced local air pollution throughout the country. It has been estimated that domestic sources have the greatest effects on air pollution's annual costs in New Zealand (NZ\$ 503 million), followed by vehicles (NZ\$ 495 million) and industry (NZ\$ 142 million) ${ }^{21}$ (Fisher, Kjellstrom, Kingham, Hales, \& Shrestha, 2007). High PM $_{10}$ concentrations usually occur in areas with colder climates that lead to a greater consumption of wood for heating, easy access to wood resource and other conditions. Areas highly exposed to pollution concentrations are Nelson, Alexandra and central Christchurch.

To address this issue, some councils, including the Christchurch City Council and the Environment Canterbury Regional Council have incentivised energy efficiency and the use of clean heaters in this region through the Environment Canterbury's Clean Heat Project (McChesney et al., 2006). The project has a range of financial assistance plans

\footnotetext{
${ }^{21}$ Annual costs include mortality (due to $\mathrm{PM}_{10}, \mathrm{NO}_{2}$ and $\mathrm{CO}$ ), bronchitis and related conditions, respiratory/cardiac admissions, cancer and restricted-activity days.
} 
available including subsidies and interest-free loans for insulation and heater replacements; however, it has been suspended in Christchurch because of the earthquake of February 2011 (Environment Canterbury Regional Council, n.d.). 


\section{Chapter 6: New Zealand results}

These findings are based on interviews, which included a questionnaire where respondents rated a range of possible benefits and co-benefits. The questionnaire results are shown in Table 6.3.

\subsection{First stage: The benefit of energy savings}

New Zealand thermal insulation policy is not new. In the late 1940s and 1950s, studies on dwellings' transmittance values confirmed that the presence of mould was due to changes in materials and construction techniques (Nigel Isaacs, 1993). At the same time, the government was expanding the electricity grid around the country and, because of the regulation the cross-subsidies of electricity, residential electricity prices were lower than prices for the commercial and industry sectors (Irwin, 1997;

McChesney, personal communication, May 19, $2011^{22}$ ). This situation changed after the electricity sector deregulation in the early 1990s, which produced an increase in household electricity prices and a reduction of commerce and industry electricity prices (Irwin, 1997).

In the late 1960s, the electricity sector continued expanding on the basis of hydroelectricity development, but the presence of drought periods increased government concern about residential space heating because it was a common belief that electricity was the dominant fuel used by households for that end (Isaac, personal communication, May 18, 2011) ${ }^{23}$. Using data from the 1966 Census, (Trethowen \& Hubbard, 1972), found that "Electricity is the largest supplier of domestic heating, being the principal heating fuel in 46\% of urban housing”. In 1963, electricity represented $70 \%$ of the annual heating in Christchurch and 60\% in Wellington-Hutt (Trethowen \& Hubbard, 1972).

Aware of the significant use of residential electricity, the National Development Conference of 1969 recommended that:

\footnotetext{
22 See footnote 26.

${ }^{23} \mathrm{Mr}$. Nigel Isaacs is a building scientist working both at Victoria University of Wellington and the Building Research Association of New Zealand.
} 
“... The Government take steps to obtain an urgent report on the cost effectiveness of heat insulation in homes, and to recommend how far and in what ways home insulation should be encouraged as a means of reducing domestic fuel consumption and the capital outlay required on further power projects” (Department of Statistics, 1976, p. 9).

The study was carried out in conjunction with the Department of Statistics household electricity survey 1971-72, obtaining additional information about the effect of ceiling insulation on electricity consumption. The study presented a theoretical estimation of the effect of insulation on electricity reduction demand concluding insulation would effect a reduction of around 30\% to 35\%; however the researchers acknowledged that ceiling insulation not would necessarily result in a reduction of electricity use (Department of Statistics, 1976). That shows that at that time, the rebound effect was known by scholars and policy makers.

The economic evaluation report that led to the development of the first New Zealand thermal standards 1978 showed that residential electricity demand was increasing by $7 \%$ per year and oil fired central heating systems were increasing dramatically by about 8,000 annually (Trethowen \& Hubbard, 1972). The authors of this report were aware that insulating houses would probably not reduce the amount of electricity used; however it could contribute to mitigating the increase in demand, particularly through the use of static control devices. Since the housing construction rate was increasing at 3\% per annum, the authors stated that "within the next 23 years it is virtually certain that space heating demands will make thermal insulation a critical issue” (Trethowen \& Hubbard, 1972, p. 10). The economic evaluation was a calculation of the optimum level of expenditure on insulation based on capital and running costs, usage and fuel costs (prices of electricity, oil, gas and coal and the insulation costs) (Trethowen \& Hubbard, 1972).

When New Zealand faced the oil shock crises of 1973-74, the reduction in electricity use became urgent for the government and it realised that insulation could assist in reducing electricity consumption without decreasing households' comfort 
(Isaacs, personal communication). The government made a first attempt for energy conservation, at a policy level, when it launched an interest free loan programme for insulating houses in 1975 trying to insulate over 50,000 homes. However, some years before (1971 and 1972), the Waimairi County and Christchurch City Council respectively passed the first insulation measures in New Zealand as by-laws. Nevertheless, these measures were focused on wood use reduction to address air pollution problems (Nigel Isaacs, 1993), rather than electricity use reduction.

The interest free loan programme for insulating, already mentioned, seems to have been aimed mainly at new homes, and was not viewed as very successful (New Zealand Parliament, 1977a). It has been estimated that the interest free loan programme for ceiling retrofits covered approximately 133,000 homes from 1975 to 1983 (McChesney et al., 2006). Later, the thermal standards were promulgated in 1978, with the purpose of energy conservation as a response to the oil crises. In the financial statement of the Appropriation Bill 1977, Rt. Hon. R.D. Muldoon (Minister of Finance) stated:

"Massive increases in oil prices in recent years have resulted in radical changes throughout the world in attitudes towards energy. For a country at present heavily dependent on imported oil as a primary energy source, we must be concerned that it will become increasingly more expensive and its supply unreliable” (New Zealand Parliament, 1977b).

The new insulation thermal standards $1978^{24}$ for new buildings were incorporated as a part of the Municipal Corporations Amendment Bill making it mandatory for councils to create bylaws "requiring thermal insulation to reduce heat losses" (New Zealand Parliament, 1977a). The government assisted the standards implementation with an interest-free loan for home owners over four years. The insulation costs were expected to be recovered through reduced energy bills (Highet, cited in New Zealand Parliament, 1977a). The standards adopted were those specified for the existing home insulation scheme (Muldoon cited in New Zealand Parliament, 1977b).

The sequence of events already mentioned shows that in New Zealand the main rationale for the first insulation measures was energy conservation. Contextual factors;

${ }^{24}$ Insulation Standards NZS 4218P:1977. 
both external (oil crisis) and internal (droughts, increase in electricity demand and the construction of new homes) were the main drivers of the first insulation measures, especially the New Zealand thermal standards 1978. Reported problems with mould, local air pollution and the growing insulation industry could also have been part of the policy discussions; however, there is no evidence readily available for this.

\subsection{Second stage: Energy efficiency and local problems}

Despite the government's increasing interest in insulation of new dwellings, there was no government funding available for retrofits until 1996, almost 20 years after the introduction of the thermal standards. By the mid-1990s, a number of issues were causing concern at a national and national level.

In the early 1990s, the government had reformed the electricity sector, introducing some competition into the industry ${ }^{25}$. At that time, it was generally held that the power generation sector did not satisfy the principle of economic efficiency because power plants were built under inefficient electricity regulation. In 1992, the electricity capacity surplus was estimated roughly at $20 \%$ and it was projected that the situation would be maintained over the next 10 years (Elliston, 1993). In addition, the presence of dry periods in the early 1990s was a threat for an electricity system highly dependent on hydro power (75\% in 1994), and a growing electricity demand (3\% annually) put policy makers in a position in which new generation capacity and energy efficiency had to be addressed: "To meet this rising demand we must either conserve electricity, be more efficient in its use or build more generation capacity. In reality, we will have to do all of these things. None of them, by themselves, will meet our future electricity requirements” (Wholesale Electricity Market Development Group, 1994, p. 10). However, the Minister of Energy believed that free market competition was going to result in the adoption of energy efficiency by customers. Customers were trying to reduce their electricity bills, so they would look for companies that offer energy efficiency: “It is clear that customers don’t simply want to buy more electricity; they want lower costs and the supplier who can deliver this will get their business” (Luxton, 1993, p. 9). At that time a warning was made by the Parliamentary Commissioner for

\footnotetext{
${ }^{25}$ Reforms for public enterprises (including the electric sector) had started in the mid-1980s.
} 
the Environment who argued that the free market would not necessarily produce energy efficiency: "The major problem is that the current economic system assigns costs to energy efficiency measures but does not fully credit the benefits” (Hughes, 1993, p. 3). In fact, since power companies’ revenues depend on electricity sales, companies do not have incentives to promote energy efficiency. Some regulatory policies such as decoupling have been introduced in the U.S. to target this problem. However, in New Zealand in the mid-1990s, when the free market framework was being introduced in the electricity sector, any type of regulation was ideologically inappropriate. Nevertheless, some government officials were aware that in a transition to a deregulated market, energy efficiency would develop very slowly. Since some authorities had some previous experiences with centrally funded energy efficiency, the Energy Saver Fund (ESF) was launched (Government official, personal communication).

In 1993, the government established the Wholesale Electricity Market Development Group to explore ways in which a wholesale market could be developed in New Zealand. The Group produced five recommendations. One of them was to implement a domestic energy efficiency and conservation levy over three to five years. It consisted of a fund available for tender open to providers of any type of domestic retrofit energy efficiency measures. The levy was set at 0.07 cents/kWh which would result in a pool of approximately NZ\$ 7 million per year. The levy was also seen as a possible future instrument to channel carbon tax revenue, should a tax be introduced to meet New Zealand's commitments on climate change (Wholesale Electricity Market Development Group, 1994).

At the same time (1993), Christchurch was facing air pollution problems, increasing residential electricity prices (as a consequence of the deregulation), and a high rate of unemployment (McChesney, personal communication, May 19, 2011) ${ }^{26}$ were a matter of concern for some citizens. These problems affected the population, particularly low-income households. To acknowledge this problem, in 1992, an organisation was created in Christchurch (Community Energy Action Trust) which informally linked with other NGOs, charitable groups, etc. that were emerging in New

\footnotetext{
${ }^{26}$ Mr. Ian McChesney co-founded the Community Energy Action Charitable Trust, worked as an officer for the Environment Canterbury, as adviser of EECA, and nowadays he is a consultant specialising in residential energy efficiency.
} 
Zealand to address energy efficiency (McChesney, ibid.). The group was aware of the importance of energy use reduction for achieving sustainable development ${ }^{27}$ and reducing carbon emissions, air pollution and fuel-poverty (McChesney, 1992). The organisation's first step was to conduct a community consultation (financed by the Canterbury Regional Council, the Christchurch City Council and the local power company Southpower) to analyse the situation of some low-income households with regard to insulation and fuels affordability. The analysis showed that the real energy purchasing power of low-income households had dropped (McChesney, Small, \& Cottrell, 1993). With the results, the Community Energy Action asked EECA to be part of funding a pilot project for retrofitting 24 households in Christchurch (The Whare Roimata Neighbourhood Energy Improvement Project). EECA contributed NZ\$ 15,000, Southpower (electricity company) contributed NZ\$ 4,800 and another NZ\$5,000 was obtained through the Christchurch City Council (Community Energy Action, 1994). The project included training sessions for unemployed or low-income people who later carried out retrofit projects. The projects included a number of different activities such as ceiling insulation, cylinder wraps for hot water systems, draught-stopping, hot water pipe lagging, compact fluorescent lights and curtains (Community Energy Action, 1994).

This experience was used by EECA when designing the Energy Saver Fund (ESF). EECA invited one of the Community Energy Action members to participate in its advisory group for setting up the ESF (McChesney, ibid.).

Within the national and local context, and building on some positive local experiences such as the Community Energy Actions pilot experience, the ESF, managed by EECA, was created in 1995 to "help kick start residential energy efficiency activities ... There will be an emphasis on local solutions for local problems” (EECA, 1995). EECA put the programme out to tender for service providers. The Fund operated as a partial grant with a budget of NZ\$ 18 million to be allocated over 5 years.

The logic behind the decision to offer a partial grant was based on an assumption that since the private benefit for homeowners was significant, the government should

\footnotetext{
${ }^{27}$ The leader of the Community Energy Action Trust, Ian McChesney, wrote The Brundland Report and Sustainable Development in New Zealand (1991), to understand the implications of sustainable development in New Zealand.
} 
not pay for the totality of the energy efficiency installations (government official, personal communication, 2011). Through the ESF, the government was mainly looking for a policy that was cost-effective in terms of energy savings. Additionally, the policy should contribute to reducing barriers for people who were less able to invest in energy efficiency (e.g. elderly people, tenants, low-income households, and people with disabilities) and to promote the development of an energy efficiency industry (government official, ibid.).

The ESF programme also sought the inclusion of vulnerable people as part of the scheme’s implementation. In the early 1990s, EECA made a first training pilot project. An external consultant designed and implemented an insulation retrofit training programme focused on low-income young men and woman with very few skills.

"Initially, I started (the training project) in Opotiki in Bay of Plenty.

Opotiki is a low-income area with lots of unemployment and poor households, and a lot of Maori people. I went there for two weeks where I worked with eight unemployed young people, training them to carry out the work. That also involved identifying one of them who could be trained to be the leader of the team, and setting up a little company or community organisation” (Smith, personal communication, May 31, 2011) ${ }^{28}$.

After the training, the Opotiki's local organisation applied to the ESF as an accredited service provider. Then, the training programme spread out around the country (Smith, ibid.).

When the ESF was set up, the quantitative impact of benefits and co-benefits was unknown (McChesney, ibid.) and no in-depth economic valuation was carried out (government official, personal communication). However, a number of qualitative studies brought to light the significance of retrofits in households. (Isaacs \& Donn, 1993) showed that the increase of mortality during the cold season in New Zealand was directly correlated with low indoor temperatures. Another study concluded that

\footnotetext{
${ }^{28}$ Norman Smith is a social entrepreneur who works to realise the environmental, health, employment and social benefits of energy efficiency.
} 
inadequate maintenance, over-crowding, low temperature, dampness and mould of houses have an impact on health; hence policies addressing a better housing quality would be beneficial (Howden-Chapman, Isaacs, Crane, \& Chapman, 1996). This last study gathered a multidisciplinary team that later set up as the Healthy Housing Programme (He Kainga Oranga) ${ }^{29}$. This group was strongly motivated by inequalities in health and how a reduction of the gap in living standards between the rich and the poor could be attained (Howden-Chapman, personal communication, May 26, 2011).

"We realised that housing is where people spend most of their time, so we thought that by improving the quality of housing it may improve health of the population” (Howden-Chapman, personal communication, May 26, $2011)^{30}$.

In the late 1990s, the impacts of insulation retrofits were emerging more clearly. Households started to notice the benefits of insulation retrofits. For instance, in Porirua, people realised that after the insulation works, their children had less time off school, better grades and fewer visits to the doctor which enables parents to increase their working time (Smith, ibid.). However, these benefits were not yet represented quantitatively; hence the real impact of the retrofitting with insulation progarmme was not clear.

At that time, the He Kainga Oranga team obtained funds ${ }^{31}$ to conduct a six year research project, the Housing, Insulation and Health Study focused on low-income communities. The study's findings were published in the prestigious British Medical Journal five years later (Howden-Chapman et al., 2007), translated into an economic valuation (Chapman, Howden-Chapman, \& O’Dea, 2004), and used by policy advisors and scholars for a number of subsequent studies. The results showed that there were significant benefits from insulating houses in comparison with uninsulated ones ${ }^{32}$.

\footnotetext{
${ }^{29}$ He Kaianga Oranga was stablished in 2001, based at the University of Otago in Wellington and funded by the Health Research Council of New Zealand.

${ }^{30}$ Ms. Philippa Howden-Chapman founded He Kaianga Oranga. She is a specialist in retrofits and health.

${ }^{31}$ Funding was from the Health Research Council of New Zealand, the Energy Efficiency and Conservation Authority, the Ministry of Health, Solid Energy, Orion, Christchurch City Council, Environment Canterbury, Hutt Mana Community Trust, MARIA, Eastern Bay of Plenty Energy Trust, Wellington City Council, and Housing New Zealand Corporation.

32 The intervention consisted of installing ceiling insulation, draught stopping around windows and doors, and fitting sisalated paper beneath floor joists and a polythene moisture barrier on the ground beneath the
} 
Statistically significant differences were found in terms of well being, respiratory symptoms, days off school and work, and medical visits. Also, people living in insulated dwellings were less likely to be admitted to hospital due to respiratory conditions; however, this variable did not present statistically significant differences between the control group and the insulated houses group (Howden-Chapman et al., 2007). In terms of energy savings, the insulated homes group decreased energy use (metered electricity and mains gas) by 5\% whereas uninsulated houses increased use by $8 \%$ (net savings of $13 \%$ or $318 \mathrm{kWh}$ per household in winter) (R. Chapman et al., 2009). Although these results on energy were not statistically significant, they were significant when self-reported energy use (bottled gas, wood and coal) were included. The economic valuation of the impact of insulated houses showed that the benefit-cost ratio of installing insulation was close to 2 and the NPV was approximately NZ\$1,570 (at a 5\% discount rate, 30 years and with insulation costs of NZ\$ 1,800 per house). Sixty one percent of the benefit accrued from health (Chapman et al., 2009). The economic valuation took into account energy and $\mathrm{CO}_{2}$ savings (approximately 6 tonnes per household over 30 years), medical visits (increase of 5\% in reported medical visits, but a decrease of $19 \%$ of self reported ones), hospital admissions (reduction of $10.5 \%$ for elderly people and $0.26 \%$ for children) and days off school (reduction of 1,828 days per 1,000 children and teenagers) and work (reduction of 102 days per 1,000 adults).

The research carried out by He Kainga Oranga was an initiative that emerged from the academic world. It was well received by the central authorities, including EECA and the Minister of the Environment, because funds for energy efficiency were scarce and these authorities were interested in how health benefits, accruing from residential energy efficiency interventions, could support related policies (HowdenChapman, personal communication). In fact, as mentioned in Chapter 5, in 2000, EECA was separated from the Minister of Economic Development and it became a Crown entity in its own right when the Energy Efficiency and Conservation Act 2000 was passed. Although the Act was a means for the expansion of EECA and its programmes,

house. The intervention group consisted of households insulated after the winter of 2001; the control group's housing was insulated a year later. 
the budget for this organisation as well as for the insulation programme was limited (Leckinger, personal communication, May 31, 2011) ${ }^{33}$. The result was a small number of dwellings being insulated annually (approximately 57,000 insulated houses from the start of the ESF started until 2009) (Leckinger, ibid.). In addition, interviewees said that some possible reasons for the limited growth of the programme were lack of information on cost-effectiveness of the programme, reluctance of some officials and politicians to introduce energy efficiency grants, lack of government management capacity, slow development of the energy efficiency industry and appropriate insulation materials, lack of co-funding and lack of skilled personnel.

\subsection{Third stage: Health benefits and climate change}

The enactment of the Energy Efficiency and Conservation Act 2000, which began life as a Green Party member's bill, under the new Labour Government ${ }^{34}$ put EECA on a solid footing and enabled it to create the first National Energy Efficiency and Conservation Strategy in 2001. The strategy consisted of six goals, including the improvement of health and welfare in low-income households. EECA projected 150,000 low-income houses to be insulated by 2012 through a grant programme in order to gain health benefits from warmer and less damp dwellings. The programme would operate on the basis of the ESF, starting in 2001/02 as a transition scheme, and then it would be reassessed in 2002 (EECA, 2001). At that time, EECA was waiting for the research results of He Kainga Oranga on health (EECA, 2001). Although the scheme provided for similar domestic applications as the ESF, the focus of this new programme was on insulation retrofits (government official, personal communication). During the period from 2000 to mid-2005 the programme's budget and outcomes were limited. The programme was questioned in terms of its delivery capacity and reliance on a number of community groups that faced difficulties in obtaining funding (Local Government and

\footnotetext{
${ }^{33}$ Mr. Richard Leckinger is a former minister's adviser for the Minister of Energy and for the Government Spokesperson of Energy Efficiency and Conservation under the last period of the Labour Government.

34 The Prime Minister Helen Clark was re-elected twice, completing a government period from 1999 to 2008. The first term started in 1999, the second in 2002 and the third in 2005.
} 
Environment Committee, 2003). In 2002, the ESF changed its name to ENERGYWISE Home Grant scheme.

In the last government under Prime Minister Helen Clark, the ENERGYWISE Home Grant scheme expanded. This expansion was related to the elaboration of the New Zealand Energy Efficiency and Conservation Strategy 2007. The government was strongly committed to insulating low-income households, due to health problems, especially those associated with asthma, as the government was able to avoid health costs (EECA, 2007). The strategy 2007 established a budget of NZ\$ 66 million for programme to be delivered in four years (EECA, 2007).

As explained in Chapter 7, climate change became an important issue on the political agenda of the Labour government, which introduced an Emissions Trading Scheme (ETS) for New Zealand in the last year its government (2008). This fact shaped a new approach to insulation retrofit policy. The Labour Party Cabinet negotiated the ETS with the Green Party in order to have a quorum to pass the ETS bill (Leckinger, ibid.). The Green Party argued that the ETS was going to increase electricity prices, hence it would have an adverse impact on low-income people. To mitigate this impact, the Green Party estimated that a budget of NZ\$ 4.6 billion dollars, accruing from the increased electricity revenue flowing to State-owned power companies under the ETS, should go to the EECA's insulation programme (Leckinger, ibid.). The Green Party knew that this proposal was not going to be accepted by the government, but it was a way to show the country's need for insulation. The Green Party representatives recognised the benefits and co-benefits that a programme of insulation retrofits could produce as well as its pay back ratio of around 2:1. They used the He Kainga Oranga research to prepare their proposal. The main arguments of the Green Party were a lower electricity bill for the most vulnerable and a lower health bill for the government (Leckinger, ibid.). The Green Party also used research on fuel poverty ${ }^{35}$ to estimate the costs and the number of households that needed to be insulated in a large retrofit programme. However, the Green Party’s documentation is not publicly available (Leckinger, ibid.). The outcome of the ETS negotiations was that the Labour government and the Green Party agreed to the establishment of a budget of NZ\$ 1 billion over 15 years for a Household Fund programme. This proposal was accepted by

\footnotetext{
${ }^{35}$ Article Fuel Poverty in New Zealand (Lloyd, 2006).
} 
the Green Party because it was significant, targeted to low-income people, and its magnitude would promote the energy efficiency market (Leckinger, ibid.). The fund would be managed by EECA and it would provide for insulation and clean heat retrofits; energy efficiency appliances and lighting; and space and water heating efficiency improvements (Climate Change Response (Emissions Trading) Amendment Act, 2008).

\subsection{Third stage: Employment and market development}

In November 2008, the Labour government was defeated by the conservative National Party. The new National government saw the insulation programme in a very different way. First of all, it disagreed with the ETS introduced through the Climate Change Response Amendment Act 2008, arguing that the economic costs of it were too high (NZ Herald, 2009). The National government reviewed and amended the ETS attenuating some of its provisions. The \$NZ 1 billion for the Household Fund programme was repealed from legislation by the new government arguing that there was a lack of revenue to support the budgetary provision. This argument was based on the fact that during 2008 State-owned power companies had anticipated that they were planning to use the extra revenue coming from the ETS in renewable energy investments (Brownlee, cited in New Zealand Parliament, 2008) ${ }^{36}$.

Second, due to the global financial crisis, the National government was looking for options of employment creation. Prime Minister John Key held a Jobs Summit in 2009, with business leaders and policy makers. The Ministry of Economic Development in conjunction with EECA prepared a proposal suggesting retrofits as a job creation activity (Government official, personal communication). Retrofitting activity is fast to set up, requires little infrastructure, does not require too much training and stimulates an increase of insulation products manufacture (Government official, ibid). In addition, the insulation market already had a number of businesses in operation and the proposed programme also incorporated a clean heating component which would extend the

\footnotetext{
${ }^{36}$ Mr. Brownlee was the National Party's Minister of Energy and Resources 2009 and Member of Parliament.
} 
impact on the economy ${ }^{37}$ (Government official, ibid.). The Ministry of Economic Development and EECA's proposal was not based on economic valuation but on a qualitative analysis. They conducted interviews to figure out the capacity of the market (e.g. the potential increase of the production of insulation and clean heaters and the potential number of installations that providers could achieve per year among other variables). Finally, making a number of assumptions, due to time constraints, the proposal was discussed in an iterative process with the Minister of Energy and Resources and the Prime Minister (Government official, ibid.). The Warm Up New Zealand: Heat Smart (WUNZ) scheme started on July $1^{\text {st }}, 2009$ with a budget of NZ\$ 347 million over four years (including grants and administration) and a goal of 188,500 retrofitted homes in the period, which represents approximately a fifth of the New Zealand homes with substandard insulation (EECA, 2011).

The focus of the insulation grants in New Zealand, since the development of the ESF was mainly on low-income people. However, the new scheme was open to all New Zealand society. Some interviewees expressed concern about the idea of subsidising all social groups, including wealthy people. The government position on this was that lowincome households will gain mainly from health benefits as they raise home temperatures while other income groups will produce energy savings through a more efficient use of energy (Government official, ibid.). Also, low-income households receive a bigger subsidy without an upper limit (Table 6.1). More information about the programme is provided in Appendix 4.

Table 6.1. Warm Up New Zealand: Heat Smart grant, by households groups.

\begin{tabular}{|l|l|l|}
\hline & Insulation and other measures & Clean heating** \\
\hline All pre-2000 NZ houses & 33\% off up to \$1300 & Grant \$500 \\
\hline $\begin{array}{l}\text { Houses owned by a Community } \\
\text { Services Card (CSC) holder* }\end{array}$ & $\begin{array}{l}60 \% \text { of the cost of } \\
\text { insulation }\end{array}$ & Grant \$1200 \\
\hline $\begin{array}{l}\text { Houses occupied by tenants that } \\
\text { hold a CSC card }\end{array}$ & $\begin{array}{l}60 \% \text { of the cost of } \\
\text { insulation }\end{array}$ & Grant \$500 \\
\hline
\end{tabular}

\footnotetext{
${ }^{37}$ Grants for heaters were previously given in the last year of the Labour government (2008), through a small programme of interest subsidies and grants for middle-income (EnergyWise TM Interest Subsidy). It consisted of subsidy toward interest on an advance to get insulation and heating. (Government official, personal communication, June 3, 2011).
} 
*A CSC is not available to high income groups (see Appendix 4).

**Includes heat pumps, wood and pellet burners, and flued gas heaters.

Source: (EECA, 2007).

Because the WUNZ scheme is a partial grant, for some households, the financial barrier still exists. This barrier has been addressed through a voluntary targeted rate increase mechanism. This mechanism operates as an advance from the local council that is paid back by borrowers through their property rates over 10 years at interest rate around 6\%. That means approximately NZ\$ 200 per year per property (Government official, ibid.).

The WUNZ scheme has been very successful, reaching 90,000 retrofits in the short period from 2009 to mid-2011. Interviewees said that the programme's good performance is mainly a result of the large budget available, the maturity of the market, the government's experience with previous programmes and the popularity of the policy among New Zealanders. Table 6.2 synthesises the programme’s evolution. 
Table 6.2. Main nationwide retrofit programmes, source, resources, beneficiaries and rationale of the insulation retrofit subsidy.

\begin{tabular}{|c|c|c|c|c|c|c|c|}
\hline Year & Programme & $\begin{array}{c}\text { Delivered } \\
\text { Budget } \\
\text { (NZ\$ million) }\end{array}$ & $\begin{array}{l}\text { Beneficiaries } \\
\text { ( } \mathbf{N}^{\circ} \text { of retrofits) }\end{array}$ & $\begin{array}{l}\text { Average } \\
\text { budget per } \\
\text { year (NZ\$ } \\
\text { million) }\end{array}$ & $\begin{array}{l}\text { Average } \mathrm{N}^{\circ} \\
\text { of households } \\
\text { per year }\end{array}$ & Retrofit measures & Contextual factors \\
\hline $\begin{array}{l}1995 / 96- \\
1999 / 00\end{array}$ & $\begin{array}{l}\text { Energy Saver } \\
\text { Fund } \\
\text { (Partial grant) }\end{array}$ & $12.4^{*}$ & 5,500 & 2.5 & 1,100 & $\begin{array}{l}\text { Insulation of hot water cylinders, } \\
\text { ceiling and walls; installation of flow } \\
\text { shower heads, draught-stopping; and } \\
\text { efficient lights among others. }\end{array}$ & $\begin{array}{l}\text { Energy efficiency within a context of } \\
\text { wholesale market development. } \\
\text { Social dimension: local problems such } \\
\text { as fuel poverty, air pollution and } \\
\text { unemployment. }\end{array}$ \\
\hline $\begin{array}{l}2000 / 01- \\
2004 / 05\end{array}$ & $\begin{array}{c}\text { Energy Saver } \\
\text { Fund until } 2002 \\
\text { and } \\
\text { ENERGYWISE } \\
\text { Home Grants } \\
\text { from } 2002 \text { to } \\
2009 \text { (Partial } \\
\text { grant) }\end{array}$ & $5.9 \S$ & 10,700 & 1.5 & 2,670 & $\begin{array}{l}\text { Main focus on insulation but also } \\
\text { other measures included such as } \\
\text { draught proofing of doors and } \\
\text { windows, hot water cylinder wraps } \\
\text { and low flow shower heads. }\end{array}$ & $\begin{array}{l}\text { Government concern about droughts. } \\
\text { First and second period of Helen Clark } \\
\text { as Prime Minister. } \\
\text { Enactment of the Energy Efficiency and } \\
\text { Conservation Act } 2000 \text { which led to the } \\
\text { creation of the National Energy } \\
\text { Efficiency Strategy } 2001 \text { with a social } \\
\text { focus on low-income and health. }\end{array}$ \\
\hline $\begin{array}{l}2005 / 06- \\
2008 / 09\end{array}$ & $\begin{array}{l}\text { ENERGYWISE } \\
\text { Home Grants } \\
\text { (Partial grant) }\end{array}$ & Approx. 27.7** & 43,000 & 6.9 & 10,750 & $\begin{array}{l}\text { 2006: Pilot project of insulation } \\
\text { retrofits in properties tenanted by } \\
\text { low-income people. } \\
\text { 2008: Insulation in pre-2000 built } \\
\text { homes; Voluntary Home Energy } \\
\text { Rating scheme. } \\
\text { 2009: pilot project heater replacement } \\
\text { (6,500 heaters replaced in middle- } \\
\text { income households) }\end{array}$ & $\begin{array}{l}\text { Third period of Helen Clark as Prime } \\
\text { Minister. } \\
\text { Enactment of the Energy Efficiency and } \\
\text { Conservation Strategy } 2007 \text { with a } \\
\text { strong social focus on low-income and } \\
\text { health, including asthma. }\end{array}$ \\
\hline 2009/10 & $\begin{array}{l}\text { Warm Up NZ: } \\
\text { Heat Smart } \\
\text { (Partial grant) }\end{array}$ & 347 & $60,000 * *$ & 92 & 30,000 & $\begin{array}{l}\text { Insulation of roofs and floors, and } \\
\text { heater replacement. }\end{array}$ & $\begin{array}{l}\text { Financial crisis focus: jobs creation. } \\
\text { Focus on all income groups. }\end{array}$ \\
\hline
\end{tabular}

*Reduced from NZ\$ 18 million (1995) to NZ\$ 12.4 in 1998.

§ The programme budget of 2003/04 was not found, so it was assumed as the same as the statement of intent of the same year (\$NZ 2.0 million). 
**The programme budget of 2008/09 was not found, so it was assumed as the same as the statement of intent of the previous year (NZ\$ 9.1 million).

***This figure only includes insulation retrofits.

Source: EECA (1998); EECA's Annual Reports from 2000 to 2010³; IEA (2006b); and material prepared by EECA for this research.

\footnotetext{
${ }^{38}$ The Annual reports from 2003 to 2010 can be found in http://www.parliament.nz/en-NZ/PB/Presented/Papers/Default.htm. The reports from 2000 to 2002 have are not available online and they can only be obtained in the Parliamentary Library.
} 


\subsection{Barriers to the retrofit policy's process}

In general, interviewees did not report barriers to the creation of the programmes. Interviewees agreed that as the programmes have funded only a part of the costs of the retrofit works, finding co-funding has been an important barrier, especially when the ESF started. In some areas of the country co-funders were generous whereas in others they were not. This barrier has been addressed by the WUNZ scheme through the voluntary targeted rate mechanism.

Another important barrier identified by respondents was the quality issue and the availability of skilled personnel. Since the programmes have operated as an annual tender, the requirement for personnel for a given area fluctuated year by year. This fluctuation sometimes resulted in the loss of trained personnel that moved to other types of jobs. Also, in some cases, the insulation installations have not been done properly.

Other barriers mentioned by interviewees were that initially, the retrofit programme's budget was limited (as noted before); on some occasions there was a lack of political will and government management capacity; and a lack of information about policy impacts to justify the programmes. In relation to lack of political will, it was noted that the introduction of the clean heating component took around 12 years (from the ESF start).

\subsection{Barriers to future policy support and expansion}

Interviewees agreed that pressure on government expenditure and government priorities could affect the future of the policy; however, the retrofit policy is perceived as well settled. The political will, particularly of the members of the Cabinet, plays a central role. The Prime Minister's support is crucial and it could be affected by contextual issues such as a financial crisis or domestic political issues such as his loss of popularity (Leckinger, ibid.). Although the impact of the Christchurch earthquake on the government's fiscal position was not identified by interviewees, it will certainly produce financial impacts in the next years.

Another possible obstacle for the programme in the future is to maintain people's interest in it (Government official, personal communication). Currently, the WUNZ 
programme has been strongly promoted by a marketing campaign which includes TV, brochures, newspapers, etc. Also, service providers can promote their retrofit business using the programme's name, and the EECA's logo. In this way, customers are assured that service providers are qualified and registered in EECA.

\subsection{Benefits and co-benefits}

This section focuses on the Warm Up New Zealand: Heat Smart scheme (WUNZ).

\subsubsection{Environmental co-benefits}

Co-benefits related to climate change (reduction in carbon emissions and reduction in fossil fuel generation) were not important in the WUNZ scheme's development; however, they could be important arguments for supporting and expanding the retrofit policy in the future. This could occur especially if the Labour Party wins the 2011 or the following election and the Emission Trading Scheme is revisited. Otherwise, the focus will probably continue to be on market development with possibly some fiscal savings in the scheme.

A reduction in energy use is generally perceived as important and likely to increase in importance. This result can be associated with the country's need to contain the increasing demand for energy across the economy; to limit new power generation costs, especially for peak winter loads; and to meet the Kyoto Protocol commitments.

The current government is also strongly promoting the use of efficient wood burners in low-income homes because wood is the cheapest fuel in the country (Government official, personal communication). However, within the national context, the programme has been strongly supported on the basis of the programme's ability to reduce electricity. Reduction of deforestation is scored lowest of any of the co-benefits in Table 6.3. The use of efficient wood burners may help to reduce wood consumption and, in principle, it has the potential to reduce deforestation.

Local air pollution was perceived as of moderate importance in the scheme. In New Zealand, the creation and implementation of air pollution reduction plans has always been managed by councils. In 1997, the establishment of the air pollution plan in Christchurch occurred in parallel but independent of the ESF (Itskovich, personal 
communication, June 9, 2011) ${ }^{39}$. Councils have obtained the WUNZ scheme's funds for some projects not solely justified on the ground of air pollution problems.

Indoor air pollution was not perceived as important by respondents (rating of 2). This can be explained because councils, through their air pollution plans, have been replacing or banning the use of open fire and highly polluting heaters. Nowadays, in New Zealand, indoor pollution is not seen as a main issue for health, unlike low temperatures.

\subsubsection{Health co-benefits}

Morbidity and mortality scored highly in the policy creation, not surprisingly as these concerns have been important arguments for policy development. In the future these co-benefits are perceived as important as well; however, less salient than originally (note negative difference scores). This may be because, as a large number of households and possibly many low-income households will have been retrofitted, fewer people will need the programme for health purposes.

\subsubsection{Economic co-benefits}

The energy security scores indicate that this issue will gain importance, especially if oil prices increase. As showed in Chapter 5, in the residential sector, space heating represents $34 \%$ of the residential energy use and electricity is used for $24 \%$ of space heating. A rise of residential electricity demand for space heating will imply higher costs of new generation capacity and electricity transmission and distribution and hence higher residential power prices. This scenario, combined with higher oil prices, droughts and an increase in the cost to build new renewable energy power plants (e.g. scarcer places to build power plants), could severely impact electricity prices and supply.

The increased ability on the part of the property owners to rent or sell energyefficient residences, reflecting a premium on well-insulated and heated homes, is not viewed as having been influential in the past, but it is considered likely to gain importance in the future. This shows that retrofits are gaining importance in the rent or purchasing decisions, which implies a better internalisation of the retrofit value by the market in the future.

\footnotetext{
${ }^{39}$ Mr. Leonid Itskovich is the Energy Manager of the Christchurch City Council. He was involved in the creation and implementation of the Christchurch's air pollution plan in 1997.
} 
Health costs as an economic consideration, although important in the programme's development, are not perceived to rise in importance in the future. The explanation is likely to lie in the same reduction in mortality and morbidity already explained.

An increase in new business opportunities and an increase in employment opportunities will continue being important in the future, but probably less salient than at the creation phase of the WUNZ scheme.

\subsubsection{Social co-benefits}

Fuel poverty was a matter about which interviewees held divergent views. Government officials argued that fuel poverty is a very subjective term, hard to define in the New Zealand case. For instance, the threshold of $10 \%$ of the household budget expended on fuel (as a definition of fuel poverty in the U.K.) was arbitrary. Successive governments (Labour and National) have focused retrofit programmes on low income people, based on the 'low income' definitions of the Ministry of Social Development (footnote 18 and Appendix 4). The government thus addresses fuel poverty indirectly. For instance, the WUNZ scheme grants a bigger subsidy to those households with a Community Services Card and it also encourages the use of wood burners among lowincome people. However, "There is little operational policy aimed to alleviate fuel poverty” (Government official, personal communication).

On the other hand, some respondents said that New Zealand governments have always been reluctant to talk explicitly about fuel poverty. A respondent said that if the real fuel poverty figures of New Zealand were published by the government, they would be higher than in other developed countries; therefore the international image of the country would deteriorate. Another interviewee argued that the introduction of market interventions such as differentiated tariffs for low-income households to target fuel poverty implies a conceptual tension with the New Zealand neoliberal context because it would mean that the choices available in the market were not sufficient to address fuel poverty.

In the case of low-income households the main benefit of insulation is taken as extra warmth due to the rebound effect, although there is evidence of modest energy savings (Chapter 2). Then, if electricity prices increase in the future, fuel poverty is 
likely to become an important issue. However, if the government encourages the use of wood-burners among low-income households along with other measures such as installation of solar hot water heaters, efficient appliances and light bulbs, fuel poverty could be reduced, avoiding the need for an explicit policy. Fuel poverty policies such as electricity bill subsidies or differentiated tariffs for low-income households would probably be difficult to introduce politically in the deregulated New Zealand electricity sector.

The benefit of the WUNZ programme in terms of social welfare was perceived as moderately important by respondents. The government subsidises partially all New Zealand income groups, although low to mid-income groups have been assisted with a larger subsidy. This shows that the development of the market was largely the main focus of the policy. In the future, the importance of social welfare as a co-benefit is scored as increasing, likely for the same reasons given for fuel-poverty.

Residential comfort was perceived as moderately important in the policy process, including the future support or expansion of the policy. Results on this co-benefit could be important for reducing the barrier associated with the maintenance of people's interest in the programme in the future, expanding market development to other aspects such as double glazing, wall insulation and other energy efficiency applications including solar systems.

An increase in awareness of energy efficiency as part of the policy was rated as having had low importance in the policy process. Awareness is necessary a side benefit of energy efficiency programmes. Despite evidence that energy efficiency is likely to play a significant role in addressing energy security and climate change in future, several key informants did not placed a high rating on this co-benefit of the scheme.

Co-benefits that were not included in the questionnaire but were reported by respondents individually as important in the policy process were avoided costs of new generation and an increase in productivity (as a result of days off work and school). Other co-benefits that were not important in the policy creation but could be important in the future were adaptation to climate change and New Zealand leadership in residential energy efficiency.

Finally, all interviewees agreed that co-benefits have been crucial to develop, support and expand retrofit policies and they would be important in the future as well. 
Co-benefits have the particular capacity to link different government agencies, providing arguments that transcend governments: "Co-benefits make the policy resilient when the government changes” (Howden-Chapman, personal communication). 
Table 6.3. Average rating on 1 to 5 scale, of the relative importance of benefits and cobenefits in the creation of the Warm Up New Zealand scheme and its support or future expansion $^{40}$.

\begin{tabular}{|c|c|c|c|c|}
\hline \multirow[b]{2}{*}{ Effects } & \multirow[b]{2}{*}{ Benefit/ co-benefit } & \multicolumn{2}{|c|}{ Rating } & \multirow[b]{2}{*}{ Delta** } \\
\hline & & Creation* & $\begin{array}{c}\text { Future support or } \\
\text { expansion* }\end{array}$ & \\
\hline \multirow{6}{*}{ 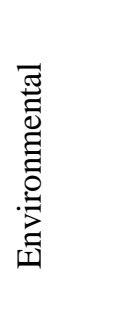 } & Reduction in carbon emissions & 2.7 & 3.8 & 1.1 \\
\hline & $\begin{array}{l}\text { Reduction in fossil fuel energy } \\
\text { generation }\end{array}$ & 2.8 & 3.6 & 0.8 \\
\hline & Reduction in energy use & 3.2 & 3.8 & 0.6 \\
\hline & Reduction in deforestation & 1.7 & 2.3 & 0.6 \\
\hline & Reduction in local outdoor air pollution & 3.0 & 3.0 & 0.0 \\
\hline & Reduction in indoor air pollution & 2.0 & 2.0 & 0.0 \\
\hline \multirow{2}{*}{$\frac{\text { E }}{\underline{\mathbb{Z}}}$} & Reduction in morbidity & 4.3 & 4.2 & -0.1 \\
\hline & Reduction in mortality & 4.0 & 3.4 & -0.6 \\
\hline \multirow{5}{*}{ 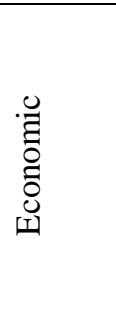 } & Increase in energy security & 1.8 & 3.0 & 1.2 \\
\hline & $\begin{array}{l}\text { Increase in ability to rent or sell } \\
\text { energy-efficient residences }\end{array}$ & 2.3 & 3.2 & 0.9 \\
\hline & $\begin{array}{l}\text { Reduction in costs associated with } \\
\text { human health }\end{array}$ & 3.8 & 3.8 & 0.0 \\
\hline & Increase in new business opportunities & 4.2 & 3.4 & -0.8 \\
\hline & Increase in employment opportunities & 4.3 & 3.4 & -0.9 \\
\hline \multirow{5}{*}{ 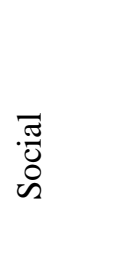 } & Reduction in fuel poverty & 2.7 & 3.8 & 1.1 \\
\hline & Improvement in social welfare & 3.5 & 3.8 & 0.3 \\
\hline & $\begin{array}{l}\text { Increase in residential safety (fewer } \\
\text { fires) }\end{array}$ & 1.7 & 1.8 & 0.1 \\
\hline & Increase in awareness & 2.3 & 2.4 & 0.1 \\
\hline & Increase in residential comfort & 3.3 & 3.2 & -0.1 \\
\hline
\end{tabular}

*Number of respondents: 6 .

***Difference, indicating direction of change.

\footnotetext{
${ }^{40}$ Very important $=5$; Important $=4$; Moderate $=3 ;$ Low $=2 ;$ Very low $=1$.
} 


\section{Chapter 7: Chilean results}

The results cover three main topics: development of the Chilean residential thermal retrofit measures at a general level; implementation of the insulation retrofit subsidy (IRS); and barriers to the creation, development, and future expansion of the IRS, focused on benefits and co-benefits.

\subsection{Development of residential thermal retrofit measures}

The development of the Chilean residential thermal retrofit measures has been a result of three different but convergent approaches to retrofit policy. These approaches came originally from the Ministry of Housing and Urbanism (MINVU), the Araucanía Regional Secretary of the National Commission of the Environment ${ }^{41}$, the National Commission of the Environment ${ }^{42}$, and the Energy Efficiency National Programme (PPEE) as part of the Ministry of Economy, Development and Reconstruction and later as part of the National Energy Commission (CNE) and the Ministry of Energy.

In Chile, housing policy has been traditionally orientated to reduce the housing deficit. In fact, during the early 1990s, the government financed the massive building of social houses, reaching an average of 90,000 dwellings per year (MINVU, 2009). However, this success in quantity was at the expense of quality (Campos, personal communication, December 14, 2010) ${ }^{43}$. For that reason, in 1994, MINVU designated a working group for incorporating quality in housing measures (Campos, ibid). This was the starting point of the Chilean residential thermal enhancement policies.

The development of the Chilean thermal housing standards ${ }^{44}$ was the result of negotiations, conducted by the Building Institute, between the authority, the private building sector and the academic world. Working together, these different entities developed two proposals and one of them was approved by MINVU in the late 1990s

\footnotetext{
${ }^{41}$ Former COREMA Araucanía and currently the Araucanía Secretariat of the Ministry of the Environment.

${ }^{42}$ Former CONAMA and currently the Ministry of the Environment.

${ }^{43} \mathrm{Mr}$. José Pedro Campos is a former MINVU official, who integrated the quality work group. He promoted and led the Chilean thermal standards development as member of the Building Institute. ${ }^{44}$ The Chilean thermal standards were included in the article $N^{\circ} 4.1 .10$ of the General Ordinance of Urbanism and Buildings (Ordenanza General de Urbanismo y Construcciones, 1992).
} 
(Campos, ibid). The proposal consisted of a multistage standards implementation: (1) roofs, (2) floors, walls, windows and (3) energy certification. Stage 1 was enacted in 2000, stage 2 in 2007 and stage 3 is still in process. The thermal standards proposal was developed as a measure for improving quality of life ${ }^{45}$, housing quality ${ }^{46}$ and optimizing or reducing energy use and expenditure (IC, 2003). With regard to energy efficiency, the standards did not pursue significant energy savings (e.g. the rebound effect was not taken into account), but created conditions for a fuel use reduction (Campos, ibid). However, the economic analysis was based on the net present value (NPV) ${ }^{47}$ of insulation costs and energy savings, assuming a target temperature of $20^{\circ} \mathrm{C}$ during the day and $17^{\circ} \mathrm{C}$ at night (CChC, 2003). Although co-benefits were recognised by the authority, they were not accounted for the economic valuation. In the case of health, the omission was a result of lack of information about the correlation between temperature and morbidity or mortality, difficulty of calculation and data availability. "We did not calculate the avoided health costs, but we assumed that households will have conditions for avoiding health problems” (Campos, ibid). In this way, MINVU targeted new dwellings quality through thermal standards; however, existing residences were devoid of any regulation.

As mentioned before, MINVU was concerned about housing quality. MINVU's officials realised that the quality problem could result in a second housing deficit and consequently, in an increase of the demand for housing subsidies as well as a reduction of housing value (Decreto $N^{\circ} 255$, 2007). To target this issue, in 2007, MINVU launched a system of subsidies for social dwellings called the Family Patrimony Protection Programme (PPPF). The subsidies target three types of different issues: (1) community facilities and/or neighbourhood improvement, (2) housing enhancement and (3) housing extension. Families are allowed to obtain only one of these three possible subsidies and they must meet certain requirements of social vulnerability (Appendix 3). As explained later in this chapter, residential energy efficiency measures are incorporated as part of the housing enhancement subsidy type.

\footnotetext{
${ }^{45}$ Reduction of indoor pollution and humidity produced by open flame fossil fuel heaters, wet wood or bad practices; thermal comfort enhancement and health problems reduction (Campos, personal communication, December 14, 2010).

${ }^{46}$ Improvement of housing habitability and durability through humidity reduction and better materials use (Campos, personal communication, December 14, 2010).

${ }^{47}$ The NPV used a discount rate of $7.8 \%$ and a time horizon of 20 years.
} 
As explained in Chapter 4, the Araucanía region was in the mid-2000, facing local air pollution problems. The creation of the pollution reduction plan was the responsibility of the COREMA Araucanía; however, in the policy making process many other relevant organisations participated as members of a pollution reduction plan operative committee (comité operativo) ${ }^{48}$. The primary goal of the pollution reduction plan is the reduction of $\mathrm{PM}_{10}$ concentrations in the air in order to protect people's health. The operative committee designed four strategic lines to achieve the goal: wood quality improvement, heater replacement, retrofit insulation and education. "We determined that the most efficient way of reducing the emissions was decreasing the energy demand for space heating” (Schiappacasse, personal communication, December $1,2010)^{49}$. The pollution reduction plan operative committee realised that the new Chilean thermal standards 2007 would enable energy use reduction in new households; however, in existing residences, energy consumption was not yet targeted by any policy instrument (Schiappacasse, ibid). But it was a suitable vehicle: "Already in existence was a subsidy of MINVU for general housing enhancement, called the Family's Patrimony Protection Programme, and through this subsidy we incorporated a thermal insulation retrofit subsidy" (Schiappacasse, ibid). In this way, the insulation retrofit subsidy (IRS) for the comunas of Temuco and Padre las Casas was proposed by the local to the central authority: "The IRS was requested by the National Commission of the Environment because they needed assistance for the critical issue of pollution in these two comunas and it was used as a subsidy pilot” (Dujovne, personal communication, March 11, 2011) $)^{50}$. In this way, the IRS was formally included, in September 2007, within the PPPF's annual 2008 budget to subsidise housing enhancement in those comunas declared as saturated by $\mathrm{PM}_{10}$ (Articulo $\mathrm{N}^{\circ}$ 6, Decreto $N^{\circ}$ 144, 2007). The first IRS benefited 504 households in Temuco and Padre las Casas with an amount of NZ\$5,900 51 per household. The enhancements aim to take existing

\footnotetext{
${ }^{48}$ SEREMIS of Health, Housing, Agriculture, Education, Transport, Government, Public Works and Economy; SERVIU; National Forestry Corporation; Superintendence of Electricity and Fuels; Customer National Service; National Energy Commission; Production Development Corporation; Regional Government and Municipalities of Temuco and Padre las Casas (COREMA Araucanía, n.d.).

${ }^{49} \mathrm{Mr}$. Nicolás Schiappacasse is a former COREMA officer who worked in the creation of the pollution reduction plan of Temuco and Padre las Casas.

${ }^{50} \mathrm{Mr}$. Leonardo Dujovne is a former MINVU official who worked in the introduction of IRS.

${ }^{51}$ The subsidy was 100 UF per household. The exchange rate between UF and Chilean peso was taken as the average of the period between September 15, 2010 and March 5, 2011. This exchange rate is 1 UF = \$21,433 Chilean pesos (CLP) (http://valoruf.cl/valores_anuales_uf otros.html). The exchange rate between \$CLP and \$NZ was assumed to be the average of the period between September 15, 2010 and
} 
housing to the thermal standards for new housing 2007. In 2008 and 2009, the authority's interpretation was that retrofitting works could cover some parts of the dwellings, in order to reach the thermal standards in those rooms that families needed the most (Photo 7.1). However, this interpretation was changed in 2010 and, as explained later in this Chapter, the retrofit works must cover the whole dwelling's envelope.

Photo 7.1. Wall insulation work in Temuco.

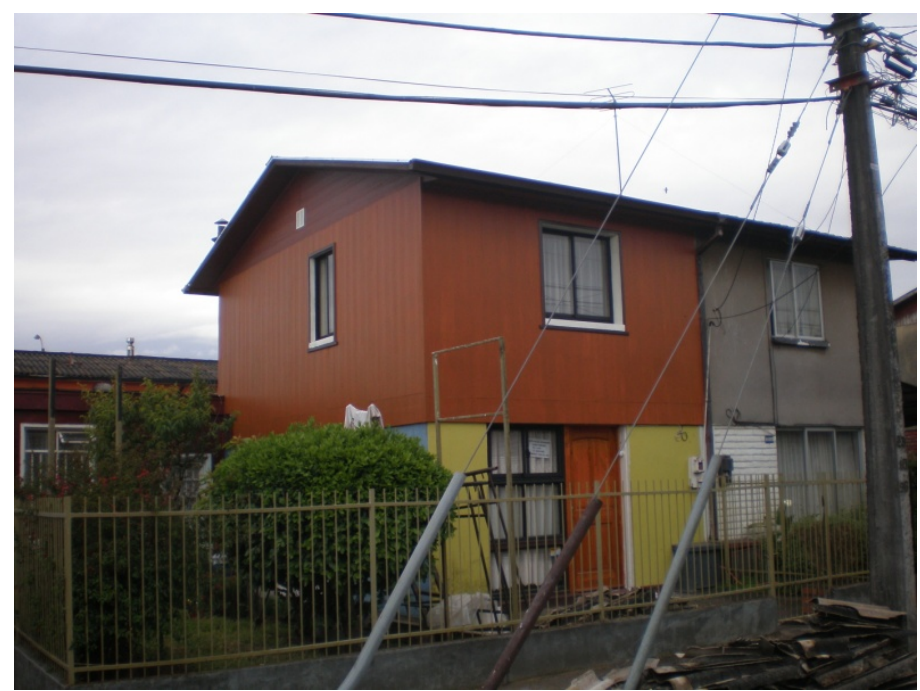

Note: In this house only the second floor was retrofitted.

Author: Alejandra Pérez.

The economic cost-benefit evaluation of the Temuco and Padre las Casas pollution reduction plan included different measures such as urban afforestation, a ban on wet wood selling, heater replacement and retrofitting with insulation. The direct quantified benefits for a retrofitting measure (focused in low-income households) were mortality and morbidity avoidance and wood energy savings. A quantified co-benefit was visibility enhancement (air quality) and a non-quantified one was house fire risk avoidance. It was estimated that an IRS that provided for roof and wall insulation of 10,000 social households in 10 years (from 2008 to 2017) could result in a reduction of 718 tonnes of $\mathrm{PM}_{10}$ for the period 2008-2022. At a discount rate of $10 \%$, the benefitcost ratio of retrofitting with insulation was estimated at 1.2 (CENMA, 2007). In the study the results were presented in an aggregate way that makes it difficult to

March 13, 2011. The exchange rate is \$1 NZ = \$364 CLP (http://www.exchangerates.org/history/CLP/NZD/G/180). 
distinguish the amount of energy savings from other benefits. However, among the whole pollution reduction plan, the insulation measure accounted for $12 \%$ of the total benefits $^{52}$ (energy savings, avoided health costs, and visibility) and $8 \%$ of the annual reductions of tonnes of $\mathrm{PM}_{10}$. Health damage ${ }^{53}$ was estimated at NZ\$12,200 per ton of $\mathrm{PM}_{10}{ }^{54}$. Visibility gains ${ }^{55}$ were estimated at NZ\$ 590 per ton of $\mathrm{PM}_{10}$ (CENMA, 2007). However, the figures could be overestimated because the rebound effect was not taken into account and a recent study showed that approximately 50\% of the $\mathrm{PM}_{10}$ emissions are produced by the three richest income deciles of the comunas whereas the lowest five income deciles only produce 28.6\% (Universidad de la Frontera, 2009).

At the same time, Chilean energy security problems (explained in Chapter 4) fostered central authorities’ cooperation. In 2006 the Ministry of Economy transferred funds to MINVU, through the PPEE, to fund a study on thermal retrofit investment for existing residences in Chile (Bardi, personal communication, November 24, 2010) ${ }^{56}$. Using information from the Census 2002, the study determined that, nationwide, 3,600,000 households could be retrofitted as the houses were built before the first stage of the thermal standards came into force in 2000. The study modelled the space heating energy consumption for 10 different types of dwellings over the country and 7 different climatic zones and different insulation scenarios concluding, among other things, that the direct benefits quantified as energy and maintenance savings and avoided heath costs $^{57}$ justify the investment in insulation to reach the 2007 thermal standards. The NPV was positive for both optimistic and negative scenarios ${ }^{58}$. The estimates were based on a goal of total residential energy use reduction of $10 \%$ within 12 to 18 years.

\footnotetext{
${ }^{52}$ The NPV of the insulation measure was NZ\$14.6 M at a discount rate of 10 and 15 years.

53 See footnote 57.

${ }^{54}$ In the original study, the figure was presented in US\$. The exchange rate between NZ\$ and US\$ was taken as the average of the period between September 18, 2010 and March 17, 2011. This exchange rate is $1 \mathrm{NZ \$}=0.76$ US\$ (http://www.exchange-rates.org/history/USD/NZD/G/180).

${ }^{55}$ Damages in visibility were calculated adjusting the previous economic valuation of the pollution reduction plan of Santiago which used contingent valuation to determine the willingness to pay (WTP) for seeing objects or landscapes more clearly.

${ }^{56}$ Ms. Carla Bardi is manager of residential energy efficiency issues at the Ministry of Energy.

${ }^{57}$ Avoided costs of mortality, bronchitis, asthma attacks, hospital admissions, emergency admissions, offwork days and restricted activity working days were estimated at US\$ 5,966 per ton of particulate matter emitted which equals NZ\$ 15 cents/kWh. The unique fuel accounted was wood and its emissions were estimated at $10.5 \mathrm{~kg}$ of particulate matter per $\mathrm{m}^{3}$ of wood. The costs were taken from the report Generación de instrumentos de gestión ambiental para la actualización del plan de descontaminación atmosférica para la región Metropolitana al año 2000 (DICTUC, 2001).

${ }^{58}$ Optimistic scenario: 10 years time horizon, discount rate of $8 \%$ and fuel price annual increase of $10 \%$ on average. The price of wood was maintained constant. This scenario assumes that the government subsidises most of the retrofit investment.

Pessimistic scenario: 10 years time horizon, discount rate of $12 \%$ and fuel price increase of $4 \%$. The price of wood was maintained constant. In this scenario private investment is crucial.
} 
That means a goal of retrofitting $20 \%$ of the houses built before 2000 , or 720,000 dwellings (Ambiente Consultores \& PRIEN, 2007). Health costs were obtained using data associated with particulate matter concentrations (PM), but not costs associated with cold temperatures because of lack of information (Collados, personal communication, November 25, 2010 ${ }^{59}$ and they were estimated at NZ\$ 7,900 per ton of emitted particulate matter (Ambiente Consultores \& PRIEN, 2007) from wood burning.

Table 7.1. NPV for a measure of retrofitting with insulation 720,000 dwellings over 10 years.

\begin{tabular}{|c|c|c|c|c|}
\hline Scenario & $\begin{array}{c}\text { Investment } \\
\text { (NZ\$ M) }\end{array}$ & $\begin{array}{l}\text { Health savings } \\
\text { (NZ\$ M) }\end{array}$ & $\begin{array}{l}\text { Energy and maintenance } \\
\text { savings }^{60}(\mathrm{NZ \$} M)\end{array}$ & $\begin{array}{l}\text { Energy savings } \\
\text { per year }(\mathrm{PJ})^{61}\end{array}$ \\
\hline Optimistic & 3,610 & 1,955 & 6,140 & 17.6 \\
\hline Pessimistic & 1,210 & 1,520 & 4,600 & 16.2 \\
\hline
\end{tabular}

Source: Ambiente Consultores and PRIEN (2007).

Additionally, the study assumed that an increase in energy efficiency will result in a decrease of energy consumption; it did not take into account the rebound effect. "We assumed that the retrofit measure results in households' energy savings, hence monetary savings ... If families decide to spend the same or more on fuel, it means that they value comfort more than the cost of energy" (Collados, ibid.). Other co-benefits were also included in the study: natural gas and LPG import reductions of 1.5\% and 17\% respectively ${ }^{62}$, creation of 3,000 - 4,600 annual direct jobs, creation of 700 small enterprises, $\mathrm{CO}_{2}$ emission reduction of 58,000 tons per year, skilled personnel training, technological innovation, a reduction of insulation input prices and an increase in transport activities (Ambiente Consultores \& PRIEN, 2007). No analysis was conducted of whether some of these co-benefits (e.g. creation of jobs or transport) were in fact real or simply a transfer of activity from another sector of the economy.

Another important element for the development of the IRS was a study carried out by the German Society for Technical Cooperation (GTZ) and the Building Institute. The

\footnotetext{
${ }^{59}$ Eugenio Collados is currently an academic expert, author of the study (Ambiente Consultores \& PRIEN, 2007).

${ }^{60}$ Energy and maintenance savings are presented aggregately; however, from the data analysis and the interview with Eugenio Collados it is possible to establish that the bulk of the savings resulted from energy.

${ }^{61}$ Or 49 TWh and 45 TWh respectively.

${ }^{62}$ Taking as a reference imports in 2003.
} 
study was financed by the PPEE and determined residential temperature, humidity and heating expenditure and consumption in 400 dwellings in five regions, valued at less than NZ\$237,000 and built after the first stage of the Chilean standards (2000). The study concluded that the average effective indoor temperature was $13.8^{\circ} \mathrm{C}$ and the lowest was $10.1^{\circ} \mathrm{C}$ in Concepción. These figures are far under the temperatures set by the World Health Organization $\left(18-21^{\circ} \mathrm{C}\right)$. Expenditure on heating was an average of NZ\$ 63 monthly. The fuels were dominated by liquefied gas (44\%), followed by wood (25\%), natural gas (13\%), electricity (12\%) and kerosene (6\%). In the southernmost evaluated region (Puerto Montt), wood was the dominant fuel. Families that noticed indoor humidity accounted for 31.1\% of households (IC \& GTZ, 2007); however humidity was not measured.

Based on this information the central authority realised that, despite the implementation of the standards in 2000, households were not warm enough. They also noticed that retrofitting with insulation was facing the 'principal-agent' problem: "Builders do not have any incentive to make investments in energy efficiency and buyers are not aware of dwellings' quality and its future consequences. To address this problem we established a public investment project to retrofit with insulation 720,000 dwellings to 2020” (Romero, personal communication, March 4, 2011) ${ }^{63}$. As a starting point, based on the recommendations of (Ambiente Consultores \& PRIEN, 2007) and the Treasury estimate of resources availability, President Michelle Bachelet committed a budget of NZ\$ 119 million to retrofit 20,000 social dwellings through the IRS in 2009 and 2010, "promoting an efficient residential energy use, improving households' heating, reducing health problems and increasing housing durability” (Bachelet, 2008).

The IRS was focused on the area from the O’Higgins to Los Lagos regions in 2009 and from the O’Higgins to the Magallanes regions in 2010 following a politicaltechnical decision. The regions were selected mainly based on the study of Ambiente Consultores and PRIEN (2007) and the capacity of different regional SERVIU to deliver the IRS (Dujovne, personal communication). Regarding this last point, the SERVIUs' management capacity was very important to allocate the resources from the annual Treasury budget. If in one year MINVU asks the Treasury for a given amount of money for the programme, these resources must be fully used, otherwise it will be

\footnotetext{
${ }^{63} \mathrm{Mr}$. Andrés Romero is the former director of the PPEE, when this programme was administrated by the National Commission of Energy.
} 
difficult to obtain them again next year (Dujovne, ibid). As noticed in Table 7.2, the IRS's regional budget changed from one year to the next reflecting the regional SERVIUs' management capacity. For instance, in those regions where the number of retrofits implemented during the first year was low, the IRS's budget for the next year was reduced. Additionally, MINVU was concerned about the very poor quality of the bricks used for residential building in the O’Higgins region as well as the pollution problem in the majority of the southern cities of Chile (already declared, or in the process of being declared as saturated with $\mathrm{PM}_{10}$ ) (Romero, personal communication). The bulk of the IRS was allocated in the Bio-Bio and Araucanía regions (Map 4.2).

The National Commission of Energy realised that in terms of energy, the IRS was not going to have a significant impact on energy savings, but the IRS linked two public organisations' goals: MINVU's quality of life enhancement and the PPEE's energy use reductions (Romero, ibid).

The benefits of the measure for MINVU were expressed as follows:

“Retrofitting existing social dwellings contributes to families' quality of life more than decreasing the country's energy use, because energy consumption in social households is insignificant within the national energy context. The benefit is an increase of quality of life and a reduction of health problems associated with heating and humidity ... At a national level (the complete existing housing sector) there is a contribution for reducing energy use for heating” (Rozas, personal communication, December 9, 2010) ${ }^{64}$.

\subsection{Implementation of the insulation retrofit subsidy}

The IRS implementation procedure consisted in transferring funds from the PPEE (Energy Efficiency National Programme) to MINVU’s PPPF (Family Patrimony Protection Programme). The IRS was included in the existing PPPF in order to avoid the bureaucracy of enacting a new decree. The transference was a political decision to maintain the whole country's expenditure on energy efficiency in a unique budget (PPEE budget), as well as to ensure that the funds were used exclusively on energy efficiency measures and not on other issues such as political emergencies (Romero,

\footnotetext{
${ }^{64}$ Ms. Yoselin Rozas is a MINVU official who manages the IRS.
} 
ibid). Accordingly, the PPPF was modified again in 2009 in order to include energy efficiency spending (as mentioned before, it was modified previously to incorporate $\mathrm{PM}_{10}$ saturated zones). The housing enhancement type subsidy of the PPPF included a section that brought into law a subsidy for works or innovations in residential energy efficiency that enable "a reduction of energy expenditure, maintenance costs and basic services costs" (Decreto $N^{\circ} 6$, 2009). According to this modification, insulation retrofit works must reach the Chilean thermal standards 2007 which require certain thermal transmittance values for the whole dwelling envelope. Table 7.2 summarises the IRS evolution. 
Table 7.2. Source, resources, beneficiaries and rationale of the insulation retrofit subsidy.

\begin{tabular}{|c|c|c|c|c|c|c|c|}
\hline Year & $\begin{array}{c}\text { Subsidy via } \\
\text { MINVU } \\
\text { (millions of NZ\$) }\end{array}$ & $\begin{array}{c}\text { Subsidy via } \\
\text { PPEE (millions } \\
\text { of NZ\$) }\end{array}$ & $\begin{array}{c}\text { Beneficiaries } \\
\text { ( } \mathrm{N}^{\circ} \text { of } \\
\text { households) }\end{array}$ & Region & $\begin{array}{c}\text { Subsidy by } \\
\text { region } \\
\text { (millions of NZ\$) }\end{array}$ & $\begin{array}{l}\text { Beneficiary } \\
\text { number by } \\
\text { region }\end{array}$ & Rationale \\
\hline 2008 & 3 & & 504 & Araucanía & 3.0 & ---- & Pollution reduction \\
\hline \multirow{7}{*}{$\begin{array}{l}\text { 2009- } \\
2010\end{array}$} & & \multirow[t]{7}{*}{60} & \multirow[t]{7}{*}{ 9,000 approx. } & O’Higgins & 5.9 & 1,000 & \multirow{7}{*}{$\begin{array}{l}\text { Pollution reduction } \\
\text { Quality of life and dwellings } \\
\text { Energy savings }\end{array}$} \\
\hline & & & & Maule & 5.9 & 1,000 & \\
\hline & & & & Bío Bío & 18.2 & 3,100 & \\
\hline & & & & Araucanía & 10.6 & 1,800 & \\
\hline & & & & De los Ríos & 8.2 & 1,400 & \\
\hline & & & & De los Lagos & 8.2 & 1,400 & \\
\hline & & & & Aysén & 2.9 & 300 & \\
\hline \multirow{8}{*}{$\begin{array}{l}2010- \\
2011\end{array}$} & & \multirow[t]{8}{*}{59} & \multirow[t]{8}{*}{ 8,900 approx. } & O’Higgins & 0.3 & 52 & \multirow{8}{*}{$\begin{array}{l}\text { Pollution reduction } \\
\text { Quality of life and dwellings } \\
\text { Energy savings }\end{array}$} \\
\hline & & & & Maule & 10.6 & 1,690 & \\
\hline & & & & Bío Bío & 16.2 & 2,500 & \\
\hline & & & & Araucanía & 16.0 & 2,554 & \\
\hline & & & & De los Ríos & 9.4 & 1,502 & \\
\hline & & & & De los Lagos & 2.4 & 348 & \\
\hline & & & & Aysén & 2.4 & 293 & \\
\hline & & & & Magallanes & 1.5 & 200 & \\
\hline
\end{tabular}

Source: Resolución exenta $N^{\circ} 2937$ (2009); Resolución exenta $N^{\circ} 5433$ (2009); Resolución exenta $N^{\circ} 5649$ (2010); Resolución exenta $N^{\circ}$ 0643 (2011). 
The practical IRS implementation procedure and the requirements of applicants are explained in Appendix 3. The subsidy process is channelled through social property management entities (EGIS) that link communities with the SERVIU and a building company. The requirements for applying for the IRS includes having a social dwelling, a bank account with NZ \$180 to contribute to the insulation investment and being officially registered as a vulnerable social household ${ }^{65}$.

\subsection{Barriers to the creation and implementation of the insulation retrofit subsidy (IRS) and its support and future expansion}

In general, interviewees did not perceive that any serious barriers had existed in the creation of the IRS policy. In fact, it was not difficult to obtain government funds for the IRS because Chile was facing energy supply problems at the time, so politicians were very sensitive to energy efficiency issues. Also, the price of copper was high, providing additional government revenue, and Chile was trying to become a member of the OECD (Romero, personal communication). Since, as explained in Chapter 4, different government and private organisations had been discussing energy efficiency issues from 2004 through the Ministry of Economy and the PPEE, interest was widespread for energy efficiency policies. When the Minister of Energy presented the IRS budget to the Treasury and the Congress to obtain annual funds, nobody questioned the petition (Romero, ibid.).

A barrier reported was the reluctance of some MINVU authorities for whom energy efficiency was an unknown issue. Energy efficiency was not seen as a matter of urgency relative to other MINVU matters of urgency, such as the housing deficit, people living in slums, neighbourhood segregation, overcrowding, and conditions of poor habitability (Dujovne, personal communication). However, in 2009 the authorities changed their mind after receiving feedback from the IRS beneficiaries. They remarked that their life quality was enhanced, that they did not feel cold and that their children did not get sick (Dujovne, ibid).

\footnotetext{
${ }^{65}$ Based on income, housing quality, property ownership, family size, family members' age, health problems and other similar considerations.
} 
The incorporation of the IRS as part of the MINVU's PPPF subsidy system with a goal of reaching the 2007 thermal standards has faced some barriers. As mentioned before, dwellings need to apply the standards to the whole envelope. This requirement constrains the number of dwellings that can apply for the IRS. Dwellings built before the first stage of the 2000 standards, need the whole envelope to be retrofitted. This is very difficult to achieve within the current subsidy amount of \$NZ 5,600 per dwelling in the Araucanía region (Sandoval, personal communication, December 1, 2010) ${ }^{66}$. For the same reason, it has been calculated that houses up to $45 \mathrm{~m}^{2}$ could be completely retrofitted. In practice, it is very difficult to find houses with such a small area because low-income people generally expand the dwelling without official permission. Therefore, before applying for the subsidy, illegal constructions have to be formalised, generating additional costs and time losses or excluding some households (Urbina, personal communication, December 3, 2010) ${ }^{67}$. In addition, the PPPF requires a minimum level of owners' bank savings that households sometimes find difficult to accumulate and it only enables one unique subsidy per household. Households that received a PPPF subsidy before the enactment of the IRS or those needing a different kind of PPPF subsidy (e.g. housing extension) are excluded from obtaining a new subsidy for energy efficiency.

Another barrier reported by the local authority is that the IRS, as part of PPPF, only targets social households; therefore the scheme is not substantial enough to produce a significant reduction in air pollution in the comunas of Temuco and Padre las Casas. During 2008, 2009 and 2010, approximately 4,900 dwellings have been retrofitted which represent only $6 \%$ of the total comunas' households. As explained before, the rebound effect was not taken into account; therefore, the households' energy use will not be reduced significantly. Leaving the social equity factor aside, if the subsidy had been delivered to higher-income households, the rebound effect would be less and energy savings greater, thus reducing $\mathrm{PM}_{10}$ emissions more.

To improve the effectiveness of the measure, most of the interviewees agreed that it is necessary to target middle class household through an incremental subsidy (inversely proportional to the families' social and economic conditions) or tax

\footnotetext{
${ }^{66} \mathrm{Mr}$. Juan Carlos Sandoval is currently a representative of a private social property management entity of Temuco. He works implementing the IRS.

${ }^{67}$ Mr. Pablo Urbina is currently a representative of the municipal social property management entity of Temuco. He works implementing the IRS.
} 
reductions. Additionally, interviewees agreed that, to be effective in $\mathrm{PM}_{10}$ emission reductions, it is necessary to implement a heater replacement measure in conjunction with the IRS. The majority of the interviewees said that effectiveness in $\mathrm{PM}_{10}$ emission reductions is crucial to support or expand the policy in the future.

Most of the interviewees recognised that a significant risk for the future support or expansion of the IRS is that MINVU does not appear to give priority for residential energy efficiency. In fact, other issues such as the 2010 earthquake and the reconstruction process, and MINVU's goals (e.g. housing deficit, neighbours enhancements, building code administration, etc.) could affect the IRS's budget in the future.

Interviewees also stated, at a most general level, that market failures are significant barriers to retrofitting households with insulation. "Currently in Chile there are no companies' associations for insulation products, buyers do not take into account energy costs in their purchase decisions, building companies have not improved building materials and banks have not taken into account the value of insulation measures” (Collados, personal communication). This problem is expected to be reduced through the introduction of the third stage of the Chilean thermal standards: certification for new and existing dwellings.

One of the main barriers to market development is that in the south of Chile wood fuel is very cheap (wood is plentiful, even if often damp) in comparison to other fuels and in Santiago, the largest city, the space heating annual consumption is relatively $\operatorname{low}^{68}$ (Yañez, personal communication, November 23, 2010) ${ }^{69}$, probably as a consequence of the high prices of space heating fuels (Chapter 2). The insulation market is small: "Insulation is more than reparation and less than construction” (Collados, ibid.). There is a lack of three things in this market: certificated or high quality materials, a large insulation products market, and skilled personnel for retrofitting with insulation (Collados, idid.) (Photo 7.1). However, the PPEE has held workshops related to the improvement of insulation installations. The workshops have targeted social property management entities (Appendix 3) and building or insulation company representatives.

\footnotetext{
${ }^{68}$ The countries' average annual energy consumption for space heating was estimated at $208 \mathrm{kWh} / \mathrm{m}^{2}$, with a standard deviation of $150 \mathrm{kWh} / \mathrm{m}^{2}$ (Ambiente Consultores \& PRIEN, 2007).

${ }^{69}$ Cristian Yañez is currently a representative of the Chilean Chamber of Building.
} 
Photo 7.2. Wall insulation work in Temuco.

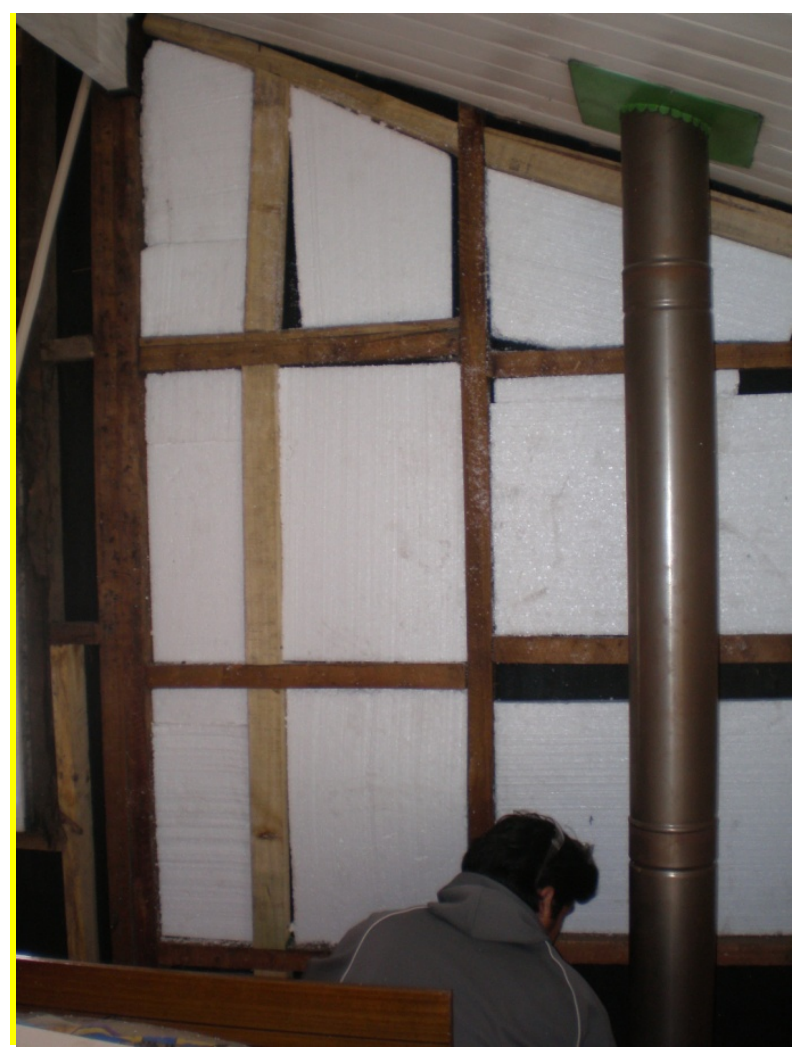

Note: This house is being retrofitted under the IRS programme. It is possible to see some "holes" in the insulation, which indicates thermal gaps.

Author: Alejandra Pérez.

Household behavioural patterns have also threatened the effectiveness of the IRS in terms of fuel use reductions and health. There is evidence that some households have presented humidity problems due to the lack of ventilation, use of open flame heaters, and practices such as drying clothes near the heater and leaving the kettle on with boiling water for long periods (Vega, personal communication, December 3, 2010) ${ }^{70}$. Nevertheless, the local authority has been targeting this issue by incorporating education through a social habilitation plan (Appendix 3). Also, preliminary measurements made by the authority have shown that some households have increased indoor temperatures more than expected (to more than $25^{\circ} \mathrm{C}$ ). However, these are not definitive results as the first study on the IRS performance is currently in process; therefore, the prevalence of such behaviour remains to be seen.

\footnotetext{
${ }^{70}$ Paula Vega is a SERVIU's officer of the Araucanía region who works in the IRS implementation.
} 
As mentioned before, the IRS's budget is discussed annually. Most of the interviewees said that the future expansion or support of the policy depends on political will. With regard to this last point, the IRS is not a long term policy that transcends governments. The Ministry of Energy cannot guarantee the funding to MINVU beyond 2011 (Bardi, personal communication). Thus, MINVU will be responsible for obtaining funds from the Treasury every year for the IRS. As explained before, this is risky because MINVU could prioritise other programmes or use the funds for emergencies. Additionally, Conservative President Sebastián Piñera has said that he will promote efficient insulation materials and informational campaigns for appliances (Piñera, 2010). Reading between the lines, it seems that the Chilean administration will focus on some aspects of the market chain without a substantial emphasis on insulation retrofitting measures.

\subsection{Benefits and co-benefits}

The following findings are based on interviews and a questionnaire where respondents rated a range of possible benefits and co-benefits. The questionnaire results are shown in Table 7.3.

\subsubsection{Environmental co-benefits}

Reduction in local outdoor air pollution, not surprisingly, scored the highest in the IRS policy creation, as concerns of local air pollution led the central and local authorities to develop the insulation retrofit policy. In the south of Chile, where wood is broadly used, this co-benefit is perceived as very important to support or expand the IRS in the future, within the framework of air pollution reduction plans.

A reduction in indoor air pollution was perceived as important in the policy creation, with rising in importance in the future. This co-benefit has not been directly targeted by the IRS or any other policy, despite the broad use of very pollutant open flame heaters throughout the country (Chapter 4 and Appendix 1). Particularly in lowincome households, insulation retrofits will probably not significantly reduce the amount of energy used (rebound effect); therefore, even though authorities are aware that the IRS could produce some positive impact on indoor air pollution, in practice it is difficult that this co-benefit can properly be addressed under the current IRS. 
A reduction in energy use was also important in the creation of the IRS. Although the IRS has a low impact on the energy savings nationwide, it is the building block of a proposal, studied during the President Bachelet administration, of retrofitting 720,000 households nationwide, and yielding overall energy savings which the authorities consider important. This benefit was the most salient argument for justifying the policy economically, followed by avoided health costs (Table 7.1). Energy savings was also perceived as a key means to reduce local air pollution.

With regard to reductions in carbon emissions, some authorities confused this cobenefit with reduction in $\mathrm{PM}_{10}$ emissions; therefore, this result is misleading. However, based on the interviews, it is possible to argue that a reduction in carbon emissions was not important for the creation of the IRS. In fact, in the economic valuation of the proposed policy of retrofitting 720,000 households nationwide, the authors estimated that the benefits accrued from $\mathrm{CO}_{2}$ emission reductions (58,000 tons per year) were very marginal (Collados, personal communication). Furthermore, it is likely that, in the future, carbon emissions will not have a significant bearing on the policy process because, as mentioned in Chapter 4, Chile does not have obligations to reduce carbon emissions within the Kyoto Protocol agreement.

A reduction in fossil-fuel energy generation (another co-benefit related to climate change) was also misunderstood by some authorities so the result is misleading. These authorities confused this co-benefit with a reduction in fossil-fuels energy use. Based on the same explanation given for reductions in carbon emissions, it is unlikely that this cobenefit has a relevant role in the future support or expansion of the policy. In fact, as mentioned in Chapter 4, Chile is expanding coal power plants which will increase carbon emissions by $130 \%$ by 2030 ; therefore, if electricity starts to be used as a fuel for residential space heating, the use of coal will probably increase. On the other hand, if current fuels for residential space heating are maintained, the future increase of energy demand in the residential sector will increase the need for fossil fuels as well. Moreover, the use of wood is forecast to decrease in the future (Chapter 4), which implies an increase of electricity and fossil fuel use for residential space heating.

A reduction of deforestation was perceived as moderately important in the IRS creation, and increasing in importance in the future. This result shows that authorities are expecting that the IRS, as a part of the Temuco and Padre las Casas air pollution plan, contributes to reducing the illegal trade of wet wood from unsustainably managed 
forests, by reducing wood use. As already discussed, a significant reduction of energy use is unlikely to occur in low-income households. In addition, stopping illegal trade of wet wood is potentially expensive for the government; therefore, this action could be difficult to maintain in the future.

\subsubsection{Health co-benefits}

A reduction in morbidity was rated as important in the IRS creation; however, their estimation was solely associated with $\mathrm{PM}_{10}$ as a local air pollutant. Therefore, this co-benefit, as an argument for new retrofit policy development or for supporting or expanding the current IRS, is only applicable to those communas affected by air pollution due to wood use. To bring the policy to a broader level it is necessary to investigate the effects of indoor air pollution and low indoor temperatures on health, and their impacts on government health expenditure. Presumably, as well as in New Zealand, the results will show a high benefit-cost ratio for retrofit policies. Furthermore, this ratio could be higher than in New Zealand (2:1) taking into account indoor pollution and very low indoor temperatures (e.g. $10.1^{\circ} \mathrm{C}$ in Concepción, as noted before). Mortality was perceived as moderately important; however, further research on this issue could assist in increasing the government's awareness of the impacts of the IRS on health. Moreover, the health issue could become a strong argument for a nationwide policy for heater replacement (in addition to insulation) focused on low-income households and meddle-income groups.

\subsubsection{Economic co-benefits}

Health costs were perceived as moderately important in the IRS creation, but increasing in importance in the future. This shows that the government is not currently aware of the significant co-benefits that could be potentially obtained from an insulation policy. In fact, the Ministry of the Environment, at both national and local levels, regard the air pollution plan (and the IRS as a part of the plan) as a policy to cost-effectively reduce local air pollution, regardless of social and economic aspects; although the air pollution plan clearly addresses these aspects indirectly (Toro, personal communication, November 29, 2010 ${ }^{71}$. Furthermore, health costs are likely to be underestimated in the

\footnotetext{
${ }^{71}$ Ms. Rocío Toro is an Araucanía SEREMI of Environment officer, responsible for the Temuco and Padre las Casas pollution reduction plan. She participated in the creation and implementation of it.
} 
NPV for justifying the policy to retrofit 720,000 dwellings with insulation (Table 7.1) and in the economic cost-benefit evaluation of the Temuco and Padre las Casas pollution reduction plan.

An increase in new employment opportunities was scored as moderately important in the policy creation and increasing in importance in the future. The IRS, as a subsidy that provides for the totality of the insulation's installation cost, is able to generate new jobs while the grant is maintained; however, it is unlikely that the jobs will be existent without it. In the case of increasing in new business opportunities, the retrofit market has not been addressed by the government directly. Chilean authorities think that the market will be stimulated through housing certification (Chapter 4) and complementary policies (e.g. informational campaigns, promotion of better insulation materials and a future possible implementation of low-interest bank loan) (Bardi, personal communication). The New Zealand retrofit policy experience shows that customers are very unlikely to adopt retrofits without a reduction of the capital costs and support to overcome other barriers to residential energy efficiency acknowledged by scholars (Chapter 2). The same analysis can be applied to the co-benefit of an increase in ability to rent or sell energy-efficient residences.

Energy security was not important as an argument in the creation of the IRS, yet in the future it is perceived as moderately important. This can be explained because insulation in low-income households is not likely to produce significant energy savings (due to the rebound effect). In the future, if other income groups invest in insulation, a larger amount of energy savings could be obtained. However, as mentioned before, the government is expecting that mainly through certification, the market will grows.

Nevertheless it is argued that, this is very unlikely to occur.

\subsubsection{Social co-benefits}

Not surprisingly, an improvement in social welfare and residential comfort were important arguments for the creation of the IRS, although they were not quantified in the policy creation process. The social focus of the IRS is well regarded by authorities in the way of a complete grant for insulation. In the future, this argument can be crucial to maintain MINVU's interest in energy efficiency. Since one of the main responsibilities of this Ministry is the enhancement of low-income people's households, 
research on these two co-benefits could provide substantial evidence to maintain an annual budget for the programme.

Interviewees perceived that a reduction in fuel poverty is important in both the creation and future of the IRS policy. However, this result is misleading because some authorities were not familiar with the definition of fuel poverty, although they were aware that the IRS could have a positive impact on households' budgets. In fact, when asked, the president of a social local committee of Temuco, who represented 78 IRS beneficiaries, said that for her, the most important arguments for supporting and expanding the IRS are an increase in thermal comfort and a reduction in fuel expenditure. Also, the Ministry of the Environment, at both national and local levels, agreed that in general, people are not very concerned about the air pollution issue; rather they are concerned about heating expenditure. Although the insulation policy could result in some reduction of expenditure on fuels by low-income households, it does not mean that households will not be facing fuel poverty in the future.

An increase in awareness of energy efficiency issues was rated as moderately important in the creation of the IRS. This result shows that authorities are aware that this co-benefit is a side effect of energy efficiency policy; however, from the interviews' results, it is possible to say that in the IRS creation process, increased awareness of energy efficiency had low importance. Respondents placed a high rating on this cobenefit in the future, which is probably related to the government's expectations for retrofitting through the insulation market development.

Finally, an increase in residential safety was ranked low in the IRS creation and moderately in the future. Presumably, due to the use of open flame heaters in houses, this co-benefit could be incorporated as part of the government's avoided health costs, especially for a future policy for heater replacements in low-income households.

As noticed, it is clear that the interviewees recognised the importance of some cobenefits as a side effect of the policy; however, there is lack of accountability for them within the policy framework. In addition, because of time and financial constraints, and lack of data, it has been difficult to incorporate them into the economic evaluation of the policy.

"To analyze the direct benefits of public policies is difficult; the analysis of cobenefits is even more difficult. Some co-benefits such as climate change and 
local air pollution are the responsibility of certain public organisations. In the case of climate change there is international concern and funds to target global problems. However, other co-benefits are not the responsibility of any organisation” (Cifuentes, personal communication, November 22, 2010) . $^{72}$.

\footnotetext{
${ }^{72}$ Luis Cifuentes is an academic, expert in impacts of pollution reduction plans.
} 
Table 7.3. Average rating on 1 to 5 scale about perceptions of the relative importance of benefits and co-benefits in the IRS creation and support or future expansion ${ }^{73}$.

\begin{tabular}{|c|c|c|c|c|}
\hline \multirow[b]{2}{*}{ Effects } & \multirow[b]{2}{*}{ Benefit/ co-benefit } & \multicolumn{2}{|c|}{ Rating } & \multirow[b]{2}{*}{ Delta§ } \\
\hline & & Creation* & $\begin{array}{l}\text { Future support or } \\
\text { expansion** }\end{array}$ & \\
\hline \multirow{6}{*}{ 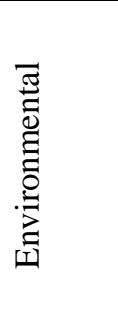 } & Reduction in local outdoor air pollution & 5.0 & 4.9 & -0.1 \\
\hline & Reduction in indoor air pollution*** & 4.5 & 4.7 & 0.2 \\
\hline & Reduction in energy use & 4.5 & 4.6 & 0.1 \\
\hline & Reduction in carbon emissions & 3.6 & 4.1 & 0.6 \\
\hline & Reduction in deforestation & 3.7 & 4.1 & 0.4 \\
\hline & $\begin{array}{l}\begin{array}{l}\text { Reduction in fossil fuel energy } \\
\text { generation }\end{array} \\
\end{array}$ & 3.5 & 3.8 & 0.3 \\
\hline \multirow{2}{*}{ 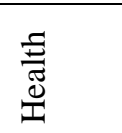 } & Reduction in morbidity & 4.3 & 4.7 & 0.5 \\
\hline & Reduction in mortality & 3.3 & 3.8 & 0.5 \\
\hline \multirow{5}{*}{ 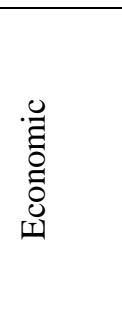 } & $\begin{array}{l}\text { Reduction in costs associated with } \\
\text { human health }\end{array}$ & 3.9 & 4.4 & 0.5 \\
\hline & $\begin{array}{l}\text { Increase in ability to rent or sell } \\
\text { energy-efficient residences }\end{array}$ & 2.8 & 3.8 & 1.0 \\
\hline & Increase in employment opportunities & 3.6 & 3.6 & 0.0 \\
\hline & Increase in energy security & 2.8 & 3.6 & 0.7 \\
\hline & Increase in new business opportunities & 3.2 & 3.5 & 0.4 \\
\hline \multirow{5}{*}{ 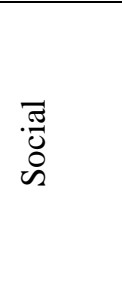 } & Increase in residential comfort & 4.5 & 4.7 & 0.2 \\
\hline & Improvement in social welfare & 4.5 & 4.7 & 0.2 \\
\hline & Reduction in fuel poverty & 4.4 & 4.5 & 0.1 \\
\hline & Increase in awareness & 3.7 & 4.4 & 0.7 \\
\hline & $\begin{array}{l}\text { Increase in residential safety (fewer } \\
\text { fires) }\end{array}$ & 2.6 & 3.1 & 0.5 \\
\hline
\end{tabular}

$* \mathrm{~N}^{\circ}$ of respondents: 6 .

$* * \mathrm{~N}^{\circ}$ of respondents: 14 .

$* * * \mathrm{~N}^{\circ}$ of respondents: 3 .

§ Difference, indicating direction of change.

\footnotetext{
${ }^{73}$ Very important $=5 ;$ Important $=4 ;$ Moderate $=3 ;$ Low $=2 ;$ Very low $=1$
} 
Photo 7.3. Roof retrofitting work in Temuco.

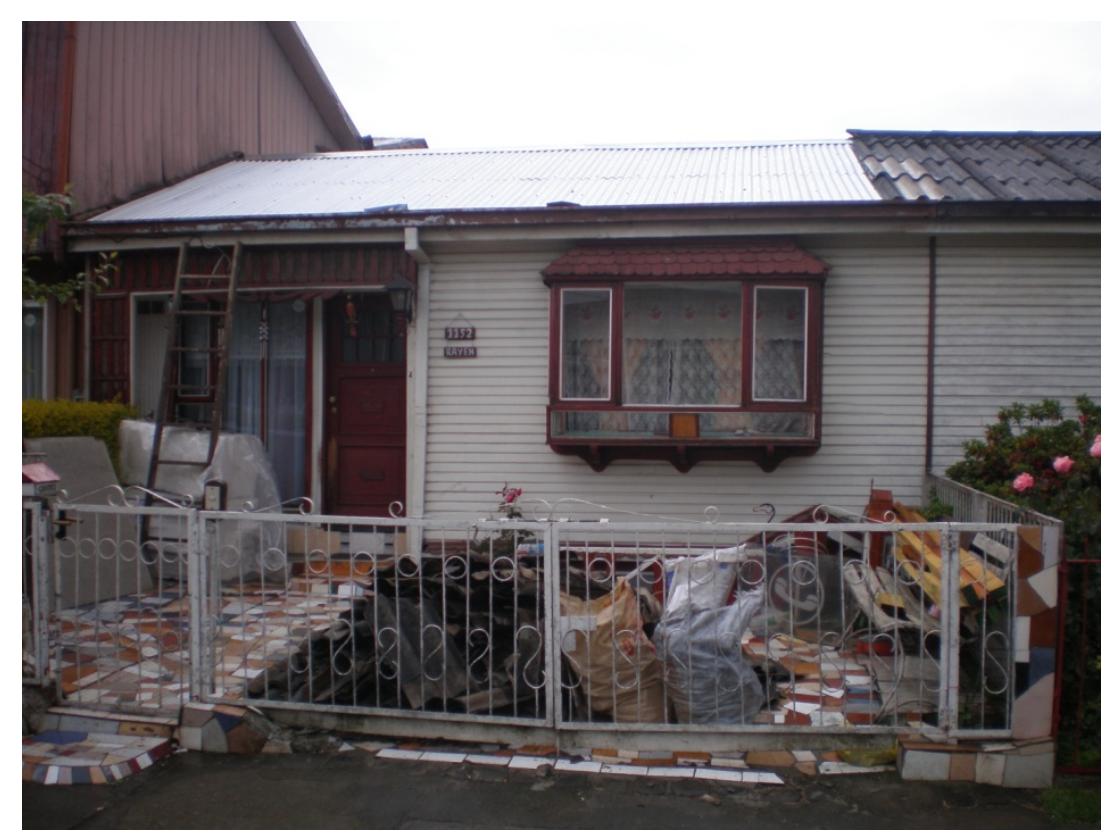

Note: This house is being retrofitted with IRS. It has a new roof and the old roof is lying in the front yard.

Author: Alejandra Pérez. 


\section{Chapter 8: Discussion}

\subsection{Discussion of the New Zealand findings}

The New Zealand retrofit policy has been evolving for approximately 25 years. The free loan programme for insulating houses (1975) led to the first thermal standards in 1978. As noted in Chapter 6, the creation of these policies was a response to the global oil crises, the increase of residential electricity demand by $7 \%$ annually, and various electricity shortages in the drought periods during the late 1960s and early 1970s. At that time, the existence of cross-subsidies kept residential electricity prices low, which encouraged households to use electricity for space heating. In addition, the regulated State-owned electricity companies were expanding with associated fiscal costs; these are likely to have increased government interest in electricity conservation.

In the 1970s, scholars and authorities already acknowledged that insulation measures would probably not result in a substantial reduction of residential electricity use due to the rebound effect (Trethowen \& Hubbard, 1972); however, as energy conservation was an urgent matter, any attempt to reduce electricity use was a sufficient argument for developing the thermal standards of 1978. The focus of the policy was new dwellings in order to target the housing stock growth (New Zealand Parliament, 1977a) which was growing at 3\% annually (around twice the growth rate of 2010) with a consequent increase of electricity use (Trethowen \& Hubbard, 1972, p. 10). Despite the importance of the standards, existing dwellings were not directly targeted until almost two decades later. This delay shows that despite the urgency for energy conservation, retrofit policies were more difficult to implement than policies for new dwellings. One explanation for this is that in the 1970s there was not sufficient evidence about the real impacts of insulation policies. In fact, as noted in Chapter 6, officials were aware that insulation measures would probably not result in significant electricity use reduction. In addition, an insulation interest free loan programme was implemented by the government in 1975, but this was not successful (New Zealand Parliament, 1977). Its lack of success suggests that insulation costs were not easily absorbed by customers; therefore, the government would have to stimulate retrofits with another policy, such as a subsidy. Clearly, the government opted for the thermal standards for 
dwellings instead of implementing a grant for existing ones. Another issue could have been the absence of appropriate insulation service providers; however, there is no evidence of that. At that time, energy conservation was not a sufficient argument for an insulation retrofit policy, but it was salient for the creation of the new dwelling thermal standards as shown in the economic evaluation of the policy.

From 1987 to the mid 1990s, the electricity sector was dramatically reformed and deregulated. This resulted in a different approach to insulation programmes. In the early 1990s, government authorities and the private sector were trying to organise a wholesale electricity market and they realised that, because of the previous model of electricity regulation, unnecessary power capacity had been developed (Elliston, 1993). Nevertheless, it was expected that demand for electricity would grow, and the recent experience of drought suggested that it was important to make the electricity supply less vulnerable to dry seasons (Wholesale Electricity Market Development Group, 1994). In this context, energy efficiency had a role to play by reducing the need for new electricity capacity, decreasing peak loads, and reducing demand growth over time. It is possible that electricity transmission and distribution were also matters of discussion; however, no evidence about this was found.

Although energy efficiency was seen as an important aspect of the wholesale market, the vehicle to incorporate it into the market was a matter of disagreement. While some, including the Minister of Energy John Luxton, thought that the market itself would encourage the adoption of energy efficiency by customers, other government officials were doubtful that energy efficiency would emerge solely from the market. Although interventions in the deregulated electricity market were considered ideologically inappropriate at the time, a partial grant fund, the Energy Saver Fund (ESF), was implemented in 1995/96. From a market based perspective, the ESF was justified on the basis of its cost-effectiveness. That is, the benefits from energy savings were assumed to cover the retrofit subsidy costs.

Also, the ESF focused on low-income people. The rationale for that can be also found in electricity sector deregulation. The removal of the cross-subsidies because of the deregulation had resulted in an increase of residential electricity prices (Irwin, 1997). This particularly affected the most vulnerable social groups. Although a partial grant for insulation retrofits would not have resulted in significant electricity demand reductions (because of the rebound effect), the government appeared to regard the ESF 
as a compensation for an increase in electricity prices. In this way, the government was reducing the up-front cost barrier to retrofits, and increasing the ability of low-income people to make rational choices.

Although the deregulation of the electricity sector was a major driver for the creation of the ESF, in the 1990s different local groups and the academic world influenced the policy process, strongly motivated by the social co-benefits of energy efficiency and the environmental co-benefit of air pollution reduction. These entities provided a series of research reports mainly focused on indoor temperatures, well-being, health, and fuel poverty. In addition, the existence of organisations that were installing retrofits in low-income households and were training low-income unemployed as skilled personnel led authorities to expand the common notion of service provider from insulation enterprises to local trusts, low-income community groups and other social organisations, addressing indirectly the co-benefits already mentioned. It also enabled government officials to design the programme based on practical previous experiences, piloting what in the future became the expanded ESF.

Later, the central government implemented a training programme focused on unemployed low-income people. This shows that local actions combined with the academic research have been crucial in making the central government more aware of the potential positive impacts of a retrofit policy and they have provided guidance to implement it.

The results of the ESF were limited (5,500 dwellings in five years) and the budget decreased from \$NZ 18 to 12.4 million (Table 6.2). As mentioned in Chapter 6, this low penetration was probably a consequence of the barriers to energy efficiency. Of the barriers reported by scholars (Golove \& Eto, 1996; Jochem, 2000; Martinot \& McDoom, 2000), the major ones were the slow adoption of insulation by customers, lack of co-funding, and lack of skilled personnel, which resulted in quality problems. From the demand side perspective, the psychological barriers to energy efficiency (Jackson, 2005; Wilson \& Dowlatabadi, 2007) could also have resulted in a limited adoption of retrofits by customers and consequently, a limited development of the market. The growth of the insulation industry and the slow development of appropriate insulation materials could have also affected policy results; however, further analysis of this issue was beyond the scope of this research. 
Another barrier that could have affected the ESF is the ideological tension between market deregulation and interventions, and hence a lack of political will to develop the Fund. Additionally, the real results of retrofit policies were unknown, which probably made the implementation of a larger programme difficult. Finally, the ESF was the first retrofit policy experience of EECA, which at that time may not have had sufficient management capacity and financial resources to run the programme.

It is also likely that in the 1990s there was a lack of strong government support for a larger programme. As noted earlier, the National-led government, in power from 1990 to 1999 , maintained a strongly market oriented policy approach. Within the policy formulation process, there was a lack of comprehensive cost-benefit analysis and cobenefits were not taken into account at a central government level. Thus, although some social and environmental co-benefits (including fuel poverty, health, well being, local air-pollution and unemployment) were acknowledged by officials, academics and local groups, their weight as arguments in retrofit policy creation and expansion was very limited.

In 1999, the Labour Party leader Helen Clark became the Prime Minister. Under her administration, the Energy Efficiency and Conservation Act 2000 was passed. The Act enabled the Energy Efficiency and Conservation Authority (EECA) to expand its framework for action and it also provided a legal framework for the development of energy efficiency policies in general. EECA developed the National Energy Efficiency and Conservation Strategy 2001 which aimed, in general terms, to foster the conservation and efficient use of energy, develop renewable sources of energy, and to contribute to meeting New Zealand's Kyoto Protocol commitments. Within this context, a new phase of the ESF was developed (2000-2005). This time the partial grant targeted low-income households directly, mainly on the basis of health issues; this shows a broader understanding of the social co-benefits associated with energy efficiency by the government.

The approach to the retrofit policy changed from a measure within the wholesale electricity market arrangements to a measure within the National Energy Efficiency and Conservation Strategy 2001. This time the retrofit policy was part of a broader policy umbrella that sought energy efficiency directly. Like the ESF 1995/96-1999/00, the new programme was probably not conceived mainly as an electricity use reduction policy because there was awareness of the rebound effect among low-income households 
(Greening, Greene, \& Difiglio, 2000; Howden-Chapman et al., 2009; Milne \& Boardman, 2000; Oikonomou, Becchis, Steg, \& Russolillo, 2009). Despite the existence of a legal and organisational framework, the budget and the number of households retrofitted from 2000 to 2005 were very limited (approximately 10,700 households in the period and an average budget of approximately NZ\$ 1.5 million per year) (Table 6.2). One of the major problems was that community-based service providers were having difficulties finding co-funding (Local Government and Environment Committee, 2003). Although in 2002 the academic world had already provided the government with in-depth information about the impact of insulation on health and the government was aware of health co-benefits, this argument alone was not enough to develop a larger programme.

It was not until the last term of the Labour-led government (2005-2008) that the programme expanded significantly. The government was developing the New Zealand Energy Efficiency and Conservation Strategy 2007, and the retrofit policy was regarded as a part of the Strategy. The ENERGYWISE Home Grants scheme was re-launched with a larger budget and subsequently the number of houses retrofitted increased significantly (around 43,000 households in the period from 2005/06 to 2008/09 with an average budget of approximately NZ\$ 6.9 million per year) (Table 6.2). The Strategy recognised that the cost-benefit analysis of insulation demonstrated that the economic value of health benefits is likely to be larger than those accruing from energy savings and that overall the benefits were worth almost double the costs of investment (Chapman, Howden-Chapman, Viggers, D. O’Dea, \& Kennedy, 2009). These research results were available in preliminary form from 2004 (Chapman, Howden-Chapman, \& Des O’Dea, 2004).

Like the ESF, the development, support and expansion of the ENERGYWISE Home Grants scheme, from 2000 to 2005, was triggered by the enactment of the Energy Efficiency and Conservation Act 2000. At this time, a case based on health or other cobenefits (e.g. air pollution, fuel poverty, unemployment) would probably not have been sufficient to produce a significant expansion of the policy beyond that prevailing from 2000 to 2005. However, from 2005 to 2008, the government seemed to strongly acknowledge the importance of the health co-benefit, when research had demonstrated the economic and social impacts of insulation on heath (Chapman et al., 2009; HowdenChapman et al., 2009). The development of the New Zealand Energy Efficiency and 
Conservation Strategy 2007 was a suitable vehicle for stimulating the retrofit policy focused on low-income people, despite the evidence suggesting that the policy would not result in significant energy savings. In the last term of the Labour government, the health issue was strong enough to expand the retrofit policy; however, this requires a major issue: the new Strategy 2007.

In 2008, the lens used by politicians to approach the retrofit policy changed again. This time, climate change played an important role. In 2008, the Labour-led Government needed Green Party support to pass the very controversial Emissions Trading Scheme (ETS). Labour was conscious of the political case for offsetting the cost impact of the ETS on low-income households by recycling ETS revenue. Research on co-benefits (health and fuel poverty) supported the Green Party’s NZ\$ 4.6 billion proposal for retrofits focused on low-income households. As a result of the negotiations between the government and the Green Party, the Household Fund programme was approved with a budget of NZ\$ 1 billion. Even though the Green Party politicians were strongly committed to a larger retrofit scheme, their will would not have been enough to expand the retrofit programme without the Cabinet being determined to pass the ETS. Without this political push, the ENERGYWISE Home Grants scheme would probably have remained largely unchanged, but with a new orientation towards the middle class. This argument is supported by the fact that in 2008, the ENERGYWISE Interest Subsidies scheme for insulation and heating was implemented by EECA as a pilot programme.

When the National government won the general election in late 2008, the political lens through which the retrofit programme was regarded changed again. The new government found the existing ETS harsh and the Household Fund programme was eliminated as well as the stream of financial resources for retrofit programmes from the ETS. In 2008, the New Zealand economy, in recession since the March quarter, was also hit by the global financial crisis. In this scenario, it became a matter of major political urgency to create jobs. This co-benefit had not been emphasized in the previous retrofit programmes. The Warm Up New Zealand (WUNZ) programme was launched in the May 2009 budget, as a programme to generate health benefits for low-income households, and energy savings from middle-income groups (who in theory should 
present a lesser rebound effect than low-income people), and general stimulatory economic benefits in terms of employment.

The number of households funded by the programme increased sharply in comparison with the previous schemes. Further research is necessary to understand what are the key factors that have produced the increasing adoption of retrofits by customers. The answer is likely to be found in the reduction of barriers such as the size of the copayment needed, the split incentives obstacle, psychological barriers, and the barrier of limited government management capacity. The financial barrier to low-income and middle class groups has been reduced by a differentiated partial grant, the psychological barriers have been addressed by a strong marketing campaign, and the split incentives barrier has been targeted through a $60 \%$ grant for landlords renting to low-income tenants. In addition, the government has worked with the supply side of the market to design the policy and implement it.

This analysis suggests the following propositions:

1) Retrofit policies face an array of barriers that make their development, implementation, support and expansion difficult. The capital cost barrier is salient.

2) The creation, support and expansion of retrofit policies depends on major contextual factors which, taken together, can trigger a sense of political urgency. Therefore, policy adoption is very sensitive to context and, hence, to political will.

3) Co-benefits are highlighted primarily by local groups when addressing local problems and by the academic world. Then, if an appropriate set of contextual factors appears, co-benefits are regarded as contributing materially to the rationale for a national policy.

4) The multiple co-benefits of retrofit policies make them more resilient to changes in the political context over time.

\subsection{Implications of the propositions in New Zealand: Retrofit policy support and expansion in the future}

The historical evolution of the residential energy efficiency retrofit policies in New Zealand shows that some form of government grant has been necessary to promote 
a significant adoption of retrofits by households. This affirms the existence of multiple barriers to residential energy efficiency acknowledged by the scholars mentioned before. Successive governments have targeted these barriers, introducing a partial grant and other complementary measures. Currently, the WUNZ scheme is well established and being successfully implemented; however, it still has a level of dependency on a grant. Therefore, if in the future the grant is reduced or even eliminated, it is likely that the adoption of retrofits by customers would drop and the market would contract, potentially producing unemployment, although the extent of this would depend on labour market conditions at the time. Thus, the creation of new jobs, as an argument for policy support in the future, is not a resilient argument, particularly if the government is unable to commit a significant forward budget to the programme. A reconsideration of the funding could be produced by a change of political urgencies due to a natural disaster or an unexpected level of fiscal pressure. Additionally, in the future, the desire to support employment could be less salient than at present, resulting in a reduction in the weight given to employment as an argument for the retrofit subsidy.

As mentioned in Chapter 5, in New Zealand the GDP economy is projected to expand in the short term, increasing energy consumption in all sectors of the economy. In fact, in New Zealand, wholesale electricity prices are forecast to rise around 30\% by 2030 with new generation investments, and residential electricity demand is estimated to increase at about $1.3 \%$ per year, while household numbers are forecast to grow at 1.4\% annually (MED, 2010). In this context, fuel affordability and energy savings as a co-benefit of residential retrofit policy could be a significant argument for maintaining and extending the retrofit policy programme. There is also encouragement from the IEA for New Zealand to maintain energy efficiency efforts (IEA, 2010b).

In terms of fuel affordability, there is likely to be future debate over the definition of fuel poverty in New Zealand. The current situation of fuel poverty in New Zealand (implicit in the NZ\$ 4.6 billion Green Party proposal) and the trend towards a greater number of people in fuel poverty (Lloyd, 2006) imply that fuel poverty may become a more prominent issue. In a high fuel price scenario, a household defined as (lower) middle-class (without a Community Services Card) could be facing fuel poverty and a case could be made that the subsidy available for an energy efficiency retrofit should increase. This argument is also supported by the fact that, as shown in Chapter 5, the 
Gini index has been growing over the last few years in New Zealand. This shows that the distribution of the total country's income is concentrating in fewer people, resulting in a relative decrease of the income received by the majority of the population and, consequently, in a drop in their ability to afford energy, especially when space heating prices rise.

Further research is necessary to better understand whether the WUNZ scheme stimulates a broad participation of middle-income groups (by reducing up-front costs) and to what extent the grant is being taken mainly by middle-income groups. This would clarify whether the current scheme is in fact reducing effectively the up-front costs of middle-income groups so they are able to invest in energy efficiency. It is also a matter for further research whether fuel affordability will decrease in future and, if so, its impact on New Zealand living standards and real disposable income inequality.

Another contextual factor that is likely to change the government's approach to the retrofit policy is climate change or mitigation policy impacts. The likely negative impacts of climate change on the economy, including GDP, agriculture, and food supply impacts and health problems, among others, could reduce the budget for retrofit policy in the future as well as contributing to increased inequalities and reduced fuel affordability. A change in climate could intensify drought periods in some areas, potentially reducing water supply for electricity production (NIWA, 2008). This situation could worsen if combined with higher gas and oil prices and/or rising costs of new renewable power generation, and rising climate-sensitive costs of transmission and distribution. Although the government is promoting the use of wood burners, particularly in low-income households, electric heaters, such as heat pumps, are also being installed under the WUNZ scheme. Even though these electric heaters may be efficient, it is not clear to what extent the current installations contribute to reducing energy use in households and energy intensity in the country. For example, in the warmer parts of New Zealand, use of heat pumps for air conditioning in summer appears to be increasing (French, 2008). Further research is necessary to clarify this issue, especially research within the framework of energy security. Increased installation of electric heaters such as heat pumps is likely to contribute to an underlying trend of increasing electricity demand as income gradually rises. To meet the increasing residential electricity demand, new generation capacity would be necessary with 
investment costs reflected in customers' electricity prices. As mentioned before, in a scenario of projected growing electricity prices, the co-benefit of greater energy security, if confirmed in future research, could be a crucial argument to support and expand retrofit policies, especially for policies that pursue a combination of energysaving heater replacement and insulation retrofitting in the same household. If it is established that heat pumps are tending to lift electricity demand, then there is a case for government to differentially support the installation of efficient wood burners, at least in areas with a lower tendency to become air polluted and on condition that the burners meet high emission standards. Finally, the ETS and potentially other climate change mitigation policies will increase most fuel prices (Ministry of the Environment, n.d.), impacting households’ budgets negatively. Thus, mitigating problems of fuel affordability and fuel-poverty are important co-benefits to lessen the social impacts of climate change policy.

Scholars argue that co-benefits of residential energy efficiency have often been ignored in the policy making process which has resulted in an underestimation of the net benefits of the policy (Jakob, 2006; Jochem \& Madlener, 2003; Ürge-Vorsatz, Novikova, Köppel, \& Boza-Kiss, 2009). The present study shows that in New Zealand, this underestimation occurred in the first stages of the retrofit policy process. However, even a clear later focus on co-benefits has not provided a sufficient argument in itself for the creation and expansion of retrofit policy; nevertheless co-benefits, particularly health co-benefits have provided the government with arguments to expand the retrofit policy when a significant contextual factor has appeared. As already discussed, in the future, the two major contextual issues likely to trigger a sense of political urgency are: an increase in residential fuel prices and climate change impacts. In this scenario, the co-benefits of fuel affordability, fuel poverty and energy security may assist the government to address these issues.

Further research is necessary to analyse how retrofit policies have been created, implemented, supported and expanded in other developed countries, although Lah (2009) has provided insight into New Zealand and Germany’s insulation policy path showing how different political structures have shaped this policy. 


\subsection{Discussion of Chilean findings}

In the mid-2000s, Chile was facing energy security problems. The reductions of gas imports from Argentina combined with drought periods produced an electricity supply deficit. To address this energy security problem the government, the academic world and the private sector worked together to create the National Energy Efficiency Programme (PPEE), under the Ministry of Economy’s leadership, in 2005. At the same time, the government was trying to develop energy efficiency policies, following the OECD's recommendations on this issue, to enable Chile to join this organisation. Additionally, the high price of copper in 2008 and a fiscal budget surplus resulted in available monetary resources to foster the PPEE. In the framework of the PPEE, residential energy efficiency was addressed by the expansion of an existing insulation retrofit subsidy (IRS). President Bachelet's administration committed funds for retrofitting 20,000 low-income households. The PPEE transferred NZ\$120 million (approximately one third of the Warm Up New Zealand programme’s financial resources) to the Ministry of Housing and Urbanism (MINVU) to implement 20,000 IRS in a period of two years (2009/10). This level of funding is significantly higher than the previous programme’s budget that only targeted air pollution problems in the comunas of Temuco and Padre las Casas (NZ\$ 3 million). This process shows that energy security was a major contextual factor, adding to the Bachelet social commitments, which triggered a political urgency for the creation or expansion of general energy efficiency policies, specially the IRS.

The local air pollution problem in Temuco and Padre las Casas led MINVU's authorities to incorporate this issue into its ministerial legislation in 2007, one year before the IRS expansion triggered by the energy security issue. The argument of air pollution would probably have not been enough to support or expand the IRS because energy efficiency is not a MINVU goal (Chapter 4). As in New Zealand, the local retrofitting experience in the comunas of Temuco and Padre las Casas provided the central authority with guidelines for a broader IRS implementation.

As shown in Chapter 7, the IRS faces multiple barriers. These barriers are similar to those found in the New Zealand retrofit policy process. These can be summarised as lack of strong political will, slow development of the market, poor quality of installation, and relatively high capital costs. In addition, the rigid Chilean policy 
structure, in which the IRS is embedded, has produced additional barriers to the IRS process. These barriers will be discussed later.

This analysis suggests that the first, second and third propositions stated for New Zealand are also applicable in Chile. Retrofit policy in Chile has not been in place long enough to analyse whether the fourth proposition also applies; however, on the basis that the final proposition is likely to be true in the Chilean case, the following policy analysis is offered.

\subsection{Implications of the propositions in Chile: Retrofit policy support and expansion in the future}

As mentioned in Chapter 4, energy demand is forecasted to increase in all Chilean economic sectors in the short term. Two important factors for that increase are an increase of population to around 20.2 million by 2020 and an expansion of the economy in the short term (IMF, 2010). In the commercial, public and residential sectors, it has been estimated that electricity use will rise at a rate of $6.5 \%$ annually until 2020, gas at a rate of 3.3\% and wood at a rate of 2.3\% (O`Ryan, 2008). More hydroelectricity generation is planned, although it is highly controversial. Moreover, the projected effects of climate change on water supply due to droughts (Comisión Nacional de Energía, 2008) could strongly affect energy security. In this context, residential space heating may play a role in terms of energy security, especially if a transition from fossil fuels and wood to electricity occurs. In this scenario, a retrofit policy could be supported and expanded on the basis the energy security co-benefit. However if residential space heating continues to be dominated by wood, oil-derivate fuels (kerosene and LPG) and natural gas, the energy security argument will be less salient. The fact that electricity is not yet widely used as residential space heating fuel, makes the energy security cobenefit relatively weak for justifying a retrofit policy cost-beneficially, particularly a significant grant. The energy security issue was partially addressed in the economic evaluation study for retrofitting 720,000 dwellings in Chile with insulation (Ambiente Consultores \& PRIEN, 2007). This policy could result in reductions of natural gas and LPG imports by $1.5 \%$ and $17 \%$ respectively. Also, the climate change mitigation cobenefit was considered marginal in this study, and the interviews conducted found that climate change was given little weight by stakeholders and policy advisers. However, 
further research is necessary to analyse the significance of a nationwide retrofit policy for energy security and climate change mitigation in future Chilean policy.

Presumably, because of the relatively low impact of residential space heating in energy security, despite it being the factor that triggered the expansion of the IRS, the current government has preferred to leave the retrofit issue to the market, mainly addressing it through housing energy certification. Also, a permanent budget for the IRS has not been guaranteed beyond 2011. As mentioned in Chapter 7, it seems unlikely that this approach will result in a significant adoption of insulation retrofits by customers. The multiple barriers to energy efficiency discussed in the New Zealand case, in particular the capital cost barrier, need to be addressed by the Chilean government in order to facilitate retrofit market development. A partial grant, along with other complementary measures to reduce those barriers (such as monetary advances, marketing campaigns, government management capacity improvement and installation quality enhancement), has been necessary to promote retrofit installations by households in New Zealand, and is likely to be equally necessary in Chile.

The IRS is a policy developed under the assumption that low-income households are able to pay only a small fraction (NZ\$ 180) of the insulation capital costs. In 2009, the Chilean poverty line was defined as a monthly per capita income of less than NZ\$ 176 (NZ\$2,100 annually) (MIDEPLAN, 2010) whereas in New Zealand the poverty threshold in 2010 was defined as NZ\$ 18,400 annually per equivalent adult (Perry, 2010). Also, energy prices in Chile are presumably more expensive than in New Zealand (not taking into account illegal or self collected wood) (Tables 4.1 and 5.1), reducing relative fuel affordability for Chilean low-income households in comparison to poor households in New Zealand. From this point of view, the Chilean IRS, that pays almost the totality of the insulation costs, is coherent; however, in general terms, the Chilean IRS seems to be less cost-effective than the New Zealand WUNZ. The Chilean IRS is concentrated in fewer households than in New Zealand. In New Zealand \$NZ 347 million is being allocated to retrofit around 188,500 homes whereas in Chile NZ\$ 120 million has been allocated in 20,000 low-income households. Also, the insulation costs are more expensive in Chile than in New Zealand (NZ\$ 5,600 and NZ\$ 1,800 per household respectively). Part of the explanation for these differences can be found in the fact that, in New Zealand, walls are not included within the retrofit installations whereas 
they are in Chile. Further research of the cost-effectiveness of insulating the whole dwelling envelope in Chile could provide insight into the targeting and implementation of the retrofit policy. As an alternative policy, a partial grant, could target the middle class, achieving a level of space heating energy efficiency nationwide, especially in the likely event that the market does not significantly internalise insulation retrofits through housing energy certification. In addition, further research is necessary to analyse the possibility of funding from the private sector, NGOs, local community groups and other entities as well as their participation and engagement in the policy process in the future.

As discussed, currently the IRS or any other type of retrofit grant lacks political support in Chile. As in New Zealand, support could be found in the co-benefits of health.

This research found that Chilean authorities are not generally aware of the potential positive impacts of retrofits on government health expenditure. As analysed in Chapter 7, research on this issue could reveal a high benefit-cost ratio for retrofit policies, potentially higher than in New Zealand (2:1) (Chapman et al., 2009) due to the very low Chilean indoor temperatures (national average of $13.8^{\circ} \mathrm{C}$ ) (IC \& GTZ, 2007) and the currently widespread use of very polluting and inefficient heaters (Appendix 1). As shown in Chapter 7, the Chilean economic evaluation of a measure for insulation in 720,000 houses estimated that health benefits are less significant than energy savings (Table 7.1), but this analysis only considered the effects of the local air pollutant $\mathrm{PM}_{10}$ on human health. This emphasis confirms the economic underestimation of the cobenefits of retrofit policy reported by scholars and the policy's dominant rationale of energy savings (Jakob, 2006; Jochem \& Madlener, 2003; Ürge-Vorsatz et al., 2009) in Chile. The same situation is found in the estimated benefit-cost ratio of the Temuco and Padre las Casas air pollution reduction plan (ratio of 1.2:1) (CENMA, 2007) which, as in the previous study, was based solely on the effects of $\mathrm{PM}_{10}$ on health. Moreover, the IRS was originally focused in those regions with comunas affected by local air pollution due to heavy residential wood use for space heating. This logic excludes other regions of Chile, such as Santiago, where around 6.8 million people or $41 \%$ of the Chilean population live (MIDEPLAN, 2010). These other regions probably have a high level of indoor pollution due to the use of open flame oil derivate heaters such as kerosene and liquefied gas as well as other fuels such as coal and natural gas (Appendix 1). Research on these matters could provide strength and resilience to the current Chilean insulation 
policy and politically provide a rationale for expanding it to all regions of Chile. In principle, an extended policy could also incorporate heater replacement. With regard to this point, the Ministry of the Environment, as noted in Chapter 4, is approaching retrofit policies more expeditiously than MINVU and the Ministry of Energy, with the development of a heater replacement policy that targets all income groups in Temuco and Padre las Casas as well as in other $\mathrm{PM}_{10}$ polluted areas. However, its approach to the retrofit policy is still limited solely to its effectiveness in reducing $\mathrm{PM}_{10}$ as part of local air pollution plans. Nevertheless, the legal framework of the air pollution plan seems to be more flexible than the legal framework of the PPPF (managed by MINVU) in which the IRS is framed. The current IRS for low-income households seems to be embedded in a rigid legal framework that adds extra barriers to the insulation retrofit policy, as shown in Chapter 7. Furthermore, the organisational framework in which the IRS operates is itself a barrier since MINVU does not have mandatory responsibilities for energy efficiency goals and, in some regions, the local authority management capacity to implement the IRS has not been sufficient. Further research is necessary to evaluate how to reduce these barriers. Finally, government expenditure on health problems related to fires and accidents due to the use of open flame heaters may also increase the benefit accruing from a retrofit policy in the future.

As in New Zealand, Chile may in future have to define criteria to evaluate fuel poverty, and adequate policies to address it, particularly in an increasing fuel price scenario. It is likely that a large percentage of the population is currently facing fuel poverty around the country. As in New Zealand, a decrease in energy affordability will probably increase the standard of living gap between low-income households and wealthier ones, raising effective inequality levels. Also, in the future, fuel poverty could be accentuated by the physical impacts of climate change. Analysis of the future possible decrease in fuel affordability and real disposable income inequality, including the direct and indirect effects of climate change merit further research.

In the future, the job creation argument may also assist in supporting and expanding Chilean retrofit policies. The current IRS has not been regarded as a job creation policy; therefore, this co-benefit is largely unseen. In the economic evaluation of the insulation policy for retrofitting 720,000 households in Chile (Ambiente Consultores \& PRIEN, 2007) it was estimated that 3,000 to 4,600 direct jobs could be created as a result of the policy implementation. Nevertheless, as previously discussed, 
it is unlikely, without a reduction of the capital cost barrier, that customers would adopt retrofits, stimulating the market and increasing the number of jobs. Moreover, during this research no evidence was found of the real and projected capacity of service providers. Although the government has run some workshops with personnel and representatives of building companies that included insulation installation within their operations in order to obtain revenues from the IRS, a major step will be necessary to considerably expand the insulation retrofit market (and providers for other retrofit installations). The government may consider an active incorporation of qualified service providers as a key element of the housing certification policy, instead of mainly focusing on households. The existence of qualified service providers who are seeking customers may stimulate households to buy retrofits, especially if a reduction of the retrofit capital costs is attained. To expand retrofit installation adoption by customers, an emphasis on the co-benefit of thermal comfort may assist to reduce the psychological and behavioural barriers to energy efficiency already discussed in the New Zealand retrofit policy process (Skumatz, Dickerson, \& Coates, 2000; Wilson \& Dowlatabadi, 2007). Also, an emphasis on thermal comfort on the part of MINVU could align energy efficiency policy with MINVU's goals with regard to low-income households (Chapter 4), making the IRS more resilient over time within this organisation.

Finally, in Chile, while the multiple benefits of retrofits have been acknowledged by authorities and the academic world, they have not been properly articulated in the policy process. A greater awareness of and accountability for them could enhance retrofit policy resilience over time as well as policy results.

\subsection{Limitations of the research}

Since interviews in this research were mainly focused on government officials, local government officers and academic experts, the study does not include politicians' opinions. These opinions would have provided an in-depth view about political will and its changes with regard to co-benefits over time. Interviewing politicians was considered; however, the idea was rejected due to time and budget constraints, and practicality. An initial exploration in New Zealand found reluctance on the part of politicians involved in retrofit policy to be interviewed, and a referral by them to 
officials involved. In Chile, politicians could not be contacted. In addition, as in both countries there is a tension between the current and former governments, politicians could have been quite sensitive to some questions and it was felt to be desirable to avoid a political interpretation of events. Moreover, government officials and officers, and academic experts were more familiar with the programmes details than politicians.

Another limitation in the New Zealand research was that the interviewees who were involved in the creation and implementation of the Energy Saver Fund and the ENERGYWISE Home Grants programmes had forgotten some details. Also, they were too busy to look for some specific information about these programmes.

With regard to the questionnaires in New Zealand, the perceptions about future support and expansion of the policy were found not to be independent of the political and personal views of respondents. The research selected participants who were involved in the retrofit policies' creation and implementation, who mostly presented a non-conservative view. This potential bias was reduced by grounding the analysis of the future support and expansion of the policy in the empirical findings and an analysis of the most likely future contextual factors. With regard to the research data collected, most of the interviewees in Chile were not familiar with co-benefits concepts and analysis as part of the policy making process and, occasionally, they did not clearly understand some concepts. Although further explanation was given in the interview, respondents sometimes showed some degree of misunderstanding. For that reason, the questionnaire about perceptions of co-benefits in the policy implementation was discarded and the remaining questionnaires related to the creation and future support or expansion of the policy were triangulated with interviews.

Initially, the research in New Zealand was intended to incorporate a survey of local retrofit programmes as well as other government retrofit measures. However, the idea was changed because of time and budget constraints, and only the most relevant programmes were studied. A study of local community energy efficiency programmes could be of significant research interest to community groups in other countries.

In Chile, the research focused mainly on the IRS, which is part of a larger policy of insulating 720,000 households nationwide, which has not yet been implemented. A deeper analysis of this larger programme was beyond the scope of the research due to time and budget constraints. The same applies to thermal retrofitting measures such as housing energy certification and heater replacement, which are currently at a very early 
stage and merit future study. The inclusion of these other programmes in future analysis could provide a more comprehensive understanding of energy efficiency retrofitting policy development in the residential sector. 


\section{Chapter 9: Conclusion}

This research has analysed the policy process of residential energy efficiency retrofits in Chile and New Zealand. Despite the importance of co-benefits in this process, this study concludes that it is the critical contextual factors and political urgencies that have determined the development of, the support for and the expansion of the retrofit policy. Co-benefits have been primarily acknowledged by local level entities, developing local retrofit measures as a response to local problems, and by the academic world. At the same time, politicians and government officials have regularly acknowledged the significance of health co-benefits in explaining residential energy efficiency programmes. The development of retrofit policies at a local level has provided the central government with guidance to implement the policy.

This research expands the current knowledge of residential energy efficiency into a political arena. The retrofit policy in both countries studied is very sensitive to political and contextual changes, which could alter its importance in future political decisions. Also, in both countries co-benefits have been salient in supporting and expanding residential energy efficiency retrofit policy, especially the health co-benefit in New Zealand and the air pollution reduction co-benefit in Chile. The co-benefits of health, fuel poverty, fuel affordability, energy security and thermal comfort are likely to provide resilience to the retrofit policy in both Chile and New Zealand, at a political level in the future.

It is very important for residential energy efficiency retrofit policy to have an organisational and legal framework, sufficient funds, an adequate cost-effective delivery vehicle, and strong political will. This research shows that a grant programme is potentially a useful vehicle through which to channel a retrofit policy because it reduces the capital cost barrier; however, the associated government financial disbursement must find a strong rationale. Co-benefits may assist to build this rationale by supporting a range of sustainable development goals -social, environmental, and economic cobenefits, including climate change mitigation.

These research findings may assist in developing retrofit policy in other countries, especially countries of the developing world which are trying to make advances in residential energy efficiency. While the New Zealand and Chilean contexts are 
different, this study has found strong similarities in the way that contextual factors have shaped energy efficiency policies, with similar barriers faced in the policy process. This suggests that the experience in these two countries may also be relevant for other nations.

Further research is necessary to understand how benefits and co-benefits could be better acknowledged by stakeholders and policy analysts, how barriers to uptake of energy efficiency measures could be reduced, and what kind of retrofit policies may be best fitted to different contexts. 


\section{Acronyms}

CONAMA: National Commission of the Environment

COREMA Araucanía: Regional Commission of the Environment Araucanía

EGIS: Social property management entity

ESF: Energy Saver Fund

ETS: Emissions Trading Scheme

GHG: Greenhouse gases

IEA: International Energy Agency

IRS: Insulation retrofit subsidy

kWh: kilo Watt hour

LPG: Liquefied petroleum gas

MINVU: Ministry of Housing and Urbanism

NPV: Net present value

OECD: Organisation for Economic Co-operation and Development

PJ: Petajoules

$\mathrm{PM}_{10}$ : Particulate matter including particles of 10 micrometers or less

PPEE: Energy Efficiency National Programme

PPPF: Family Patrimony Protection Programme

WUNZ: Warm Up New Zealand: Heat Smart programme 


\section{BIBLIOGRAPHY}

APEC [Asia-Pacific Economic Cooperation]. (2009). Peer Review on energy efficiency in New Zealand. Retrieved from www.ieej.or.jp/aperc/PREE/PREE_New_Zealand.pdf

Affordable Housing Energy Efficiency Alliance. (2008). The affordable housing energy efficiency handbook. Retrieved from http://www.h-mg.com/multifamily/aheea/Handbook/default.htm

Aguirre, F. (2008, September 30). Sector eléctrico en Chile: Evolución del negocio y sus precios. Presented at the Conferencia Banco BICE, Antofagasta, Chile. Retrieved from http://www.bice.cl/datos/docs/20081014100638/Mercado_Electrico_Chile.pdf

Ambiente Consultores \& PRIEN. (2007). Programa de inversión pública para fomentar el reacondicionamiento térmico del parque construido de viviendas (No. Licitación pública N 587-368-LE06). Santiago, Chile: MINVU.

Auckland Council. (2011). Aucklanders to benefit from house warming programme. Media releases. Retrieved May 12, 2011, from http://www.aucklandcouncil.govt.nz/EN/News/NewsArticles/Pages/aucklanderst obenefitfromhousewarmingprogramme.aspx

BCN [Biblioteca del Congreso Nacional de Chile]. (n.d.). Ficha de protección social. Retrieved March 11, 2011, from http://www.bcn.cl/guias/ficha_proteccion_social

Bachelet, M. (2008, May 21). Mensaje presidencial del 21 de mayo. Presented at the Cuenta Anual del Presidente de la República de Chile. Retrieved from http://www.bcn.cl/susparlamentarios/mensajes_presidenciales/

Bartelmus, P., Moll, S., Bringezu, S., Nowak, \& Bleischwitz, R. (2004). Translating sustainable development into practice: a "patchwork" of some new concepts and an introduction to material flows analysis. Eco-efficiency, regulation and sustainable business, ESRI studies series on the environment. Cheltenham, England: Northampton, MA: Edward Elgar.

Bemelmans-Videc, M.L. \& Vedung, E. (1998). Conclusions: Policy instruments types, packages, choices, and evaluations. In M.L. Bemelmans-Videc, R. C. Rist, \& E. Vedung (Eds.), Carrots, sticks, and sermons: Policy instruments and their evaluation. New Brunswick, NJ: Transaction. Retrieved from http://books.google.co.nz

Boardman, B. (1991). Fuel poverty: from cold homes to affordable warmth. London, England; New York, NY: Belhaven Press.

Bryman, A. (2008). Social research methods (3rd ed.). Oxford, England; New York, NY: Oxford University Press.

Bulkeley, H., \& Kern, K. (2006). Local government and the governing of climate change in Germany and the United Kingdom. Urban Studies, 43(12), 22372259. 
CChC [Cámara Chilena de la Construcción]. (2003). Reglamentación térmica (No. 10). Fundamenta. Santiago, Chile: Retrieved from http://www.cchc.cl/DATA/Fotos_Link/Fundamenta10.pdf

CENMA [Centro Nacional del Medio Ambiente]. (2007). Análisis general del impacto económico y social del plan de descontaminación atmosférica de Temuco y Padre las Casas. Retrieved from http://www.pdatemucopadrelascasas.cl/5_Documentos/categorias/pda/1.pdf

CNE [Comisión Nacional de Energía]. (n.d.). Operación real por sistema eléctrico nacional. Periodo 1998-2009. Retrieved from http://www.cne.cl/cnewww/opencms/06_Estadisticas/energia/Electricidad.html (2008). Política energética: Nuevos lineamientos. Retrieved from http://www.cne.cl/archivos_bajar/Politica_Energetica_Nuevos_Lineamientos_08 .pdf

COREMA Araucanía. (n.d.). Coordinación del PDA. Retrieved February 10, 2011, from http://www.pdatemucopadrelascasas.cl/

Central Heating New Zealand. (2011). Central heating running costs. Retrieved May 4, 2011, from http://www.centralheating.co.nz/net/running-costs.aspx

Chapman, R., Howden-Chapman, P., \& O’Dea, D. (2004). A cost-benefit evaluation of housing insulation: Results from the New Zealand housing, insulation and health study. Retrieved from http://www.healthyhousing.org.nz/publications/

Chapman, R., Howden-Chapman, P., Viggers, H., O’Dea, D., \& Kennedy, M. (2009). Retrofitting houses with insulation: a cost-benefit analysis of a randomised community trial. Journal of Epidemiology \& Community Health, 63(4), 271277. doi:10.1136/jech.2007.070037

Climate Change Response (Emissions Trading) Amendment Act. Public Act No 85. (2008). Retrieved from http://www.legislation.govt.nz

Community Energy Action. (1994). Te Whare Roimata neighbourhood energy improvement project. Christchurch, New Zealand.

Cárdenas-Lailhacar, C. (2010, November 19). Lanzamiento AChEE. Retrieved from http://www.expoeficienciaenergetica.cl/sistema/noticias.php

DEFRA [Department for Environment Food and Rural Affairs] \& DTI [Department for Trade and Insdustry]. (2001). The United Kingdom fuel poverty strategy. Retrieved from http://webarchive.nationalarchives.gov.uk/+/http://www.berr.gov.uk/files/file16 495.pdf

DICTUC [Dirección de Investigaciones Científicas y Tecnológicas de la Pontificia Universidad Católica de Chile]. (2001). Generación de instrumentos de gestión ambiental para la actualización del plan de descontaminación atmosférica para la región Metropolitana al año 2000: Estimación de beneficios sociales de la reducción de emisiones y concentraciones de contaminantes atmosféricos en la región Metropolitana. Retrieved from http://www.eclac.cl/ilpes/noticias/paginas/3/36023/2008-PPDA-AgiesInforme.pdf 
(2008). Actualización del inventario de emisiones atmostéricas en las Comunas de Temuco y Padre las Casas. Retrieved from http://www.sinia.cl/1292/articles46042_recurso_1.pdf

Davis, D., Krupnick, A., \& McGlynn, G. (2000). Ancillary benefits and costs of greenhouse gas mitigation: An overview. Ancillary benefits and costs of greenhouse gas mitigation: Proceedings of an IPCC Workshop. Paris, France: OECD. Retrieved from http://books.google.co.nz

Decreto N 144. Modificación del Decreto 255 que reglamenta el Programa de Protección al Patrimonio Familiar. (2007). Retrieved from http://www.leychile.cl/Navegar?idNorma=257828\&idVersion=2007-09-27\&r=1

Decreto $\mathrm{N}^{\circ}$ 255. Reglamenta el Programa de Protección al Patrimonio Familiar. (2007).Retrieved from http://www.leychile.cl

Decreto $\mathrm{N}^{\circ} 35$. Declara zona saturada por material particulado respirable $\mathrm{MP}_{10}$, como concentración de 24 horas, a las comunas de Temuco y Padre las Casas. (2005). Retrieved from http://www.leychile.cl

Decreto $N^{\circ}$ 59. Establece norma de calidad primaria para material particulado respirable $\mathrm{PM}_{10}$, en especial los valores que definen situaciones de emergencia.

(1998).Retrieved from http://www.leychile.cl

Decreto $\mathrm{N}^{\circ}$ 6. Modificación del Decreto 255 que reglamenta el Programa de Protección del Patrimonio Familiar. (2009). Retrieved from http://www.leychile.cl/N?i=257828\&f=2009-04-03\&

Decreto $\mathrm{N}^{\circ}$ 94. Reglamento que fija el procedimiento y etapas para establecer planes de prevención y descontaminación. (1995). Retrieved from http://www.leychile.cl

Department of Statistics. (1976). Survey of household electricity consumption 1971-72. Report on the temperature/insulation study. Wellington, New Zealand.

EECA [Energy Efficiency and Conservation Authority]. (1995, August). Introduction. Energy Saver Fund Newsletter, (1), 1-2.

(1998, September). Grants focus on assisting elderly and low-income families. Energy (2001). National energy efficiency and conservation strategy. Retrieved from http://www.eeca.govt.nz/node/2640

(2007). New Zealand energy efficiency and conservation strategy. Wellington, New Zealand: EECA.

(2009). Warm Up New Zealand: Heat Smart: Funding Agreement. Retrieved from www.eeca.govt.nz

(2010). Annual Report 2009-2010. Retrieved from http://www.eeca.govt.nz/node/10993

(2011). Warm Up New Zealand: Heat Smart. Retrieved June 14, 2011, from http://www.eeca.govt.nz/node/3107

Elliston, B. (1993). Provision of new capacity: Looking at our long term supply.

Presented at the Electricity Reform Conference, Wellington, New Zealand: AIC Conferences. 
Environment Canterbury Regional Council. (n.d.). Christchurch: Clean Heat Project. Together we can improve our air. Retrieved May 12, 2011, from http://www.cleanheat.co.nz/christchurch.html

European Commission. (2010). Chile: Country strategy paper 2007-2013. European Union. Retrieved from http://www.eeas.europa.eu/chile/csp/mtr_nip_chile_07_13_en.pdf

Fisher, G., Kjellstrom, T., Kingham, S., Hales, S., \& Shrestha, R. (2007). Health and air pollution in New Zealand. Wellington, New Zealand: Health Research Council of New Zealand; Ministry for the Environment; Ministry of Transport.

French, L. (2008). Active cooling and heat pump use in New Zealand. Survey results (No. 186). Retrieved from http://www.branz.co.nz/cms_show_download.php?id=67ce30a9e121d2516f8e2c 54957ba9209e73966f

Golove, W. H., \& Eto, J. H. (1996). Market barriers to energy efficiency: A critical reappraisal of the rationale for public policies to promote energy efficiency (No. LBL-38059 UC-1322). Retrieved from http://eetd.lbl.gov/ea/emp/reports/38059.pdf

Greening, L. A., Greene, D. L., \& Difiglio, C. (2000). Energy efficiency and consumption — the rebound effect — a survey. Energy Policy, 28(6-7), 389401.

Gurría, Á. (2010, January 11). Speech of the OCDE General Secretary. Presented at the Ceremonia de la Firma del Acuerdo de Adhesión de Chile a la OCDE, Santiago, Chile. Retrieved from http://www.oecd.org/document/43/0,3343,en_2649_34487_44373995_1_1_1_1, 00.html

Howden-Chapman, P., Isaacs, N., Crane, J., \& Chapman, R. (1996). Housing and health: The relationship between research and policy. International Journal of Environmental Health Research, 6(3), 173-185.

Howden-Chapman, P., Viggers, H., Chapman, R., O’Dea, D., Free, S., \& O’Sullivan, K. (2009). Warm homes: Drivers of the demand for heating in the residential sector in New Zealand. Energy Policy, 37(9), 3387-3399.

Howden-Chapman, P., Matheson, A., Crane, J., Viggers, H., Cunningham, M., Blakely, T. \& Cunningham, C. (2007). Effect of insulating existing houses on health inequality: Cluster randomised study in the community. British Medical Journal, 334(7591), 460-464.

Hughes, H. (1993). Energy Efficiency: Is it being encouraged? Presented at the Electricity Reform Conference, Wellington, New Zealand: AIC Conferences.

IC [Instituto de la Construcción] \& GTZ [Deutsche Gesellschaft fuer Technische Zusammenarbeit] (2007). Determinación de línea de base para la evaluación de la inversión en eficiencia energética en el sector residencial correspondiente a invierno 2007. Santiago, Chile: IC/GTZ (2003). Propuesta de 2a etapa de reglamentación sobre acondicionamiento térmico en viviendas. Santiago, Chile: Instituto de la Construcción.

IEA [International Energy Agency]. (2001). Energy policies of IEA countries: New Zealand 2001 review. Paris, France: OECD/IEA. 
(2006a). Energy technology perspectives: Scenarios \& strategies to 2050. Paris, France: OECD/IEA.

(2006b). Energy policies of IEA countries: New Zealand 2006 review. Paris, France: OECD/IEA.

(2008). World energy outlook 2008. Paris, France: OECD/IEA.

(2009). Chile energy policy review 2009. Paris, France: OECD/IEA.

(2010a). Energy technology perspectives: Scenarios \& Strategies to 2050. Paris, France: OECD/IEA.

(2010b). Energy policies of IEA countries: New Zealand 2010 review. Paris, France: OECD/IEA.

IMF [International Monetary Fund]. (2010). World economic outlook. October 2010. Retrieved from http://www.imf.org/external/pubs/ft/weo/2010/01/pdf/text.pdf

INE [Instituto Nacional de Estadísticas]. (2010). Compendio Estadístico Año 2010. Retrieved from http://www.ine.cl/canales/menu/publicaciones/compendio_estadistico/compendi o_estadistico2010.php?lang=esp

INE [Instituto Nacional de Estadísticas] \& CEPAL [Comisión Económica para América Latina y el Caribe]. (n.d.). Chile: Proyecciones y estimaciones de población. Total País 1950 - 2050 (No. CEPAL OI No 208). Santiago, Chile: CEPAL/INE.

Irwin, T. (1997). Price structures, cross-subsidies, and competition in infrastructure. Public policy for the private sector, the World Bank Group, (107).

Isaacs, N., \& Donn, M. (1993). Health and housing--seasonality in New Zealand mortality. Australian Journal of Public Health, 17(1), 68-70.

Isaacs, N. P., Camilleri, M., Burrough, L., Pollard, A., Saville-Smith, K., Fraser, R. \& Rossouw, P. (2010). Energy use in New Zealand households: Final report on the household energy end-use project (HEEP) (No. BRANZ study report 211). Retrieved from http://www.branz.co.nz/HEEP

Isaacs, N. (1993). Thermal efficiency in New Zealand buildings: A historical overview. Wellington, New Zealand: Building Industry Authority.

Jack, D. W., \& Kinney, P. L. (2010). Health co-benefits of climate mitigation in urban areas. Current Opinion in Environmental Sustainability, 2(3), 172-177. doi:10.1016/j.cosust.2010.06.007

Jackson, T. (2005). Motivating sustainable consumption: A review of evidence on consumer behaviour and behavioural change. Retrieved from www.c2p2online.com/documents/MotivatingSC.pdf

Jakob, M. (2006). Marginal costs and co-benefits of energy efficiency investments: The case of the Swiss residential sector. Energy Policy, 34(2), 172-187.

Jochem, E. (2000). Energy end-use efficiency. World Energy Assessment: Energy and the challenge of sustainability. New York, NY: United Nations.

Jochem, E., \& Madlener, R. (2003). The forgotten benefits of climate change mitigation: Innovation, technological leapfrogging, employment, and sustainable development. Presented at the OECD Workshop on the Benefits of Climate 
Policy: Improving Information for Policy Makers.

doi=10.1.1.153.3050\&rep=rep1\&type $=$ pdf

Lah, O. (2009). The climate for change: the conditions for effective climate change policies : a case study on residential home insulation policies in New Zealand and German (Master's thesis). Victoria University of Wellington, Wellington, New Zealand. Retrieved from http://victoria.lconz.ac.nz/vwebv/search?searchArg=thesis+lah\&searchCode $=\mathrm{G}$ KEY\%5E*\&limitTo=none\&searchType=1\&page.search.search.button=Search

Legatum Institute. (2010). The 2010 Legatum prosperity index. Retrieved from http://www.prosperity.com/downloads/2010LegatumProsperityIndexBrochure.p df

Levine, M., Ürge-Vorsatz, D., Block, K., Geng, L., Harvey, D., Lang, S. and Levermore, G. (2007). Residential and commercial buildings. Climate change 2007: Mitigation. Contribution of Working Group III to the fourth assessment report of the Intergovernmental Panel on Climate Change. Cambridge, U.K. and New York, NY, USA: Cambridge University Press.

Ley Sobre Bases Generales del Medio Ambiente. N 19,300. (1994). Retrieved from http://www.leychile.clB

Ley Orgánica Constitucional sobre Gobierno y Administración Regional. N 19,175. (2005). Retrieved from http://www.leychile.cl/Navegar?idNorma=243771\&buscar=19.175

Ley Orgánica de Municipalidades. N 18,695. (1988).Retrieved from http://www.leychile.cl/Consulta/nav_vinc_texto_refundido?idNorma=30077\&ti poParte $=0$ \&idParte $=\&$ fechaVigencia $=2007-11-$ 16\&clase_vinculacion=TEXTO+REFUNDIDO

Lloyd, B. (2006). Fuel Poverty in New Zealand. Social Policy Journal of New Zealand: Te Puna Whakaaro, (27), 142-155. Retrieved from http://www.msd.govt.nz/about-msd-and-our-work/publicationsresources/journals-and-magazines/social-policy-journal/spj27/fuel-poverty-onnew-zealand-27-pages142-155.html

Local Government New Zealand. (2011). Council websites and boundary maps. Retrieved July 20, 2011, from http://www.lgnz.co.nz/lg-sector/maps/index.html

Local Government Online. (n.d.). Local government, local governance, local decisionmaking. Guide to local government. Retrieved May 11, 2011, from http://www.localgovt.co.nz/site/Local_Government/guide_to_local_government. aspx

Local Government and Environment Committee. (2003). 2002/03 Financial review of the Energy Efficiency and Conservation Authority. Retrieved from http://www.parliament.nz/enNZ/PB/SC/Documents/Reports/2/0/0/2005fef3dbe9432b99f07662e9622e71.htm

Luxton, J. (1993). New directions for electricity. Presented at the Electricity Reform Conference, Wellington, New Zealand: AIC Conferences.

MED [Ministry of Economic Development]. (2007). New Zealand energy strategy to 2050: Powering our future towards a sustainable low emissions energy system. Wellington, New Zealand: MED. 
(2010a). New Zealand's energy outlook 2010. Retrieved from www.med.govt.nz/upload/76133/Energy\%20Outlook\%202010.pdf

(2010b). Draft New Zealand energy strategy: Developing our energy potential and the draft New Zealand energy efficiency and conservation strategy. Wellington, New Zealand: MED. (2010c). New Zealand energy data file. Retrieved from http://www.med.govt.nz/templates/StandardSummary 15169.aspx (n.d.). Gas. Retrieved July 3, 2011, from http://www.med.govt.nz/templates/ContentTopicSummary 21218.aspx

MIDEPLAN [Ministerio de Planificación y Cooperación]. (2006). Encuesta CASEN: Límites mínimos y máximos del ingreso autónomo per-cápita que definen cada uno de los quintiles por quintil de ingreso autónomo del hogar regional según región, zona y quintil. Retrieved from http://www.mideplan.gob.cl/casen/en/Estadisticas/ingresos.html (2010). Encuesta Casen. Retrieved January 31, 2011, from http://www.mideplan.cl/casen/Estadisticas/demografia.html

MINVU [Ministerio de Vivienda y Urbanismo]. (2009). Déficit urbano habitacional: Una mirada integral a la calidad de vida y el hábitat residencial en Chile. Retrieved from http://www.minvu.cl/opensite_20070411164536.aspx

Martinot, E., \& McDoom, O. (2000). Barriers to renewable energy and energy efficiency. Washington D.C.: Global Environmental Facility.

McChesney, I. (1992). Draft proposal: EnergyWise Christchurch. Christchurch, New Zealand.

McChesney, I., Small, D., \& Cottrell, R. (1993). Formulation of a community energy efficiency programme for Christchurch. Christchurch, New Zealand.

McChesney, I., Smith, N., \& Baines, J. (2006). The impact on housing energy efficiency of market prices, incentives and regulatory requirements. Retrieved from www.chranz.co.nz/pdfs/housing-energy-efficiency-report.pd

Mills, E., \& Rosenfeld, A. (1996). Consumer non-energy benefits as a motivation for making energy-efficiency improvements. Energy, 21(7-8), 707-720.

Milne, G., \& Boardman, B. (2000). Making cold homes warmer: the effect of energy efficiency improvements in low-income homes. A report to the Energy Action Grants Agency Charitable Trust. Energy Policy, 28(6-7), 411-424.

Ministerio de Energía. (2010). Balance nacional de energía 2009. Retrieved from http://www.minenergia.cl/minwww/opencms/14_portal_informacion/06_Estadis ticas/Balances_Energ.html

Ministry for the Environment. (2008). Climate change effects and impacts assessment: A guide manual for local government in New Zealand. (ME 870) ISBN: 978-0478-30217-2.

(2010). The Kyoto Protocol. Retrieved May 9, 2011, from http://www.mfe.govt.nz/issues/climate/international/kyoto-protocol.html 
(n.d.). What the ETS mean for me: Householders and individuals. Retrieved July 27, 2011, from http://www.climatechange.govt.nz/emissions-tradingscheme/about/what-it-means-for-me/households.html\#pietsh

Ministry of Social Development. (2010). The social report 2010. Retrieved May 3, 2011, from http://www.socialreport.msd.govt.nz/economic-standardliving/population-low-incomes.html

NIWA. (2008). Climate change scenarios for New Zealand. Retrieved July 4, 2011, from http://www.niwa.co.nz/our-science/climate/information-andresources/clivar/scenarios

(n.d.). Overview of New Zealand climate. Retrieved May 1, 2011, from http://www.niwa.co.nz/education-andtraining/schools/resources/climate/overview

NZ Herald. (2009, September 1). Key keen on bipartisan emissions trading scheme. The New Zealand Herald. Retrieved from http://www.nzherald.co.nz/nz/news/article.cfm?c_id=1\&objectid=10594548

New Zealand Parliament. (1977a). Parliamentary debates (Hansard) (Vol. 416). Wellington, New Zealand: Government Printer. (1977b). Parliamentary debates (Hansard) (Vol. 411). Wellington, New Zealand: Government Printer. (2008). Parliamentary debates (Hansard). Questions for oral answer Questions to ministers (Vol. 649). Retrieved from http://www.parliament.nz/enNZ/PB/Business/QOA/9/8/5/48HansQ_20080828_00000291-3-ElectricityRevenue-Insulation-and-Household.htm

OECD [Organisation for Economic Cooperation and Development]. (2010). Country statistical profiles 2010: Chile. Retrieved January 26, 2011, from http://stats.oecd.org/Index.aspx?DataSetCode=PPPGDP (2011, January 22). Decisions, recommendations and other instruments. Instruments. Retrieved January 22, 2011, from http://acts.oecd.org/Instruments/ListNoGroupView.aspx?order=title

O`Ryan, R. (2008). Modelo de proyección de una demanda energética nacional de largo plazo. Retrieved from http://www.minenergia.gob.cl/minwww/opencms/05_Public_Estudios/introducc ion.html

Oikonomou, V., Becchis, F., Steg, L., \& Russolillo, D. (2009). Energy savings and energy efficiency concepts for policy making. Energy Policy, 37(11), 47874796.

Perry, B. (2010). Household incomes in New Zealand: Trends in indicators of inequality and hardship 1982 to 2009. Retrieved from http://www.msd.govt.nz/about-msdand-our-work/publications-resources/monitoring/household-incomes/index.html

Piñera, S. (2010, May 21). Mensaje presidencial del 21 de mayo. Presented at the Cuenta Anual del Presidente de la República de Chile. Retrieved from http://www.bcn.cl/susparlamentarios/mensajes_presidenciales/ 
Preval, N., Chapman, R., Pierse, N., \& Howden-Chapman, P. (2010). Evaluating energy, health and carbon co-benefits from improved domestic space heating: A randomised community trial. Energy Policy, 38, 3965-3972.

Protocolo de Kyoto. Decreto $N^{\circ}$ 349. (2005). Retrieved from http://www.leychile.cl/Navegar?idNorma=235585\&buscar=kyoto

Resolución exenta $\mathrm{N}^{\circ}$ 0643. Modifica convenio de transferencia entre la Subsecreatría de Energía y la Subsecretaría de Vivienda y Urbanismo (2011). Santiago, Chile: MINVU.

Resolución exenta $\mathrm{N}^{\circ}$ 2937. Llamado a postulación para subsidio al reacondicionamiento térmico de la vivienda. (2009). Santiago, Chile: MINVU.

Resolución exenta $\mathrm{N}^{\circ}$ 5433. Llamado a postulación para subsidio al reacondicionamiento térmico de la vivienda. (2009). Santiago, Chile: MINVU.

Resolución exenta $\mathrm{N}^{\circ}$ 5649. Llamado a postulación para subsidio al reacondicionamiento térmico de la vivienda (2010). Santiago, Chile: MINVU.

Resource Management Act. Public Act No 69 (1991). Retrieved from http://www.legislation.govt.nz/

Rezessy, S., Dimitrov, K., Urge-Vorsatz, D., \& Baruch, S. (2006). Municipalities and energy efficiency in countries in transition: Review of factors that determine municipal involvement in the markets for energy services and energy efficient equipment, or how to augment the role of municipalities as market players. Energy Policy, 34(2), 223-237. doi:10.1016/j.enpol.2004.08.030

Rioseco, R., \& Tesser, C. (n.d.). Cartografía interactiva de los climas de Chile. Retrieved February 3, 2011, from http://www.uc.cl/sw_educ/geografia/cartografiainteractiva/Continental/Paginas/ UntitledFrameset-1.htm

Robson, C. (1993). Real world research: A resource for social scientists and practitioner-researchers. Oxford, U.K.; Cambridge, Mass: Blackwell.

Rubio, L. (2008, May). Roces energéticos. Interview to Nicola Borregaard. Revista Capital, (228). Retrieved from http://www.capital.cl/reportajes-yentrevistas/roces-energ-ticos-3.html

SERVIU Araucanía [Servicio de Vivienda y Urbanización región Araucanía]. (n.d.). Protección patrimonio familiar. Retrieved March 11, 2011, from http://www.serviuaraucania.cl/opensite_20100730115430.aspx

Sanhueza, P. (2005). Identificación de una relación entre las emisiones de fuentes de material particulado y las concentraciones de material particulado respirable en las comunas de Temuco y Padre las Casas. Retrieved from http://www.sinia.cl/1292/articles-45973_recurso_1.pdf

Schweitzer, M., \& Tonn, B. (2003). Non-energy benefits of the US Weatherization Assistance Program: A summary of their scope and magnitude. Applied Energy, 76(4), 321-335.

Sims, R. (2009). Cities, towns and renewable energy: Yes in my front yard. Paris: IEA.

Skumatz, L., Dickerson, C., \& Coates, B. (2000). Non-energy benefits in the residential and non-residential sectors: Innovative measurements and results for participant benefits. Proceedings from the 2000 ACEEE summer study on 
energy efficiency buildings (pp. 8,353-364). Retrieved from http://www.eceee.org/conference_proceedings/ACEEE_buildings/2000/Panel_8/ p8_29/

Statistics New Zealand. (2010a). National family and household projections: 2006(base)-2031 update. Retrieved July 4, 2011, from http://www.population.govt.nz/sitecore/content/statistics/Home/browse_for_stat s/population/estimates_and_projections/NationalFamilyAndHouseholdProjectio ns_HOTP2006-2031update.aspx

(2010b). Sub-national population Eestimates: At 30 June 2010. Retrieved July 3, 2011, from

http://www.stats.govt.nz/browse_for_stats/population/estimates_and_projections /SubnationalPopulationEstimates_HOTP30Jun10.aspx

(n.d.a). Land and environment: Geography - physical features. Retrieved May 1, 2011a, from

http://www2.stats.govt.nz/domino/external/web/nzstories.nsf/092edeb76ed5aa6b cc256afe0081d84e/54e50d25aff60a7bcc256b1e007adcb6?

(n.d.b). Population clock. Retrieved July 3, 2011b, from

http://www.stats.govt.nz/tools_and_services/tools/population_clock.aspx

Stoecklein, A., \& Skumatz, L. (2007). Zero and low energy homes in New Zealand: The value of non-energy benefits and their use in attracting homeowners. eceee 2007 Summer Study (pp. 1959-1967). Presented at the Saving energy - just do it!. Retrieved from http://www.eceee.org/conference_proceedings/eceee/2007/Panel_9/9.314/

Taylor, R. P., Govindarajalu, C., Levin, J., Meyer, A. S., \& Ward, W. A. (2008). Financing energy efficiency: Lessons from Brazil, China, India, and beyond. Retrieved from http://wwwwds.worldbank.org/external/default/WDSContentServer/WDSP/IB/2008/02/18/ 000333037_20080218015226/Rendered/PDF/425290PUB0ISBN11OFFICIAL0 USE0ONLY10.pdf

The Treasury. (2010). New Zealand Economic and financial overview 2010. Wellington, New Zealand. Retrieved from http://www.treasury.govt.nz/economy/overview/2010/nzefo-10-1.pdf

Tokman, M. (2007, July 20). Situación eléctrica: Diagnóstico y líneas de acción. Presented at the Conference Crisis Energética: Instrumentos para Superarla, Santiago, Chile. Retrieved from http://www.freewebs.com/infoenergia/20_mtokman_intervencion.pdf

Trethowen, H. A., \& Hubbard, E. F. (1972). Economics of thermal insulation ( No. C.R.1). Wellington, New Zealand: Building Research Association of New Zealand.

UNDP [United Nations Development Programme]. (2010a). International human development indicators: Chile. Retrieved January 31, 2011, from http://hdrstats.undp.org/en/countries/profiles/CHL.html (2010b). International human development indicators: New Zealand. Retrieved May 3, 2011, from http://hdrstats.undp.org/en/countries/profiles/NZL.html 
Universidad de la Frontera. (2009). Diseño de un programa de recambio de artefactos existentes que combustionan leña por tecnología menos contaminante, en las comunas de Temuco y Padre las Casas. Temuco, Chile: Comisión Nacional del Medio Ambiente región de la Araucanía.

Wholesale Electricity Market Development Group. (1994). New Zealand wholesale electricity market. Auckland, New Zealand: The Group.

Wilson, C., \& Dowlatabadi, H. (2007). Models of decision making and residential energy use. Annual Review of Environment and Resources, 32(1), 169-203. doi:10.1146/annurev.energy.32.053006.141137

World Bank. (2000). Bolivia: Final report on operational activities. Rural energy and energy efficiency (No. ESM235). Retrieved from http://wwwwds.worldbank.org/servlet/main?menuPK=64187510\&pagePK=64193027\&piP $\mathrm{K}=64187937$ \&theSitePK=523679\&entityID=000094946_00112105321116

World Bank. (2011a). Gini index. Retrieved January 31, 2011, from http://search.worldbank.org/data?qterm=gini\&language=EN\&format=html (2011b). Income share held by highest 20\%. Retrieved January 31, 2011, from http://data.worldbank.org/indicator/SI.DST.05TH.20

World Energy Council. (2004). Energy efficiency: A worldwide review: Indicators, policies, evaluation. Retrieved from http://www.worldenergy.org/documents/eepi04.pdf (2008). Energy efficiency policies around the world: Review and evaluation. Executive summary. Retrieved from http://www.worldenergy.org/documents/energy_efficiency_es_final_online_1.p df

Ürge-Vorsatz, D., Novikova, A., Köppel, S., \& Boza-Kiss, B. (2009). Bottom-up assessment of potentials and costs of $\mathrm{CO}_{2}$ emission mitigation in the buildings sector: Insights into the missing elements. Energy Efficiency, 2(4), 293-316. doi:10.1007/s12053-009-9051-0 


\section{APPENDICES}

\section{APPENDIX 1}

Table A1. Percentage of residential space heating fuels by type of dwelling used in Santiago and two large southern cities.

\begin{tabular}{|l|c|c|c|c|c|c|c|c|}
\hline \multirow{2}{*}{ City } & \multicolumn{2}{|c|}{$\begin{array}{c}\text { Liquefied gas } \\
(\%)\end{array}$} & \multicolumn{2}{c|}{$\begin{array}{c}\text { Kerosene } \\
(\%)\end{array}$} & \multicolumn{2}{c|}{$\begin{array}{c}\text { Wood } \\
(\%)\end{array}$} & \multicolumn{2}{c|}{$\begin{array}{c}\text { Natural gas } \\
\text { (\%) }\end{array}$} \\
\cline { 2 - 10 } & House & Flat & House & Flat & House & Flat & House & Flat \\
\hline Santiago & 54 & 56 & 33 & 34 & 5 & 0 & 9 & 10 \\
\hline Concepción & 17 & 28 & 27 & 45 & 40 & 0 & 17 & 28 \\
\hline Temuco & 20 & 67 & 10 & 33 & 70 & 0 & 0 & 0 \\
\hline
\end{tabular}

Source: Adapted from Ambiente Consultores and PRIEN (2007).

Table A.2. Residential space heating energy use (kWh) by type of fuel and type of dwelling in Santiago and two large southern cities.

\begin{tabular}{|c|c|c|c|c|c|c|c|c|c|}
\hline \multirow[t]{2}{*}{ City } & \multirow[t]{2}{*}{$\begin{array}{c}\text { Energy use } \\
\left(\mathrm{kWh} / \mathrm{m}^{2} \text { per }\right. \\
\text { year })\end{array}$} & \multicolumn{2}{|c|}{$\begin{array}{l}\text { Liquefied gas } \\
\text { (kWh per } \\
\text { household per } \\
\text { year) }^{74}\end{array}$} & \multicolumn{2}{|c|}{$\begin{array}{c}\text { Kerosene } \\
\text { (kWh per } \\
\text { household per } \\
\text { year) }\end{array}$} & \multicolumn{2}{|c|}{$\begin{array}{c}\text { Wood } \\
\text { (kWh per } \\
\text { household per } \\
\text { year) }\end{array}$} & \multicolumn{2}{|c|}{$\begin{array}{l}\text { Natural gas } \\
(\mathrm{kWh} \text { per } \\
\text { household per } \\
\text { year) }\end{array}$} \\
\hline & & House & Flat & House & Flat & House & Flat & House & Flat \\
\hline Santiago & 123 & 3,919 & 4,064 & 2,395 & 2,467 & 327 & 0 & 668 & 726 \\
\hline Concepción & 132 & 1,324 & 2,181 & 2,103 & 3,505 & 3,115 & 0 & 1,301 & 2,181 \\
\hline Temuco & 245 & 2,891 & 9,685 & 1,446 & 4,770 & 10,119 & 0 & 0 & 0 \\
\hline Average $^{75}$ & 166 & 3,919 & 4,064 & 2,395 & 2,467 & 327 & 0 & 668 & 726 \\
\hline
\end{tabular}

Source: Adapted from Ambiente Consultores and PRIEN (2007).

\footnotetext{
${ }^{74}$ In the study conducted by Ambiente Consultores and PRIEN (2007) the information about energy use was presented in $\mathrm{kWh} / \mathrm{m}^{2}$ per year. In order to obtain an average of energy use per household, in this thesis, the average household's size was estimated at $56 \mathrm{~m}^{2}$. This figure is the average of Chilean dwellings' minimum and maximum size $\left(38 \mathrm{~m}^{2}\right.$ and $\left.80 \mathrm{~m}^{2}\right)$ presented by Ambiente Consultores and PRIEN (2007).

${ }^{75}$ In the study conducted by Ambiente Consultores and PRIEN (2007) a number of cities throughout the country were taken into account. The national average energy use was estimated at $208 \mathrm{in} \mathrm{kWh} / \mathrm{m}^{2}$ per year with a standard deviation of $150 \mathrm{KWh} / \mathrm{m}^{2}$ in residential space heating.
} 


\section{APPENDIX2}

The regional climate is defined as rainy temperate according to the Köppen classification. In Temuco, the average annual temperature is $11.2^{\circ} \mathrm{C}$ and the average annual rain fall is $1,157 \mathrm{~mm}$. In the coldest month (July), the average temperature is

$7.2^{\circ} \mathrm{C}$. The minimum extreme temperature registered was $-6.9^{\circ} \mathrm{C}$ (Rioseco \& Tesser, n.d.).

In terms of population, the Araucanía represents 5.6\% of the Chilean population. According to the last CASEN survey of 2009, Araucanía's population was 936,783 persons consisting of 634,071 (70\%) urban and 302,712 (30\%) rural inhabitants (MIDEPLAN, 2010). The Araucanía region has the biggest concentration of indigenous people and poor people in the country. In relation to the total regional population, indigenous people make up $27 \%$ of the regional population and poor people account for 15\% (MIDEPLAN, 2010). The number of households in 2006 was estimated at 68,883 in Temuco and at 9,710 in Padre las Casas (MIDEPLAN, 2006, cited in Universidad de la Frontera, 2009). 


\begin{abstract}
APPENDIX 3
The IRS works in the same way that other PPPF's subsidies. That is, every year MINVU calls participants to apply for the subsidy. The demand for the subsidy is organised by social property management entities (entidad de gestión inmobiliaria social, EGIS), that are enterprises or municipalities through which MINVU has contracted out some social services. These entities work with the potential beneficiaries in order to help them to meet the legal, social and economic requirements of the PPPF. Participants can apply individually or collectively.

The EGIS also proposes insulation retrofit solutions case by case and implements a social habilitation plan which consists of a series of workshops carried out before and during the retrofit works. In these workshops the EGIS presents the purpose of the subsidy, the beneficiaries' rights and duties (such as housing use, care and maintenance) and agrees a contract between the participants, a building company and the EGIS. During the building works stage the workshops are used to show the working progress and solve problems.
\end{abstract}

The applications are submitted to the respective regional SERVIU, which reviews them. If the applications meet the requirements, SERVIU issues a qualification certificate or, where they do not meet the requirements, SERVIU provides feedback to the EGIS to amend the application. All the qualified applications are sent to MINVU in Santiago, which finally decides the IRS committees to benefit based on scores (Decreto $N^{\circ}$ 255, 2007).

The basic requirements for applying to the IRS are:

- Potential beneficiaries must have a social protection file (ficha de protección social), that scores less than 13.484 points (SERVIU Araucanía, n.d.). The score shows the level of social vulnerability and takes into account social variables such as number of family members, health conditions, income, house size, and others (BCN, n.d.). This score covers households up to the third most vulnerable quintile of the population. In terms of salary, the third quintile includes households earning up to NZ\$260 per capita at a national level and NZ\$440 in the Araucanía region’s urban areas (MIDEPLAN, 2006). In collective applications this score can be an average and $40 \%$ of the applicants can have higher scores. In practice, most of the applications are collective because participants have more chance of being selected 
and are more profitable for the building company and the EGIS (Sandoval, personal communication, December 2, 2010) ${ }^{76}$. Also, in collective applications, it is possible to expand the potential beneficiaries beyond the third quintile of vulnerability.

- Households have to be social dwellings with a commercial value less than NZD\$ 38,000

- Households need to have bank savings of NZ\$ 180 to contribute to the investment in insulation.

${ }^{76}$ Mr. Juan Carlos Sandoval is an EGIS representative in Temuco. 


\section{APPENDIX 4}

The Warm Up New Zealand: Heat Smart programme operates in the same way that previous programmes administrated by EECA. The scheme is a tender for service providers that make a contract with property owners. Service providers vary from local community groups to nationwide companies with the only requirement being compliance with the New Zealand Standard 4246:2006 ${ }^{77}$. The first step is to retrofit all parts of the house ${ }^{78}$ that are possible to insulate, excluding walls ${ }^{79}$. Once the dwelling has been insulated, the owner can apply for a clean heater device (EECA, 2007, 2009). The programme requires insulation of the whole house. This is because the grant is a legacy issue that seeks to improve the New Zealand housing stock (Government official, personal communication, June 3, 2011).

The original idea was to have an annual fund pool, but during the first year the demand exceeded the annual pool so the government make a unique pool to be distributed according to the demand (Government official, ibid). In some cases when retrofitting the whole dwelling is not technically possible, this requirement does not apply.

In New Zealand, low to middle income families can apply for a Community Services Card (CSC) that sets income limits as shown in the following table:

\footnotetext{
77 NZS 4246 Energy Efficiency: Installing Insulation in Residential Buildings (2006).

${ }^{78}$ Eligible dwellings are those built before 2000. In 2000 the Building Code was amended

${ }^{79}$ Walls are excluded for technical reasons as their insulation is not yet cost-effective (Government official, personal communication, June 3, 2011).
} 
Table A4. Income limits for receiving a Community Services Card.

\begin{tabular}{|l|l|}
\hline Family members & Upper yearly income (before tax) (NZ\$)* \\
\hline Single living with others & $\$ 24,461$ \\
\hline Single living alone & $\$ 25,933$ \\
\hline Married, civil union or de facto couple (no children) & $\$ 38,737$ \\
\hline Family of 2 & $\$ 46,769.00$ \\
\hline Family of 3 & $\$ 56,637$ \\
\hline Family of 4 & $\$ 64,485$ \\
\hline Family of 5 & $\$ 72,172$ \\
\hline Family of 6 & $\$ 80,763$ \\
\hline
\end{tabular}

*Rates at as at 1 April 2011.

Source: Work and Income, New Zealand Government.

http://www.workandincome.govt.nz/individuals/forms-and-brochures/communityservices-card.html 


\section{APPENDIX 5}

Table A5.1. Chilean interviewees and the organisations to which they belonged.

\begin{tabular}{|c|c|c|}
\hline Entity & Organisation & Number \\
\hline \multirow[t]{4}{*}{ Central authority } & Ministry of Housing and Urbanism & $\begin{array}{l}1 \text { official involved in policy implementation } \\
1 \text { former official involved in policy making }\end{array}$ \\
\hline & National Commission of Energy & 1 former official involved in policy making \\
\hline & National Ministry of Energy & $\begin{array}{l}1 \text { official involved in policy creation and } \\
\text { implementation }\end{array}$ \\
\hline & $\begin{array}{l}\text { Minister of the Environment (former } \\
\text { National Commission of the } \\
\text { Environment) }\end{array}$ & 1 official involved in policy implementation \\
\hline \multirow[t]{5}{*}{ Local authority } & $\begin{array}{l}\text { Minister of the Environment (former } \\
\text { National Commission of the } \\
\text { Environment) }\end{array}$ & $\begin{array}{l}1 \text { official involved in policy creation and } \\
\text { implementation } \\
1 \text { former official involved in policy making }\end{array}$ \\
\hline & $\begin{array}{l}\text { National Service of Housing and } \\
\text { Urbanism }\end{array}$ & $\begin{array}{l}1 \text { official involved in policy creation and } \\
\text { implementation }\end{array}$ \\
\hline & Municipality of Padre las Casas & 1 official involved in policy implementation \\
\hline & Municipality of Temuco & $\begin{array}{l}1 \text { government official who participated in a } \\
\text { Social Property Management Entity }\end{array}$ \\
\hline & Local government & $\begin{array}{l}1 \text { official representative of the energy } \\
\text { efficiency regional board }\end{array}$ \\
\hline Academic experts & & $\begin{array}{l}1 \text { scholar who participated in the policy } \\
\text { study }^{80} \\
1 \text { scholar involved in the area of pollution } \\
\text { reductions plans and co-benefits }\end{array}$ \\
\hline Entrepreneur & & $\begin{array}{l}1 \text { representative of a Social Property } \\
\text { Management Entity }\end{array}$ \\
\hline Community leader & & 1 representative \\
\hline \multirow[t]{2}{*}{$\begin{array}{l}\text { Building research } \\
\text { organizations }\end{array}$} & Building Institute & $\begin{array}{l}1 \text { representative, involved in the thermal } \\
\text { standards creation }\end{array}$ \\
\hline & Chilean Chamber of Building & 1 representative \\
\hline
\end{tabular}

\footnotetext{
${ }^{80}$ The policy study that led up to the policy: Ambiente Consultores and PRIEN, (2007).
} 
Table A5.2. New Zealand interviewees and the organisations to which they belonged.

\begin{tabular}{|l|l|l|}
\hline \multicolumn{1}{|c|}{ Entity } & \multicolumn{1}{|c|}{ Organisation } & \multicolumn{1}{c|}{ Number } \\
\hline Central authority & $\begin{array}{l}\text { Energy Efficiency and Conservation } \\
\text { Authority }\end{array}$ & $\begin{array}{l}\text { 1 official involved in the Warm Up New } \\
\text { Zealand creation and implementation } \\
1 \text { official involved in previous policy } \\
\text { programmes' creation and implementation }\end{array}$ \\
\hline Local authority & Christchurch City Council & $\begin{array}{l}1 \text { official involved in retrofit policy creation } \\
\text { and implementation }\end{array}$ \\
\hline Political party & & $\begin{array}{l}1 \text { former policy adviser involved in retrofit } \\
\text { policy making }\end{array}$ \\
\hline Academic experts & & $\begin{array}{l}1 \text { scholar who has conducted most of the } \\
\text { health studies related to retrofit improvements } \\
\text { in New Zealand } \\
1 \text { scholar who has investigated the thermal } \\
\text { improvements of retrofit policies }\end{array}$ \\
\hline $\begin{array}{l}\text { Social } \\
\text { Entrepreneur }\end{array}$ & & $\begin{array}{l}1 \text { representative who conducted training pilot } \\
\text { projects for the Energy Saver Fund }\end{array}$ \\
\hline Community leader & & $\begin{array}{l}1 \text { representative who set up the Community } \\
\text { Energy Action Trust }\end{array}$ \\
\hline
\end{tabular}




\section{APPENDIX 6}

\section{Chilean geography and climate}

Chile's continental surface area is $760,000 \mathrm{~km}^{2}$, its continental length exceeds 4,300 km and its width varies from 90 to $445 \mathrm{~km}$. Chile borders Peru, Bolivia and Argentina and the country's boundaries produce a semi-island effect. These boundaries are the Atacama desert (the driest desert of the world) in the north, the Magellan Strait and the pole in the south, the Andes in the east and the Pacific ocean in the west. Thus, latitude, geography, and oceanic influence are the main factors that influence the climate (INE, 2010).

\section{Chilean economic context}

Chile increased its GDP per capita from US\$ 9,300 in 2000 to US\$ 14,500 in 2008. However, this last figure is still well under the OECD countries' average (US\$33,700 in 2008) (OECD, 2010). In 2009, the GDP reached US\$ 243 billion (OECD, 2010) and the most important economic activities were manufacturing and financial and business services (INE, 2010). Despite the devastating earthquake at the beginning of 2010, the growth projections for that year and 2011 have been estimated at $5 \%$ and 6\% respectively (IMF, 2010).

The OECD membership was a result of the improvement of economic, social and environmental Chilean policies such as policies on taxes, corruption, public and private companies and climate change (Gurría, 2010).

\section{Chilean social context}

The Chilean human development index is high (0.783 points in 2010) and increasing (UNDP, 2010). The index is above the Latin American and Caribbean region average (0.706) and ranks the country 45th worldwide (UNDP, 2010).

Prosperity, in terms of GDP per capita and wellbeing or happiness of citizens, leaves room for improvement. Chile has achieved a strong ranking in governance and personal freedom, but an average ranking in economy, entrepreneurship and opportunity, education, health, safe and security and social capital (Legatum Institute, 2010). This result shows that, despite its impressive economic growth in terms of GDP, Chile needs to enhance the quality of life of its people. 


\section{APPENDIX 7}

\section{New Zealand geography and climate}

The future effects of climate change on New Zealand have been estimated based on various models. NIWA (2008) conducted research regarding these impacts on different climatic variables, with the results showing that the mean temperature will increase fairly uniformly over the country, from around 0.2 to $2.0^{\circ} \mathrm{C}$ by 2040 to 0.7 to 5.1 by 2090 . The annual average rainfall is forecasted to increase in the west and decrease in the north and east in winter and spring; however, during summer and autumn seasons the pattern is reversed. Changes in climate extremes (e.g. floods, droughts, frosts, strong winds, tropical cyclones and storm surges) are estimated to have the greatest effect on the environment, the society and the economy. However, estimations of changes in climate extremes are more uncertain than mean conditions, for example snowfall is likely to decrease and snowline is likely to rise, although some events can increase the amount of snow. Yet, as the environment is getting warmer, the snow will melt more quickly, and consequently, the duration of seasonal snowfall will decrease. Droughts are estimated to increase in frequency in areas that are currently drought prone. Furthermore, a decrease in the number of frost days and an increase in the number of days with temperatures over $25^{\circ} \mathrm{C}$ are expected around the country. Heavy rain is also likely to occur over most areas of New Zealand.

\section{New Zealand economy}

In 2009, the GDP was NZ\$ 185 billion with the main contributions coming from finance insurance and business services (27.6\% of the GDP) followed by manufacturing (13.2\%) (The Treasury, 2010).

\section{Social context}

The country's population consists of an array of different ethnicities: around 80\% of the population recognize themselves as European descent, $14.6 \%$ as Māori, $9.2 \%$ as Asian, 6.9\% as Pacific Islanders and 0.9\% as other (The Treasury, 2010). People living in urban areas represents 78\% of the total population (Statistics New Zealand, 2010a), concentrated mainly in the Auckland region (1.46 million) (Statistics New Zealand, 2010a). 
New Zealand's human development index (0.907) was higher than the average of the OECD countries (0.853) in 2010, ranking the country third worldwide (UNDP, 2010). At the same time, New Zealand is one of the top five countries in the world in terms of prosperity, showing a high level of wellbeing and happiness of citizens in relation to per capita GDP (Legatum Institute, 2010). 


\section{APPENDIX 8}

\section{Interview for key informants}

\section{Questions for national and local government officials, academic experts, NGO experts or}

representatives, energy efficiency company executives and community leaders:

1. What has been the role and contribution of your organisation or group in developing residential energy efficiency policies, especially retrofit policies?

2. What has been the role and contribution of your organisation or group in implementing retrofit policies?

3. What are the practical barriers and issues when developing residential energy efficiency measures, especially retrofit policies?

4. What are the practical barriers and issues when implementing residential energy efficiency measures, especially retrofit policies?

5. How the retrofit policy could be enhanced in the future?

6. What are the main issues and barriers to support and expand the retrofit policy?

7. Was the rebound effect taken into account in the development of the retrofit policy?

8. Any other comments? 